\title{
MICROENVIRONMENTAL FORCES REGULATE NOTCH SIGNALING THROUGH INTEGRINS
}

by

Michael Allen Detweiler

\author{
A thesis \\ submitted in partial fulfillment \\ of the requirements for the degree of \\ Master of Science in Biology \\ Boise State University
}

December 2018 
(C) 2018

Michael Allen Detweiler

ALL RIGHTS RESERVED 


\title{
BOISE STATE UNIVERSITY GRADUATE COLLEGE
}

\section{DEFENSE COMMITTEE AND FINAL READING APPROVALS}

\author{
of the thesis submitted by
}

Michael Allen Detweiler

Thesis Title: Microenvironmental Forces Regulate Notch Signaling Through Integrins

Date of Final Oral Examination: $\quad 25$ October 2018

The following individuals read and discussed the thesis submitted by student Michael Allen Detweiler, and they evaluated his presentation and response to questions during the final oral examination. They found that the student passed the final oral examination.

Allan Albig, Ph.D. Chair, Supervisory Committee

Brad E. Morrison, Ph.D. Member, Supervisory Committee

Troy Rohn, Ph.D. Member, Supervisory Committee

The final reading approval of the thesis was granted by Allan Albig, Ph.D., Chair of the Supervisory Committee. The thesis was approved by the Graduate College. 


\section{ACKNOWLEDGEMENTS}

First and foremost, I would like to thank my advisor, Dr. Allan Albig, for being an incredible mentor and friend. With his guidance and moral support, I have been able to fully understand and integrate the ethics and investigative nature of science. I would also

like to thank Dr. Brad Morrison and Dr. Troy Rohn for being on my thesis committee and for their very helpful suggestions.

Through my time at Boise State I have had the pleasure of working with and learning from my fellow colleagues, and for this I would like to thank the Albig lab members, Jacob Crow, Bryce Lafoya, Jordan Munroe, Shelby Havel, and Dr. Allison Myamoto.

I would also like to give thanks to the National Institute of Health for providing the funding to support this thesis. 


\begin{abstract}
The extracellular microenvironment contributes significantly to a cell's function and behavior. For instance, cell-cell interactions, cell-substrate interactions, and physical forces are all factors of the extracellular environment that can alter cellular behavior. Cells can receive these signals and forces through various membrane channels and receptors that transmit the signals from the extracellular to the intracellular space. Canonical Notch signaling is induced by ligand interactions with neighboring cells, but recent evidence has revealed that Notch signaling can occur through a variety of extracellular stimuli including hyperglycemia, hypoxia, multiple growth factors, fluid shear stress, and extracellular matrix (ECM) composition. Although Notch activation through ligand interactions with adjacent cells have been well established, non-canonical Notch signaling through the microenvironment is poorly understood. Previous evidence suggests a novel activation of Notch signaling through an integrin pathway, proposing Notch as a microenvironmental sensor. Integrins are cell membrane receptors that are mainly recognized for cell-ECM attachment and induction of cellular signaling cascades but have also been shown to respond and transmit signaling through fluid shear stress and ECM stiffness. Since integrins have been shown to regulate Notch signaling and both exhibit a response to fluid shear stress, we hypothesized that Notch signaling responds to fluid shear stress through integrin activation. To test this, we compared Notch activation following exposure to fluid shear stress and Notch activation following shear stress after inhibiting integrin function. Our data confirms that Notch activation is significantly
\end{abstract}


upregulated from fluid shear stress compared to a static control and inhibiting integrin function attenuates this response, suggesting integrins are required for Notch's upregulation from shear stress. Because integrins also respond and transmit signals from varying ECM stiffness and Notch has been shown to be upregulated during conditions of fibrosis, we hypothesized that Notch signaling will be regulated by varying degrees of ECM stiffness through integrin activation. To investigate this hypothesis, we cultured cells on hydrogels with multiple levels of stiffness and measured Notch signaling. Our results indicate that like shear stress, Notch signaling is influenced by ECM stiffness. Collectively our results indicate that Notch signaling is regulated through microenvironmental forces like fluid shear stress and ECM stiffness and is regulated through integrins. This furthers our understanding of the variations of Notch signaling in response to microenvironmental stimuli and the mechanisms involved. Notch has been implicated in a variety of diseases and our results improve our knowledge of Notch signaling in pathological conditions of the microenvironment including abnormal shear stress (e.g. atherosclerosis) and tissue stiffness (e.g. fibrosis). 


\section{TABLE OF CONTENTS}

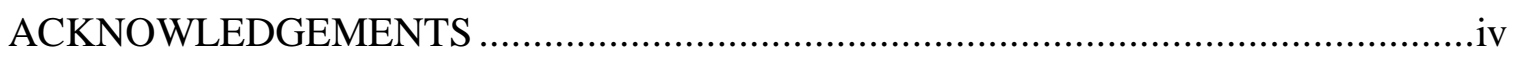

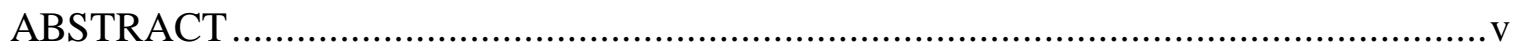

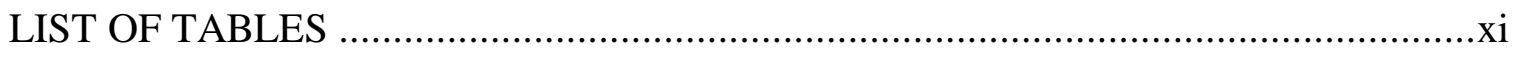

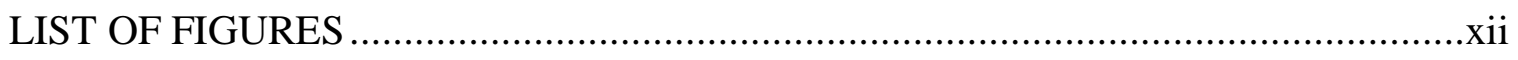

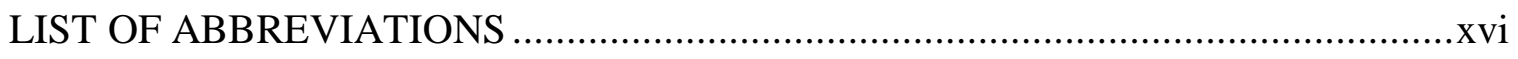

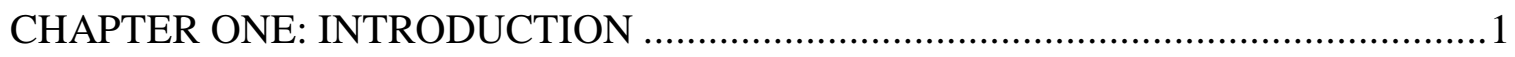

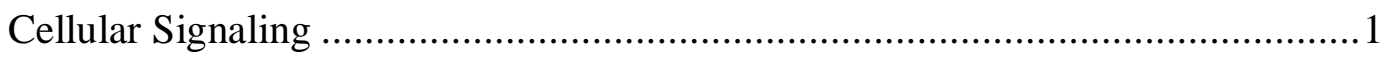

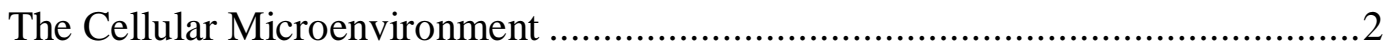

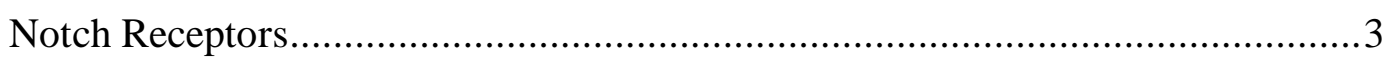

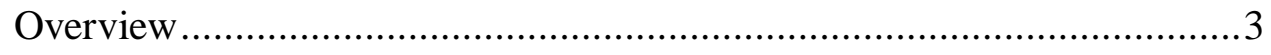

Downstream Notch Signaling ...........................................................

Canonical vs Non-Canonical Activation .................................................

Notch Signaling and Disease ………….............................................

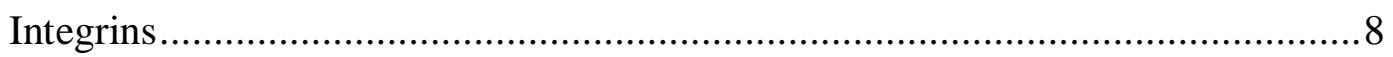

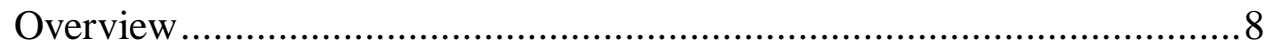

Integrin Downstream Signaling ..........................................................

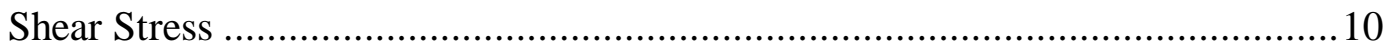

Cardiovascular System ...................................................................... 10

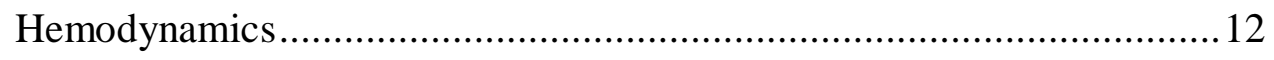




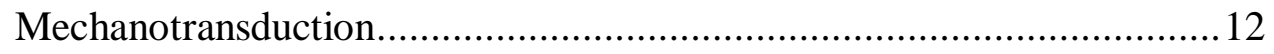

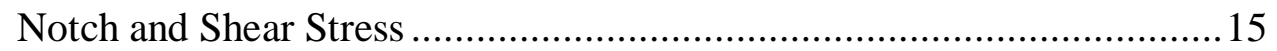

ECM

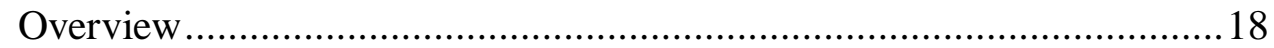

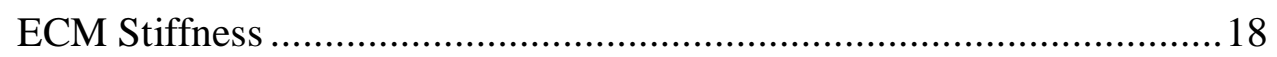

CHAPTER TWO: INITIAL SHEAR STRESS-INDUCED NOTCH SIGNALING IS REGULATED THROUGH AND INTEGRIN PATHWAY .......................................21

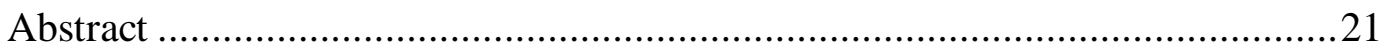

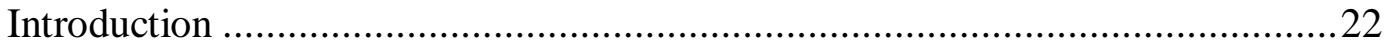

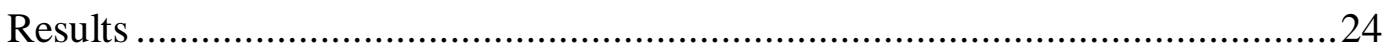

Notch Signaling is induced by Shear Stress. ...........................................24

Notch Activation from Shear Stress Is Regulated by Integrins. ................27

Notch Activation from Shear Stress Is Regulated Via Integrin Downstream Pathways Src and Enos ………………............................29

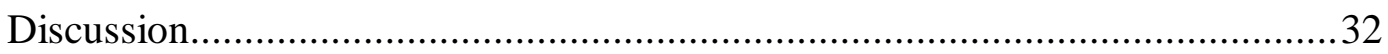

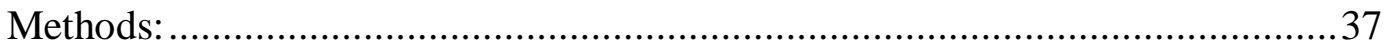

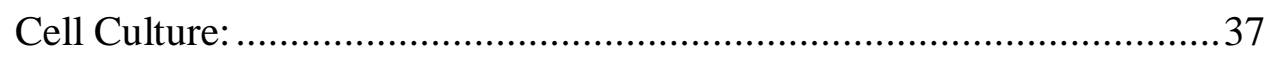

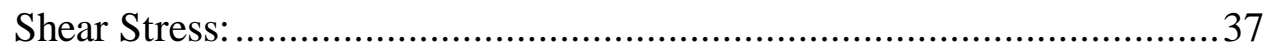

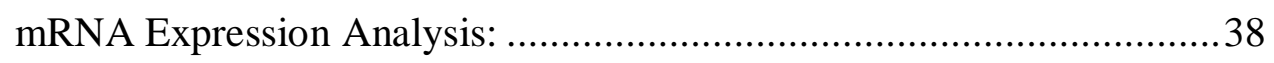

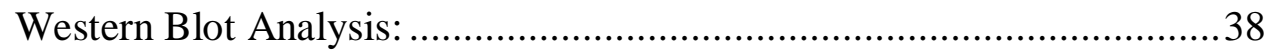

CHAPTER THREE: MATRIX STIFFNESS REGULATES NOTCH ACTIVATION ...40

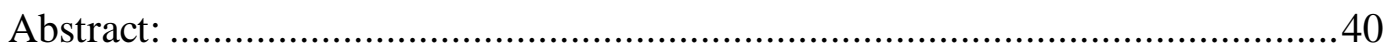

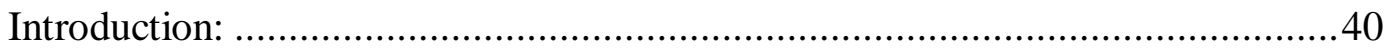

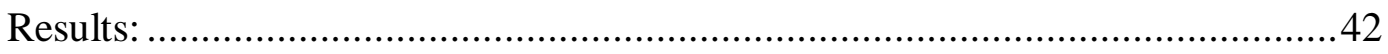


Notch Activation Changes with Varying Degrees of Matrix Stiffness in Endothelial Cells ..................................................................................42

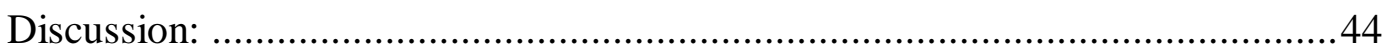

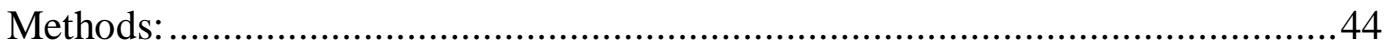

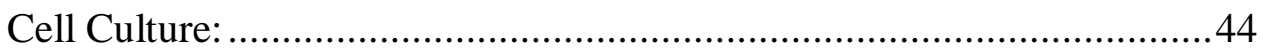

Polyacrylamide Hydrogels:..................................................................45

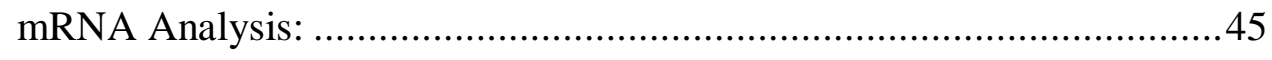

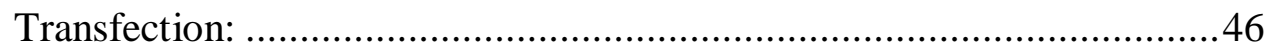

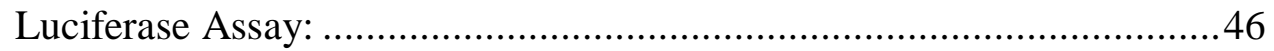

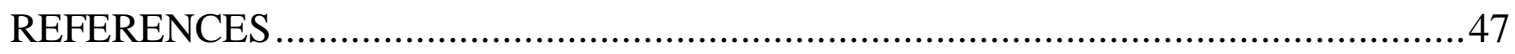

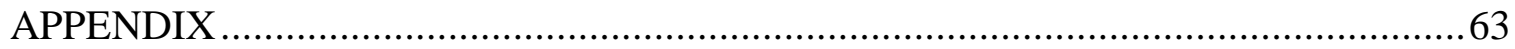

Notch: A multi-functional integrating system of microenvironmental signals. ....64

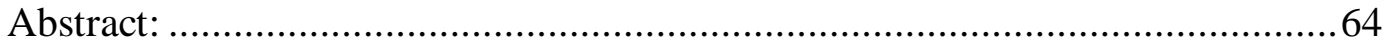

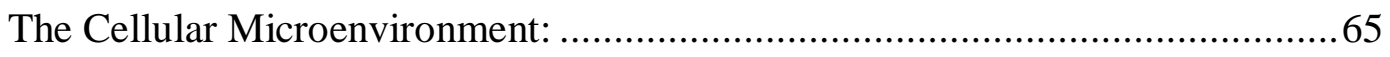

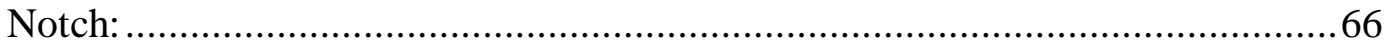

Notch as an Integrator of Cellular Microenvironments: .....................................69

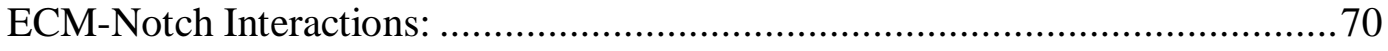

Direct ECM-Notch Interactions That Control Notch Signaling ..................70

Indirect ECM-Notch Interactions that Control Notch Signaling

(Transcriptional Mechanisms) ................................................................76

Direct ECM Notch Interactions That Control Notch Signaling (Crosstalk

Mechanisms). ..............................................................................

Notch crosstalk with other signaling networks. Integrins, TGF- $\beta$, WNT, and

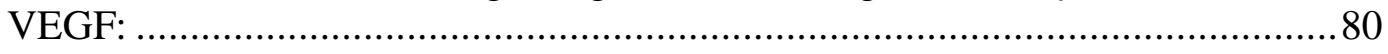

Crosstalk between Notch and Integrins: ................................................. 80 
Notch and TGF- $\beta$ :

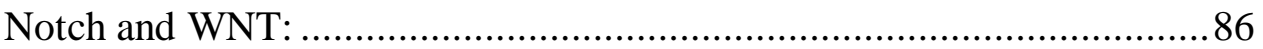

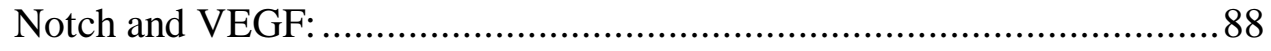

Other Microenvironment Conditions That Control Notch (Shear stress, hypoxia,

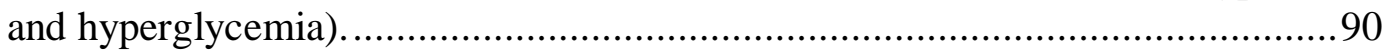

Notch and Shear Stress: ........................................................................

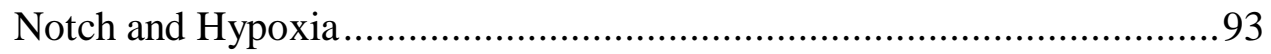

Notch and Hyperglycemia: .................................................................94

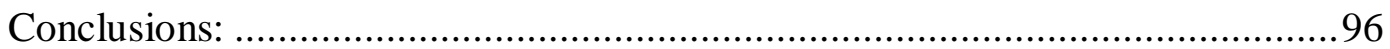

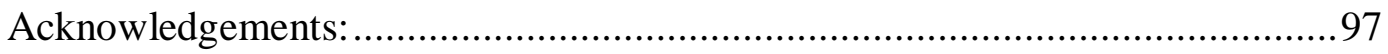

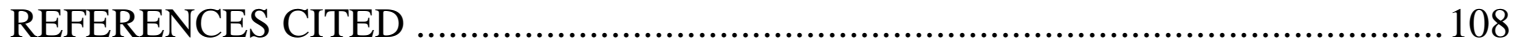




\section{LIST OF TABLES}

Table A.1: $\quad$ Basic and proposed mechanisms by which Notch responds to various

microenvironmental signals. ................................................................98 


\section{LIST OF FIGURES}

Figure 1.1: Domains of the Notch receptor. The extracellular domain (NECD) of Notch contains 36 epidermal growth factor (EGF)-like repeats, followed by a transmembrane portion containing Lin-12-Notch repeats. The intracellular domain (NICD) consists of RAM, Ankyrin repeats, transactivation domain (TAD) and proline, glutamine, serine, and threonine (PEST)-rich domains and is responsible for transcriptional control.

Figure 1.2: Blood vessels consist of 3 main layers. The tunica intima is composed of endothelial cells surrounded by a basement membrane and regulates vessel permeability and integrity. The tunica media has smooth muscle cells and matrix proteins and is mainly responsible for contraction/dilation of the vessel, and the tunica adventitia consists of mostly ECM proteins and associates the vessels with the surrounding tissue and provides elasticity.

Figure 1.3: Mechanotransduction. Illustration showing the proposed method of mechanotransduction. As shear stress forces are implemented to the apical surface of cells, the force applies tension to the cytoskeleton where it will then transmit to the focal adhesions and junctions of the cell.

Figure 1.4: Polyacrylamide hydrogel. Illustration of experimental hydrogels. A glass coverslip is used to attach polyacrylamide hydrogel. The hydrogel is then crosslinked to an ECM protein using crosslinkers like L-DOPA or Sulfosanpah. The cells are then cultured on the surface attaching to the ECM protein with focal adhesions.

Figure 2.1: Notch signaling is induced via shear stress. HMEC1s exposed to $\sim 12 \mathrm{dyn} / \mathrm{cm}^{\wedge} 2$ of orbital shear stress. A) Notch intracellular domain (N1ICD) and full length Notch1 whole cell lysates detected by Western blot and normalized to Vinculin control. b) Downstream Notch genes Hey1, Hes 1, and Hey2 expression levels detected by qPCR, Klf2 used as a positive shear stress control. Values are mean $+/-\mathrm{SEM} ; *=\mathrm{p}<0.05$, ** $=$ $\mathrm{p}<0.01$. c) Downstream Notch genes Heyl and Hes1 expression levels detected by qPCR following treatment with Doxycycline in N1ICD transgenic HMEC1s to overexpress Notch signaling. .26

Figure 2.2: $\quad$ Shear Stress-induced Notch is regulated through integrins. HMEC1s exposed to $\sim 12 \mathrm{dyn} / \mathrm{cm}^{\wedge 2}$ of shear stress following integrin inhibition. a) 
Notch downstream genes Heyl and Hes 1 mRNA expression detected by qPCR following treatment with RGD peptides $(5 \mu \mathrm{g} / \mathrm{ml})$ and 90 minutes of orbital shear stress. Klf 2 used as a positive shear stress control. b) Notch downstream genes Heyl and Hes 1 mRNA expression detected by qPCR following treatment with MBCD $(10 \mathrm{mM})$ and 90 minutes of orbital shear stress. Klf2 used as a positive shear stress control. Values are mean $+/-$ SEM; $*=\mathrm{p}<0.05, * *=\mathrm{p}<0.01$. c) N1ICD fragment whole cell lysate detected via western blot and folded to Vinculin following treatment with RGD peptide and MBCD and exposed to orbital shear stress for 45 and 90 minutes.

Figure 2.3: $\quad$ Shear stress-induced Notch activation is regulated by integrin downstream pathways, Src \& eNOS. HMEC1s exposed to $\sim 12 \mathrm{dyn} / \mathrm{cm}^{\wedge 2}$ of shear stress following treatment with AZM and DPI. a) mRNA expression of Heyl and Hesl detected by qPCR when AZM $(10 \mu \mathrm{m})$ is folded to vehicle control following shear stress. b) mRNA expression of Heyl, Hesl, and Hey2 detected by qPCR when DPI $(100 \mu \mathrm{M})$ treatment is folded to static control following shear stress. Values are mean $+/-$ SEM; $*=p<0.05$, ** $=\mathrm{p}<0.01$. c) Western blot analysis of NICD with AZM, DPI, and vehicle control.

Figure 2.4: $\quad$ Shear stress induces Notch activation through Integrin-Src-eNOS pathway. Illustration representing the suggested regulation of Notch activation following shear stress via an integrin-Src-eNOS pathway.......36

Figure 3.1: $\quad$ Notch downstream genes are regulated through ECM stiffness. a) Downstream Notch genes Heyl and Hesl were analyzed via qPCR following culturing on polyacrylamide hydrogels with stiffnesses of 10 , 20 , and $40 \mathrm{kPa}$. B) Downstream Notch gene Hes5 was analyzed via luciferase assay after being cultured on various stiffness of polyacrylamide hydrogels at $10,20, \& 40 \mathrm{kPa}$. Values are mean $+/-\mathrm{SEM} ; *=\mathrm{p}<.05, * *$ $=\mathrm{p}<.01$

Figure A.1: Canonical Notch signaling and Notch conservation between human and Monosiga brevicollis. Throughout Figure 1, conservation of Notch proteins or domains between human and $M$. brevicollis is indicated by green (positive), yellow (unknown), or red (negative) shading according to references (King, Westbrook et al. 2008) and (Gazave, Lapebie et al. 2009). (A) Conservation of mammalian Notch receptor domains in $M$. brevicollis. Mammalian (human) Notch receptors contain 36 EGF-like repeats and three LNR or NRR (Lin-12 Notch Repeats or Negative Regulatory Region) repeats in the extracellular domain. The intracellular portion of human Notch contains seven ankyrin domains and a PEST sequence at the C-terminal. For simplicity, the intracellular RAM (RBPj Association Module) domain, two NLS (Nuclear Localization sequence) domains, and TAD (Transactivation Domain) are not shown in this figure. 
Please refer to references (Kopan and Ilagan 2009, Kopan 2010) for complete details. Three separate proteins (N1, N2, and N3) in $M$.

brevicollis contain six Ankyrin domains, two LNR domains, and 36 EGFlike repeats respectively (King, Westbrook et al. 2008). (B) Model of canonical Notch activation mechanism. Notch receptors are modified in the secretory pathway (ER/golgi) by Furin cleavage ( $\mathrm{S} 1$ cleavage) and glycosylation of EGF-like domains by O-fucosyltransferase (O-fut), Rumi/Poglut1 (Protein O-Glycosyltransferase 1), and fringe family glycosyltransferases. The Furin cleavage products remain non-covalently associated in the membrane where a pulling force initiated by Notch ligand endocytosis in sending cells enables further cleavage by $\alpha$-secretase (S2 cleavage, NEXT fragment) at the LNR domain, and $\gamma$-secretase (S3 cleavage, NICD fragment) in the membrane of receiving cells. Several regulatory proteins including Numb, Notchless, and Deltex control Notch availability at the membrane. After $\gamma$-secretase cleavage, the NICD fragment translocates to the nucleus where it displaces the transcriptional co-repressor SMRT from CSL/RBP-jk. NICD participates in a transcriptional complex with CSL, MAML, and p300 to drive transcription of Notch targets such as Hes and Hey genes. NICD steadystate levels are controlled by nuclear export, ubiquitination (Ub) by Sel10, and subsequent degradation in the proteasome.

Figure A.2: $\quad$ Summary of ECM control of Notch signaling. Canonical activation of Notch receptors by Notch ligands can be manipulated in three ways by cellular interactions with ECM. 1.) Direct interactions between Notch receptors or ligands and various ECM molecules can either inhibit or promote activation of Notch signaling. 2.) Indirect interactions between ECM and Notch are characterized by ECM mediated increased or decreased expression of Notch ligands on sending cells or Notch receptors on receiving cells. 3.) Indirect interactions between Notch and ECM are characterized by ECM mediated activation of signaling pathways that post-translationally intersect with Notch proteins or signaling intermediates.

Figure A.3: Crosstalk between Notch and other signaling pathways. Crosstalk between WNT and Notch occurs on several levels including the formation of a $\beta$ catenin-NICD transcriptional complex, interaction between Notch receptors and $\beta$-catenin at the membrane, phosphorylation of NICD by GSK3 $\beta$, and inhibitory interactions between Dishevelled and CSL. The mechanistic interaction between integrins and Notch is poorly characterized, but existing evidence suggests ubiquitination and/or phosphorylation of NICD by SRC and ILK kinases. Interaction between the Notch and VEGF pathways involves the reciprocal transcriptional regulation of Notch ligands by VEGF, and VEGFR2 by Notch. Notch/TGF- $\beta$, or Notch/BMP crosstalk occurs downstream of ALK (TBR1/TBR2 or BMPR1/BMPR2) receptors and is dependent on R- 
SMAD and Co-SMAD activation and subsequent formation of a SMAD/NICD transcriptional complex similar to the $\beta$-catenin/NICD complex

Figure A.4: Summary of microenvironmental conditions (shear stress, hypoxia, and hyperglycemia) that control Notch. Depicted is a cross-sectional view through a blood vessel showing endothelial cells (EC) and vascular basement membrane. Shear stress (laminar versus disturbed or nonlaminar) controls Notch by largely undefined mechanisms that may include regulation of Notch receptors and/or ligands. Hypoxia controls Notch signaling by several mechanisms including the formation of HIF1 $\alpha$ NICD transcriptional complexes, HIF1 $\alpha$ mediated stabilization of NICD, enhanced $\gamma$-secretase activity, and FIH mediated NICD destabilization. Hyperglycemia controls Notch by largely uncharacterized mechanisms that may include increased NICD stability due to decreased CARM1 expression and/or increased VEGF release from other cells in the vascular microenvironement 


\section{LIST OF ABBREVIATIONS}

\begin{tabular}{|c|c|}
\hline $\mathrm{ECM}$ & Extracellular Matrix \\
\hline NECD & Notch Extracellular Domain \\
\hline NICD & Notch Intracellular Domain \\
\hline EGF & Epidermal Growth Factor \\
\hline $\mathrm{LN}$ & Lin-12-Notch Repeats \\
\hline RAM & RBP-J Associated Module \\
\hline PEST & Proline Glutamine Serine Threonine \\
\hline TAD & Transactivational Domain \\
\hline RBP-J & Recombining Binding Protein Suppressor of Hairless \\
\hline bHLH & Basic Helix-Loop-Helix \\
\hline HIF- $\alpha$ & Hypoxia Inducible Factor Alpha \\
\hline $\mathrm{T}-\mathrm{ALL}$ & T-cell Acute Lymphoblastic Leukemia \\
\hline FAK & Focal Adhesion Kinase \\
\hline $\mathrm{EC}$ & Endothelial Cell \\
\hline KLF2 & Kruppel-like Factor 2 \\
\hline NRF2 & Nuclear Factor (Erythroid-Derived 2) Like 2 \\
\hline ROS & Reactive Oxygen Species \\
\hline VEGF & Vascular Endothelial Growth Factor \\
\hline eNOS & Endothelia Nitric Oxide Synthase \\
\hline MAML & Mastermind Like \\
\hline
\end{tabular}


CSL

GAG

DSL

HES

HEY

MBCD

RGD

DPI

$\alpha-S M A$

HDF

HMEC1

LX2

PEI
CBF1, Suppressor of Hairless, LAG-1

Glycosaminoglycan

Delta/Serrate/LAG-22

Hairy Enhancer of Split

Hairy/Enhancer-Of-Split Related With YRPW Motif 1

Methyl-Beta-Cyclodextrin

Arginylglycylaspartic Acid

Diphenyliodonium

Alpha Smooth Muscle Actin

Human Dermal Fibroblast

Human Microvascular Endothelial Cells 1

Human Hepatic Stellate Cells

Polythylenimine 


\section{CHAPTER ONE: INTRODUCTION}

\section{Cellular Signaling}

The biological cell is the fundamental unit that make up living organisms. Each cell contains the individual's genetic information that will induce certain phenotypes to regulate functions like cellular differentiation and homeostasis. One of the ways that cells fulfill these necessary tasks is by communicating with the genome from extracellular cues. When receptors receive these microenvironmental triggers, a biochemical cascade event will ensue transferring information via small molecules (e.g. phosphorylation, ubiquitination) via specific transporters (e.g. kinases, ubiquitin ligases) between signaling intermediates. Kinases can phosphorylate either tyrosine residues or serine/threonine residues on proteins which will alter their behavior and phosphatases can counteract this event by removing the phosphate group. Eventually this cascading phenomena will influence genetic expression by molecules either binding to the DNA itself (e.g. transcription factors) or by binding to existing proteins on the DNA (co-transcription factors). This will cause genes to either upregulate or downregulate the expression of mRNA leading to the construction or degradation of functional proteins. Ultimately, without cellular signaling, cells would have no information as to guide them to differentiation, apoptosis, migration, mitosis, and many other cellular fates. 


\section{The Cellular Microenvironment}

Cells exist in a large variety of local microenvironments and the scope of these environments largely depend on the type of cell and its physiological location in the body. Each cell's specific location offers differing micro environmental stimuli like neighboring cell interactions (e.g. cell-cell, signaling molecules), extracellular matrix composition (e.g. stiffness, stretching), osmolality, temperature, acidity, and fluid shear stress. Cells can also manipulate their own microenvironment. Fibroblasts secrete extracellular matrix (ECM) proteins changing the surrounding matrix composition and stiffness. Arguably, the most notable example of cells manipulating their surroundings is the tumor microenvironment. Tumor cells display an autocrine-like behavior with the microenvironment, creating their own physical surroundings like $\mathrm{pH}$ change and hypoxia to promote the degradation of the extracellular matrix to increase invasiveness (Gillies \& Gatenby, 2007). They have also been shown to manipulate production of growth factors (e.g. VEGF) to promote angiogenesis from nearby vessels to supply the starving tumors with the appropriate nutrients and oxygen (Juczewska \& Chyczewski, 1997). Many pathologies are related to micro environmental changes like abnormal ECM stiffness, a common characteristic of fibrosis, and abnormal shear stress, which is linked to atherosclerosis. Because the microenvironment is involved in a large portion of ailments, it has become a focal point for numerous research studies. Understanding how cells respond to their microenvironment and the molecular mechanisms involved is crucial for developing strategies to counteract related pathologies. 


\section{Notch Receptors}

Overview

Notch is a heterodimeric, transmembrane ligand receptor that when activated becomes a co-transcription factor and is important in most tissues for functions like proliferation, development, and migration. The discovery of Notch occurred more than 100 years ago (1914) and was linked to a loss of function "notch" phenotype in the wings of Drosophila melanogaster (Metz \& Bridges, 1917). In mammals, four homologs of Notch (Notch 1-4) and five canonical ligands (Jagged1, and 2 and Delta-like 1,3 and 4), which are exhibited on adjacent cells, have been recognized. The Notch receptor can be divided into three domains: the extracellular, transmembrane and intracellular domain. The extracellular domain (NECD) is made up of 36 epidermal growth factor (EGF)-like repeats responsible for ligation (Wharton, Johansen, Xu, \& Artavanis-Tsakonas, 1985). The transmembrane portion consists of three Lin-12-Notch (LN) repeats mediating the extracellular-intracellular interactions (Fiuza \& Arias, 2007), and the intracellular domain (NICD) which has an RBP-J associated molecule (RAM) followed by seven ankyrin repeats connected to a proline, glutamine, serine, and threonine-rich (PEST) domain and a transactivation domain (TAD) responsible for transcriptional activity (Fiuza \& Arias, 2007) (figure 1.1). From initial expression to transcriptional regulation, Notch experiences a total of three cleavage events. The first cleavage (S1) of Notch is carried out by the cleaving enzyme Furin and occurs during transportation through the Golgi complex morphing the full length protein into two non-covalently attached heterodimeric portions (Logeat et al., 1998). Notch is then O-linked glycosylated for the proper folding conformation to occur before it is secreted to the cell membrane. Once the final 
membrane destination is reached, Notch activation may occur via ligand binding or independently of ligand binding. The second cleavage (S2) is carried out by the metalloproteinase ADAM, completing the extracellular domain separation. This cleavage may happen through a ligand-dependent or independent manner. Recent work has revealed that ADAM10 cleavage activation might happen through ligand-dependent activation whereas ADAM17 may be responsible for ligand-independent activation (Bozkulak \& Weinmaster, 2009; Christian, 2012). During Notch ligand-dependent activation in vertebrates, membrane proteins on adjacent cells (Jagged, Delta-like) activate Notch by attaching to the extracellular domain. The adjacent cells then endocytose the ligand and NECD which induces ADAM to cleave the extracellular domain. Finally, a subsequent third cleavage (S3) takes place in which gamma secretase excises the intracellular domain at the plasma membrane (Sorensen \& Conner, 2010; Struhl \& Adachi, 2000) where the NICD will then travel to the nucleus to take part in transcriptional regulation. 


\section{The Notch Receptor}

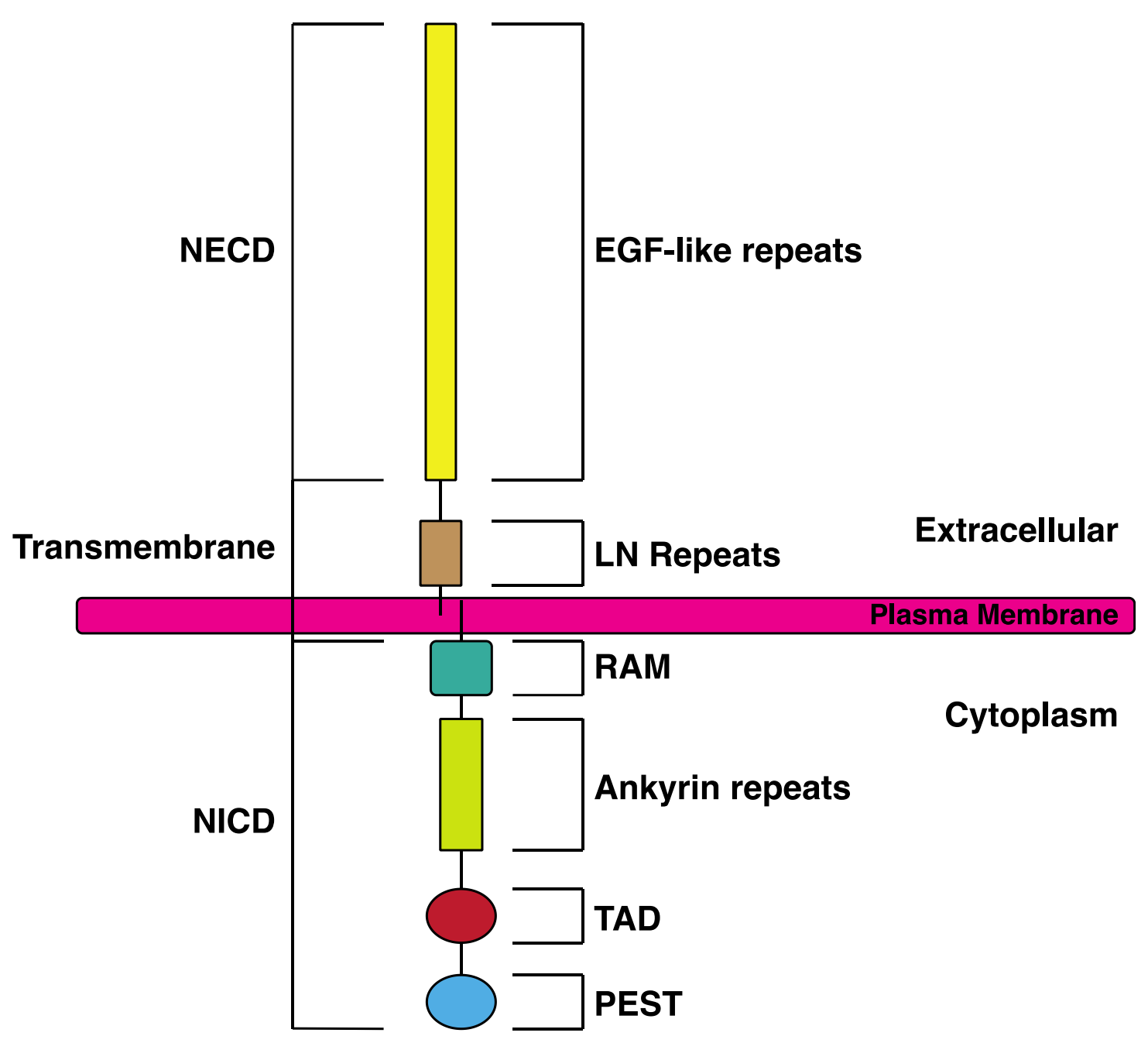

Figure 1.1: Domains of the Notch receptor. The extracellular domain (NECD) of Notch contains 36 epidermal growth factor (EGF)-like repeats, followed by a transmembrane portion containing Lin-12-Notch repeats. The intracellular domain (NICD) consists of RAM, Ankyrin repeats, transactivation domain (TAD) and proline, glutamine, serine, and threonine (PEST)-rich domains and is responsible for transcriptional control.

\section{Downstream Notch Signaling}

For transcriptional activity, the NICD doesn't actually bind to the DNA, but rather dimerizes with recombining binding protein suppressor of hairless (RBP-J or CSL) where it acts as a co-transcription factor along with other factors like p300 and MAML. The 
most widely recognized downstream targets of Notch signaling are the Hair and Enhancer of Split Family (Hes, Hey) genes. In Drosophila melanogaster, these genes regulate developmental processes like segmentation through expression of basic Helixloop-helix (bHLH) proteins. In rodent genomes, seven Hes and three Hey genes have been recognized, whereas only Hesl, 5 , and 7 have been shown to be activated by Notch while all three of the Hey genes (Heyl, 2, and $L$ ) show induction by Notch signaling as reviewed by Fischer and Gessler (Fischer \& Gessler, 2007). Hes genes are involved in sensory organ, nervous system, pancreas and endocrine cell development, where the Hey genes tend to be involved in the cardiovascular system (Fischer \& Gessler, 2003, 2007). Canonical vs Non-Canonical Activation

The most widely understood mechanism for Notch activation is through ligand binding from adjacent cells. As previously mentioned, Delta and Jagged are membrane bound ligands that bind Notch on adjacent cells causing endocytosis and inducing the Notch cleavage events leading to downstream genetic signaling. Conversely, during a "cis-ligand" interaction, Notch interacts with Delta and Jagged on the same cell, which inhibits Notch activation (Palmer, Jia, \& Deng, 2014). Recently, evidence has surfaced that Notch signaling can be induced through ligand-independent methods rather than by conventional means. One method proposed that Notch signaling can happen by a disruption in genes, causing abnormal endosomal sorting and ubiquitination. When Notch is ready for degradation, Notch is polyubiquinated and is sorted into intraluminal vesicles for transport to the lysosome. The NICD can be accidently removed from the NECD when ensnared on the outer endosome membrane, mimicking activation (Palmer \& Deng, 2015). Other methods have also been proposed to induce Notch signaling independent of 
ligand activity through micro environmental stimuli. In Drosophila, it was shown that the homolog to mammalian hypoxia inducible factor- $\alpha$ (HIF- $\alpha$ ) activated Notch signaling independent of ligand interactions (Mukherjee, Kim, Mandal, \& Banerjee, 2011), suggesting hypoxic environments lead to the signaling event. Experimentally, Notch can be activated independent of ligand binding by calcium chelation. Notch LN repeats are connected to the NECD by calcium bridges, and when a calcium chelator (e.g. EDTA) is applied, the NECD dissociates and induces the cleavage activation events. Knowing that Notch signaling can be induced in a ligand-independent manner has opened many doors into the investigation of Notch signaling by other non-canonical means.

\section{Notch Signaling and Disease}

Since Notch signaling is involved in countless cellular functions, it's not surprising that Notch signaling is also associated with many diseases. Hereditary pleiotropic disease, metabolic bone disease, cardiovascular and cerebrovascular disease, and most notably cancers are just a few of the associated ailments involving Notch signaling (Louvi \& Artavanis-Tsakonas, 2012). Notch was first recognized as an oncogene in 1991 when chromosomal rearrangements were discovered in human T-cell acute lymphoblastic leukemia (T-ALL), an aggressive hematologic tumor, effecting the human Notch1 gene by causing abnormal activation of Notch signaling (Chan et al., 2013; Louvi \& Artavanis-Tsakonas, 2012; Tosello \& Ferrando, 2013). Notch has also been shown to be involved in breast cancer (Gallahan \& Callahan, 1997), multiple myeloma (plasma cell cancer) (Colombo et al., 2015), and adenocarcinomas (Yuan et al., 2015) among others. Notch also aids tumor progression by inducing pro-angiogenic effects and is involved in the epithelial to mesenchymal transition process contributing to 
tumor metastasis. Due to the numerous activities that Notch regulates, therapeutic targeting of Notch is extremely difficult. Further understanding of Notch and its relation to these pathologies will aid researchers in potentially circumventing these possible pitfalls.

\section{Integrins}

\section{$\underline{\text { Overview }}$}

Integrins are transmembrane receptors that heterodimerize between two subunits, alpha and beta, and are mainly known for attaching the cell to a matrix substrate creating focal adhesions. Apart from this, integrins have the capability of signaling into the cell to aid in numerous functions like the cell cycle, shape, and cell migration (Giancotti \& Ruoslahti, 1999), and focal adhesion tension. In mammals, 18 alpha subunit and 8 beta subunits have been recognized and form 24 different integrin molecules. Both of the subunits contain large $\mathrm{N}$-terminal extracellular domains responsible for binding to ECM proteins, followed by a short membrane spanning domain which is then linked to a short intracellular domain. Once integrins have made the ECM attachment, they go through conformational changes that will increase association with focal adhesion molecules like talin, vinculin, and Rho GTPase family molecules Rho, Rac, and Cdc42. ECM- or Ligand-bound conformational changes in integrins have been suggested to induce outside-in signaling, and if multiple ECM binding sites are provided, integrins will cluster, promoting kinase activity for downstream signaling (C. Kim, Ye, \& Ginsberg, 2011). We have previously reviewed that integrins not only bind to the ECM, but also bind to a multitude of factors including viruses, bacteria, growth factors, and hormones (Lafoya et al., 2018). Integrins transmit signals from the extracellular space to the interior 
referred to "outside-in" signaling, but signals can be transduced from inside the cell called "inside-out" signaling as well, dictating ECM binding affinity. Molecules like thrombin can manipulate integrin binding affinity through the protein Talin, which is responsible for binding to the beta subunit tail of integrin heterodimers, essentially connecting integrins to the actin cytoskeleton (Ginsberg, 2014; Ratnikov, Partridge, \& Ginsberg, 2005).

Integrin Downstream Signaling

It has been established that integrin attachment to the ECM is important for cell survival and in the absence of cellular attachment, cells can undergo apoptosis (Frisch \& Francis, 1994; Meredith Jr., Fazeli, \& Schwartz, 1993). ECM attachment has also been found to regulate genetic expression involved in multiple cellular functions like survival, proliferation, motility, and cytoskeleton remodeling. Evidence has uncovered multiple tyrosine kinases (e.g. Src, FAK) (Kornberg, Earp, Turner, Prockop, \& Juliano, 1991; Rohrschneider, 1980) that localize to focal adhesions and are phosphorylated following integrin attachment to the ECM. There have also been integrin-associated membrane proteins that have been identified to couple with integrins and regulate their response including CD47, growth factor receptors, syndecan heparin sulfate proteoglycan receptors, and many more (Miranti \& Brugge, 2002). Since these connections have been established, studies have investigated the downstream genetic effects of integrins and the roles they play in cellular behavior. Recent evidence has also revealed that integrins influence downstream pathways through extracellular cues like shear stress and matrix stiffness (J. Chen et al., 2015; D A Chistiakov, Orekhov, \& Bobryshev, 2016; Du et al., 2016; Shih, Tseng, Lai, Lin, \& Lee, 2011; Y. Wang et al., 2002). 


\section{Shear Stress}

\section{Cardiovascular System}

The cardiovascular system is a network of vasculature that provides nutrients and oxygen via blood to the cells throughout the body. Blood consists of red and white blood cells, plasma, and platelets and is pumped through the vasculature by contractions from the heart. The cardiovascular system can be divided into two main groups: arteries and veins. Arteries function to deliver oxygenated blood (pulmonary artery is an exception) from the heart to the tissues of the body. Tissues receive oxygen and nutrients from the blood through "leaky" capillary beds into the interstitial fluid of the tissues. Capillaries connect the arteries to the veins, where oxygen/nutrient deficient blood (pulmonary vein is an exception) is carried back to the heart. Blood vessels are essentially made up of three layers, the tunica intima, media, and adventitia. Tunica intima is the inner most layer and consists of a monolayer of epithelial cells called the endothelium that line the interior of vessels and are attached to a substrate of extracellular matrix made up of mostly structural proteins (e.g. collagen) called the basement membrane. Endothelial cells (ECs) are responsible for vascular permeability, regulating inflammation, preventing thrombosis, and controlling the integrity of the vessel (Dimitry A. Chistiakov, Orekhov, $\&$ Bobryshev, 2015). Surrounding the intima is the tunica media which is comprised of smooth muscle cells and interstitial ECM molecules that are responsible for vasoconstriction and dilation of the vessel tube. Finally, the external layer, the tunica adventitia, mainly made up of collagen, provides elasticity and connects the vessels to the surrounding tissue (figure 1.2). 


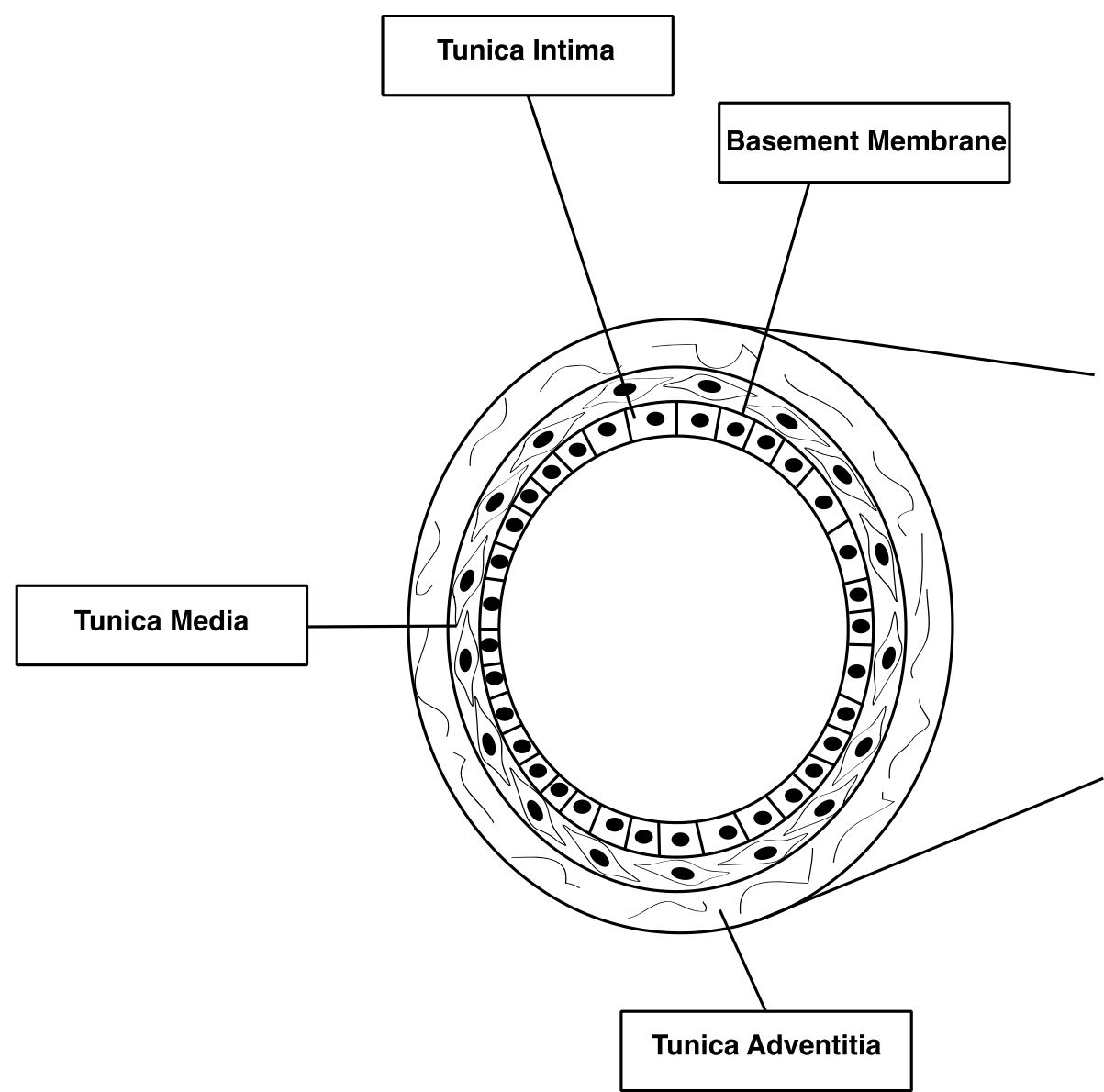

Figure 1.2: Blood vessels consist of 3 main layers. The tunica intima is composed of endothelial cells surrounded by a basement membrane and regulates vessel permeability and integrity. The tunica media has smooth muscle cells and matrix proteins and is mainly responsible for contraction/dilation of the vessel, and the tunica adventitia consists of mostly ECM proteins and associates the vessels with the surrounding tissue and provides elasticity. 


\section{$\underline{\text { Hemodynamics }}$}

Hemodynamics refer to the physical forces on the endothelium of blood pumping through the vasculature from the contractions of the heart. Shear stress is a parallel, hemodynamic force from the flow of blood acting on the endothelium of the vessel walls. The force from blood flow is considered to be non-Newtonian in the sense that the vessels are non-uniform and the blood viscosity changes with varying shear stress which is why it is calculated with considerations of fluid flow, viscosity, and vessel dimensions (Ballermann, Dardik, Eng, \& Liu, 1998). Shear stress is typically measured in $\mathrm{dyn} / \mathrm{cm}^{\wedge 2}$ where $1 \mathrm{dyn} / \mathrm{cm}^{\wedge 2}$ is equal to 0.1 pascals. This force can be conducted via a constant (laminar) flow seen in normal vasculature conditions or can be a disturbed or oscillatory flow which can be seen in vascular curvatures, bifurcations, branching and abnormalities like atherosclerotic plaques and displays a reversal characteristic in the flow. Laminar flow on ECs induces properties like cell survival, barrier function, antithrombotic properties, and inhibits immune cell extravasation(D A Chistiakov et al., 2016), whereas disturbed or oscillatory flow promotes increased permeability of the endothelium, apoptosis, immune cell adhesion and alters cell morphology, all characteristics of atherosusceptibility (D A Chistiakov et al., 2016; Zhou, Li, \& Chien, 2014). Mechanotransduction

Upon the implementation of shear stress to ECs, it has been suggested that the force is first transmitted from the apical surface of the cell to the cytoskeleton. A major characteristic of EC's response to laminar shear stress is the morphological alignment of 
the cells parallel to the flow of blood by reorganizing the cytoskeleton and developing actin stress fibers (Mengistu, Brotzman, Ghadiali, \& Lowe-Krentz, 2011; Noria et al., 2004). Malek and Izumo were able to show that by disrupting microtubules, the morphological alignment of the cells to blood flow did not occur and actually caused the cell shape to be a rounded structure, suggesting that microtubules are responsible for flow-induced alignment (A M Malek \& Izumo, 1996). Also, disturbed flow has been shown to have a similar response to microtubule disruption where ECs fail to align with the direction of flow and show this rounded shape, causing greater resistance to the flow force inducing pro-atherogenic characteristics (Heo, Fujiwara, \& Abe, 2011; Zhou et al., 2012). Rho-family GTPases have been widely demonstrated to also control actin fiber development and cytoskeleton rearrangement through integrin activation following shear stress (Tzima, 2006; Tzima, Del Pozo, Shattil, Chien, \& Schwartz, 2001; Yang, Radel, Hughes, Kelemen, \& Rizzo, 2012; Zhou et al., 2014). Secondly, stress of the cytoskeleton is intracellularly transmitted to the sites of cell-cell adhesion and cell-ECM attachment (P F Davies, 1997). Some of the main proposed mechanisms of these sites are tight junctions (occludins) (DeMaio, Chang, Gardner, Tarbell, \& Antonetti, 2001), adherin junctions (VE-cadherins)(Caolo et al., 2018), Tyrosine Kinase receptors (VEGFR2)(dela Paz, Walshe, Leach, Saint-Geniez, \& D’Amore, 2012; Masumura, Yamamoto, Shimizu, Obi, \& Ando, 2009), and focal adhesions (integrins)(Tzima et al., 2001) among many others (Figure 1.3). Finally, downstream signaling occurs as a result. Many molecules are known to have expression changes or modifications (e.g. phosphorylation) from shear 
stress applications. It has been reported that hundreds of genes respond to shear stress, upregulated and downregulated, and under laminar flow induce anti-atherogenic characteristics (Resnick et al., 2003). Downstream markers that are used in research to identify a change in shear stress on cells include endothelial nitric oxide synthase (eNOS), kruppel-like factor 2 (KLF2), nuclear factor (erythroid-derived 2) like 2 (NRF2), reactive oxygen species (ROS), vascular endothelial growth factor (VEGF), and more recently Notch (D A Chistiakov et al., 2016; X.-L. Wang, Fu, Raghavakaimal, \& Lee, 2007; Wragg et al., 2014; Zhou et al., 2014).

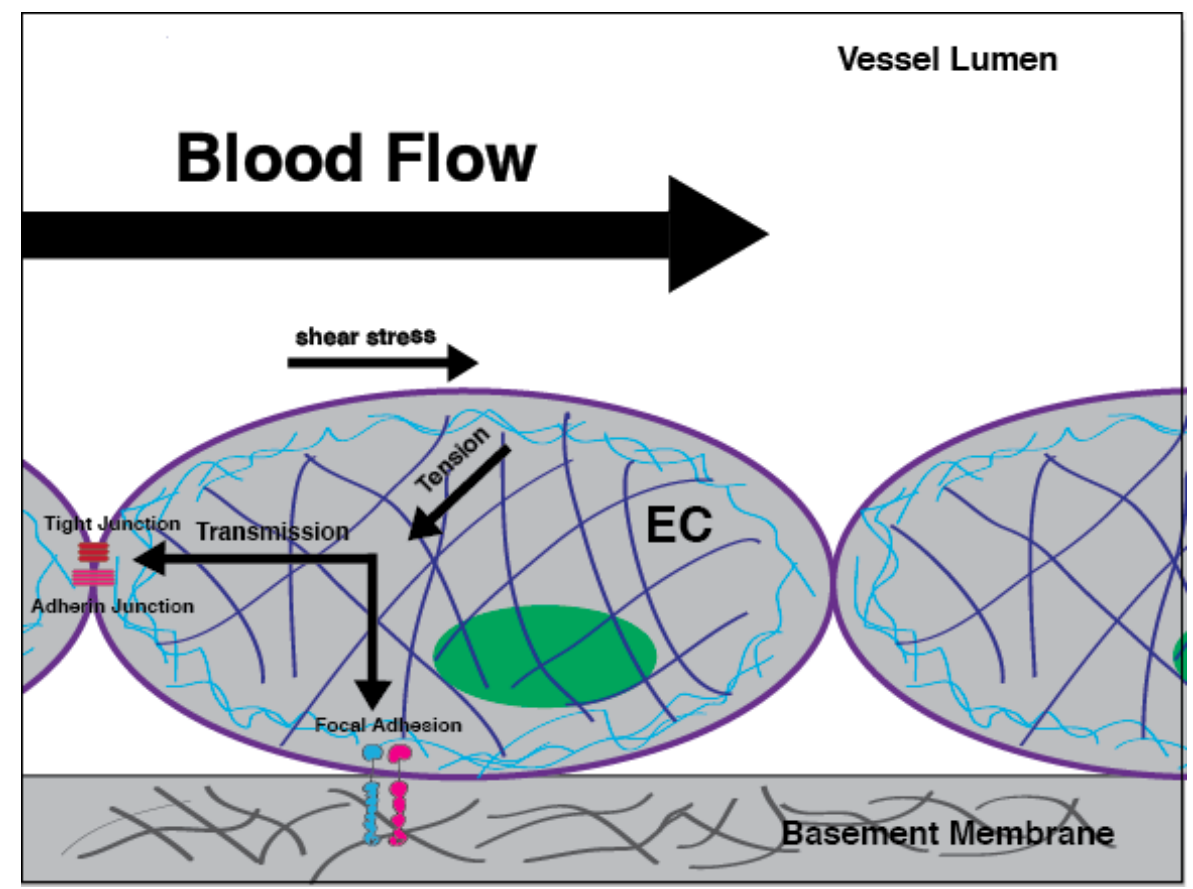

Figure 1.3: Mechanotransduction. Illustration showing the proposed method of mechanotransduction. As shear stress forces are implemented to the apical surface of cells, the force applies tension to the cytoskeleton where it will then transmit to the focal adhesions and junctions of the cell. 


\section{$\underline{\text { Notch and Shear Stress }}$}

Notch signaling is regulated under the physical conditions of shear stress caused by blood flow in vascular endothelial cells (Fang et al., 2018; Jahnsen et al., 2015; Mack et al., 2017; Tu, Li, \& Hu, 2014), and lymph flow in lymphatic endothelial cells (Choi et al., 2017). In vivo and in vitro studies have both revealed Notch activation under a variety of shear stress conditions. A study in rats determined Notch activation from wall shear stress by modeling arteriovenous malformations via connecting the jugular vein to the carotid artery which revealed Notch1 expression to be significantly increased after one day of wall shear stress in the abnormal junction, and interestingly Notch4 expression showed a significant upregulation after 3 weeks post Notch1 increase (Tu et al., 2014). Another in vivo experiment in transgenic adult mice where an inducible deletion of Notch1 was created presenting evidence that flow-induced Notch1 controls cell polarity, cell-cell junction maintenance, and the ability to suppress cell proliferation (Mack et al., 2017).

To receive a shear stress response in vitro, many methods are utilized from orbital shakers (H. Kim et al., 2015) to flow-loop perfusion devices (Frangos, Eskin, McIntire, \& Ives, 1985; X.-L. Wang et al., 2007). Physiological arterial shear stress typically ranges between 10-40 dyn/cm^2 (Resnick et al., 2003) whereas physiological venous shear stress ranges from approximately 1-6 dyn/ $\mathrm{cm}^{\wedge} 2$ (Wragg et al., 2014). In the case of atherosclerotic plaques in the arterial system, the fatty buildups tend to form near bifurcations, arterial arches, and branching points where disturbance in flow occurs 
causing a variation in the shear stress forces along the vessel walls (Chiu \& Chien, 2011). An interesting dynamic recently demonstrated the variation in rate of flow $\left(\mathrm{dyn} / \mathrm{cm}^{\wedge}{ }^{2}\right)$ in vitro that is necessary to activate Notch signaling. In recent in vitro studies, Notch1 expression or activation occurred from $1-5 \mathrm{dyn} / \mathrm{cm}^{\wedge} 2$ up to $15 \mathrm{dyn} / \mathrm{cm}^{\wedge} 2$ (Jahnsen et al., 2015; White et al., 2015), opening the novel topic to many new questions.

As previously mentioned, upon activation of the Notch receptor, which induces the cleavage events, the separate cytosolic portion of the protein (NICD) travels to the nucleus where it engages with the co-transcriptional factors MAML and RBP-J inducing transcription of particular genes. Among these genes the most widely accepted and used targets are the mammalian homologs of hairy and enhancer-of-split in drosophila, hes and hey genes (Fischer \& Gessler, 2007; Tosello \& Ferrando, 2013). These genes are common markers for activation of Notch signaling in mammalian cells. Since these genes do seem to be upregulated during shear stress, this suggests that Notch receptor activation is being increased under these conditions. This raises the question of whether this phenomenon is taking place due to increased activation of the receptor itself or is the upregulation taking place due to increased expression of Notch, thus creating a higher concentration of receptors at the membrane. One way this can be examined is by detecting the expression levels of the Notch protein. Not only does the majority of the recent literature show the expression levels of Notch increase from shear stress (Jahnsen et al., 2015; Qin et al., 2016; Tu et al., 2014; White et al., 2015), but also expression levels of Notch ligands show increase (Fang et al., 2018; Jahnsen et al., 2015; Qin et al., 
2016; Tu et al., 2014) suggesting higher levels of Notch activation due to an increase in membrane concentration of the proteins and its ligands. Although, the upregulation in expression mainly occurs hours after shear stress implementation. Further research could address this by possibly inhibiting protein translation (e.g. via cycloheximide) and testing downstream genes to see if upregulation still takes place.

Variations in hemodynamic shear stress is a major contributor to the development of atherosclerotic plaques. Steady, laminar flow induces anti-atherosclerotic properties in endothelial cells by promoting certain phenotypes including inhibition of thrombotic activity, inflammation, proliferation, etc (Gimbrone \& Garcia-Cardena, 2013). As previously mentioned, atherosclerotic plaques tend to form near branch points, curvatures, and bifurcations where the shear stress forces on the endothelium exhibit a low non-laminar style, disturbed flow inducing pro-atherosclerotic vascular properties like endothelial dysfunction and inflammation(Chiu \& Chien, 2011; Cunningham \& Gotlieb, 2004; Gimbrone \& Garcia-Cardena, 2013; Heo, Fujiwara, \& Abe, 2014; Ravensbergen, Ravensbergen, Hillen, \& Hoogstraten, 1998). Canonical Notch1 activity in the endothelium has been shown to suppress endothelial cell activation, white blood cell attachment, and pro-atherosclerotic molecule overexpression (Anaïs Briot et al., 2015; Anais Briot, Bouloumie, \& Iruela-Arispe, 2016). 


\section{ECM}

\section{$\underline{\text { Overview }}$}

Tissues comprise of cells and ECM. The ECM is a highly variable collection of secreted structural and non-structural molecules in the intercellular space of tissues to provide functions like cell adhesion (e.g. focal adhesions, cell-cell attachment), communication, and differentiation. In mammals, two types of ECM exist and are located in the interstitial space of tissue that or in the basement membranes separating epithelial layers from surrounding connective tissues and regulates cell polarity, proliferation, and migration. The ECM is composed of mainly proteins and glycosaminoglycans (GAGs). GAGs in the ECM can connect to protein cores to establish a proteoglycan molecule which serves to keep the ECM hydrated and gel-like. Major proteins of the interstitial ECM include collagen, elastin, and fibronectin, whereas in the basement membrane the ECM proteins are mainly collagen and laminin.

\section{$\underline{\text { ECM Stiffness }}$}

When cells adhere to the ECM via focal adhesions, the actin cytoskeleton senses tension and responds. The stiffness of the ECM is dictated by the concentration of structural proteins like collagen. It has been shown that cells on stiffer ECM show higher organization in the cytoskeleton and more stability in the focal adhesion complex (Discher, Janmey, \& Wang, 2005). Young's elastic modulus is used to measure the resistance from substrates by the application of force to a specific area and measuring the change in length (Wells, 2008). This is recorded in Pascal units (newtons $/ \mathrm{m}^{2}$ ). Stiffness in 
tissues varies greatly throughout the body where brain tissue stiffness measures in the hundreds of pascals (Miller, Chinzei, Orssengo, \& Bednarz, 2000) compared to muscle tissue which measures from 5-12 kPa (Cox \& Erler, 2011). Cells respond and regulate their behavior depending on the stiffness of their substrate matrix including proliferation (LaValley et al., 2017), migration (Asano et al., 2017), and differentiation (Shih et al., 2011). Fibrosis is a hallmark pathology that is associated with matrix stiffness and results from excessive accumulation of ECM components secreted typically by fibroblasts and eventually can result in organ failure. The onset of this condition is commonly a result of organ or tissue injury and mimics scarring. There are also molecular pathways involved in fibrosis, most notably transforming growth factor-beta (TGF- $\beta$ ) which induces Smad signaling pathways causing activation of fibroblasts, excessive ECM production, and inhibition of degradation. In recent years, Notch has been shown to be associated with fibrosis. For instance, during liver and kidney fibrosis in rodents, Notch was shown to be significantly upregulated (Bielesz et al., 2010; Y. Chen et al., 2012).

Experimentally, polyacrylamide hydrogels with variable stiffnesses can be used to test cell's response in vitro. This can be done by mixing acrylamide and biz-acrylamide, with stiffness depending on the ratio of each, and allowing the solution to polymerize on glass surfaces. Following this, a cross-linker must be used (e.g. L-DOPA, Sulfo-sanpah) to link the acrylamide to an ECM protein where then cells may be cultured on the surface (Tse \& Engler, 2010; Wouters, Ploeger, van Putten, \& Bank, 2016a, 2016b) (figure 1.4). 


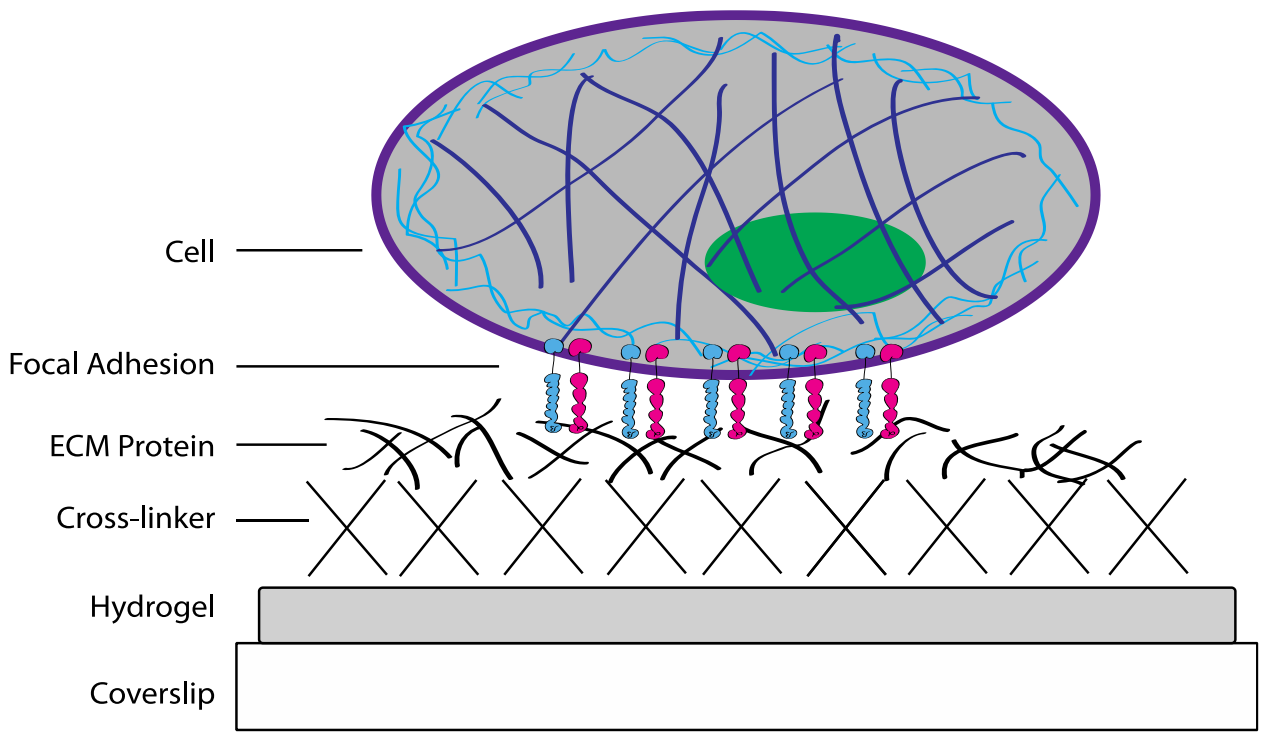

Figure 1.4: Polyacrylamide hydrogel. Illustration of experimental hydrogels. A glass coverslip is used to attach polyacrylamide hydrogel. The hydrogel is then crosslinked to an ECM protein using crosslinkers like L-DOPA or Sulfo-sanpah. The cells are then cultured on the surface attaching to the ECM protein with focal adhesions. 


\title{
CHAPTER TWO: INITIAL SHEAR STRESS-INDUCED NOTCH SIGNALING IS REGULATED THROUGH AND INTEGRIN PATHWAY
}

\begin{abstract}
The hemodynamic forces that manipulate cellular signaling in endothelial cells play an important role in the differentiation and the overall behavior of these cells. Notch activation is an important factor in regulating endothelial cell behavior including antiatherosclerotic properties. Previous studies have revealed that Notch signaling is upregulated from the forces of blood flow acting on the cell, yet the intermediate mechanisms remain unknown. We demonstrate that Notch signaling is indeed upregulated following $\sim 12 \mathrm{dyn} / \mathrm{cm}^{\wedge} 2$ of shear stress and that by inhibiting integrin activation the shear stress upregulation of Notch signaling is abrogated, specifically through a Heyl downstream pathway. Also, we have identified that by inhibiting integrin-activation downstream molecules, Src and eNOS, the shear-stress-induced Notch activation is again significantly reduced, suggesting these molecules are required for this event. From these findings, we can deduce that Notch activation is regulated by the micro environmental pressures of shear stress through an integrin pathway.
\end{abstract}




\section{Introduction}

Hemodynamic forces play an important role in the vascular system by regulating the behavior of endothelial cells and vascular smooth muscle cells. A specific example of these forces called shear stress is implemented to the apical surface of endothelial cells by the flow of blood. Measurements in the vasculature show that in the arterial system, average shear stress can measure between $10-40 \mathrm{dyn} / \mathrm{cm}^{\wedge} 2$ and in the venous system about 1- 6 dyn/ $\mathrm{cm}^{\wedge} 2$ (Adel M Malek \& Alper, 1999). The impact of force on these cells has been shown to be involved in numerous cellular responses like morphology, proliferation, and signaling events(D A Chistiakov et al., 2016; Resnick et al., 2003; Zhou et al., 2014). Many different molecules of the cell act as mechanosensors that transduce a signal to the cell which will then respond accordingly. These molecules include junctional proteins (e.g. occludins)(DeMaio et al., 2001; Gulino-Debrac, 2013), growth factors (e.g. VEGF)(dela Paz et al., 2012), and focal adhesions (e.g. integrins)(Ross et al., 2013). Integrins consist of two subunits, alpha and beta, that heterodimerize to become a functional unit that attaches to the extracellular matrix in endothelial cells. This connection to the ECM allows for focal adhesion, ultimately connecting the exterior of the cell to the interior cytoskeleton. Many studies have linked integrins and shear stress, showing a tendency for the proteins to regulate mechanotransductional signals from the blood-flow force (J. Chen et al., 2015; K. Chen et al., 1999a; Y. Wang et al., 2002; Yang \& Rizzo, 2013). 
Notch proteins are transmembrane, heterodimeric receptors that respond to Delta/Serrate/LAG-2 (DSL) ligands on adjacent cells. When ligand binding occurs, the adjacent cell proceeds to endocytose the ligand-receptor complex inducing ADAM metalloproteinase to cleave the extracellular domain from the receptor. Subsequently, gamma secretase then cleaves the intracellular domain (NICD) from the remaining transmembrane portion. The NICD then travels into the nucleus where it behaves as a cotranscription factor by binding and inhibiting RBPJ (CSL), a negative transcriptional regulator, causing expression of downstream genes, namely the Hairy/Enhancer of Split (Hes, Hey) family (Fischer \& Gessler, 2003, 2007). Recent publications have recognized that under the influence of shear stress, Notch signaling is upregulated and acts as a mechanosensor for the arterial endothelium inhibiting pro-atherosclerotic events (Fang et al., 2018; Jahnsen et al., 2015; Mack et al., 2017; X.-L. Wang et al., 2007). Contrary to this, it has been shown that shear stress downregulates Notch signaling in the lymphatic endothelium (Choi et al., 2017). A reduction in Notch1 has also been implicated in endothelial activation which results in increased leukocyte attachment to the endothelium and increased expression of pro-atherosclerotic molecules (Anaïs Briot et al., 2015; Anais Briot et al., 2016). Although Notch activation via shear stress has been established, little is known about the actual mechanics regulating these phenomena. Our data aims to answer our hypothesis that integrins regulate Notch activation from shear stress and that the downstream pathway to this event involves Src kinase and endothelial nitric oxide synthase (eNOS). 


\section{Results:}

Notch Signaling is induced by Shear Stress.

Endothelial Notch signaling is important for cell alignment, endothelium repair, cellular growth arrest, and maintaining a deactivated endothelial state (Anais Briot et al., 2016; Z. J. Liu et al., 2012; Theodoris et al., 2015; Venkatesh et al., 2011). The endothelium relies on a steady laminar flow to maintain these anti-atherosclerotic properties (Peter F Davies, 2009; Gimbrone \& Garcia-Cardena, 2013). Previous studies reported that Notch signaling was activated when shear stress forces were applied in vitro and in vivo (Fang et al., 2018; Mack et al., 2017; X.-L. Wang et al., 2007). Notch signaling has also been shown to be reduced when exposed to circulating lipids. Additionally, when the lipids reduced Notch signaling, endothelial activation occurred increasing leukocyte binding and upregulation of pro-atherosclerotic molecules (Anaïs Briot et al., 2015). To confirm Notch signaling is activated via shear stress, orbital shear stress was applied to confluent HMEC1s at $\sim 12$ dyne/cm^2 for 15 minute increments up to 90 minutes, which were then compared to a static control. To verify that Notch signaling was being upregulated under shear stress at the actual receptor, a Western blot analysis was used with an antibody targeting the cleaved intracellular domain (N1ICD) as shown in figure 2.1a. The results revealed that the NICD was upregulated after 15 minutes of shear stress and had a peak expression at 45 minutes which then showed decreasing activity as it approached 90 minutes. To understand if Notch activation following shear stress is a mechanical response to the force itself or if the response is a 
result of an increase in basal concentrations of Notch at the membrane, we tested the quantity of full length Notch1 protein and found no change over the time period tested (figure 2.1a). Previous studies have shown that Notch1 expression does increase from shear stress, but typically doesn't show a significant increase until $\sim 4$ hours (Mack et al., 2017; Masumura et al., 2009). Since activated Notch signaling causes a cleavage event of the receptor, the latent shear stress response of the expression of the full-length receptor might be to replenish basal levels at the membrane, and not necessarily to increase Notch activation.

Activation of the Notch receptor triggers the NICD to behave as a co-transcription factor and induces downstream genetic expression. Since the NICD showed peak levels after 45 minutes of shear stress, we determined that 90 minutes would be appropriate amount of time for the downstream genetic expression analysis. qPCR revealed that Notch downstream genes Heyl, Hey2, and Hesl were significantly upregulated from the shear stress forces compared to a static control after 90 minutes of orbital shear stress, with Heyl and Hes 1 showing the most increase. Krupple-Like Factor 2 (Klf2), a known gene that is upregulated from shear stress, was used to verify that the cells were responding to shear stress (figure 2.1b). Surprisingly, Hesl seems to have a stronger response to shear stress than does Klf 2 under these circumstances. To verify the Hes family genetic expressions were induced by Notch cleavage, we used a transgenic cell line that contained a doxycycline inducible promoter that was used to express a truncated version of mouse Notch1 that excluded the extracellular domain, therefore only 
producing an intracellular domain. After applying doxycycline, Heyl and Hesl were upregulated from the vehicle control, confirming that these genes are induced by Notch signaling (figure 2.1c). Through cleavage of the Notch receptor itself at the membrane and Notch downstream gene expression, we have confirmed that Notch activation and signaling is upregulated under the hemodynamic force of shear stress.

a

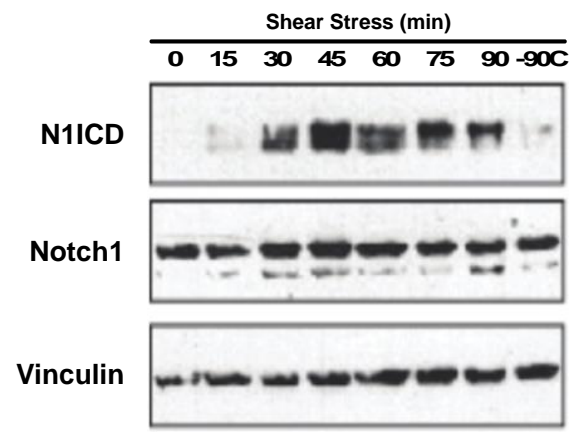

C

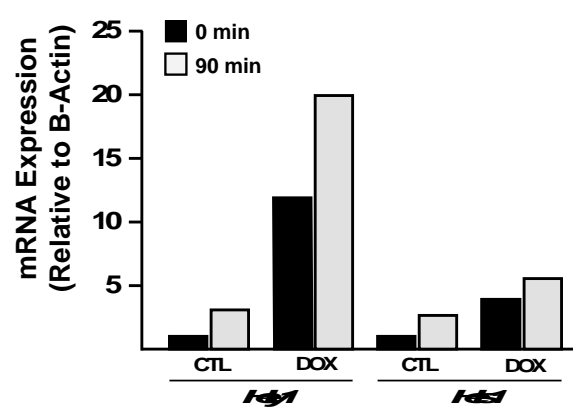

b

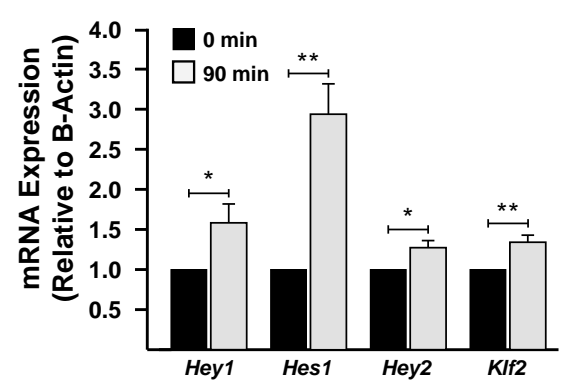

Figure 2.1: Notch signaling is induced via shear stress. HMEC1s exposed to $\sim 12 \mathrm{dyn} / \mathrm{cm}^{\wedge} 2$ of orbital shear stress. A) Notch intracellular domain (N1ICD) and full length Notch1 whole cell lysates detected by Western blot and normalized to Vinculin control. b) Downstream Notch genes Hey1, Hes1, and Hey2 expression levels detected by qPCR, Klf2 used as a positive shear stress control. Values are mean +/- SEM; * $=\mathbf{p}<0.05, * *=\mathbf{p}<0.01$. c) Downstream Notch genes Hey1 and Hes1 expression levels detected by qPCR following treatment with Doxycycline in N1ICD transgenic HMEC1s to overexpress Notch signaling. 


\section{Notch Activation from Shear Stress Is Regulated by Integrins.}

Evidence has recently shown that extracellular matrix molecules can regulate Notch signaling in endothelial cells through an Arginine-Glycine-Aspartate (RGD) binding integrin pathway (Albig, Becenti, Roy, \& Schiemann, 2008; Deford et al., 2016). Over half of the recognized integrins have binding sites for this amino acid motif (Ruoslahti, 1996). To clarify if these RGD-binding integrins play a role in shear-stressinduced Notch signaling, RGD peptides $(5 \mu \mathrm{g} / \mathrm{ml})$ were added to the culture media of HMEC1s, incubated for 24 hours and exposed to orbital shear stress for 45 and 90 minutes. Interestingly, after being treated with the RGD peptide, Heyl mRNA expression levels were reduced compared to the vehicle control following shear stress whereas Hes 1 mRNA expression showed no response to the peptide after being exposed to shear stress (figure 2.2a). Since Heyl mRNA expression is affected by RGD-binding integrins following shear stress, we decided to inhibit integrins with an alternative method using Methyl-Beta-Cyclodextrin (MBCD). Methyl-Beta-Cyclodextrin (MBCD) is a chemical compound that solubilizes cholesterol, therefore, eliminating lipid rafts. As a second alternative to confirm if integrins are involved in Notch activation following shear stress, HMEC1s were treated with MBCD (10 mM) for 90 minutes before being exposed to orbital shear stress for 45 and 90 minutes (figure 2.2b). Upregulation of Heyl mRNA expression via shear stress did show a suppression from the treatment of MBCD, although there was no significant difference between the shear-stress-induced expressions between the drug and the control, the treatment does abrogate the significance compared 
to the non-flow condition confirming that integrins are involved in the induction of Notch activation following shear stress. As seen with the RGD binding peptides, flow-induced Hes 1 mRNA remained unchanged from the vehicle control following treatment with MBCD. Since the Notch downstream genetic expression is affected by the two integrin inhibiting treatments, activation of the Notch protein at the membrane was tested via Western blotting (figure 2.2c). The N1ICD quantity did show a suppression of the shear stress response following treatment with the RGD peptide compared to the vehicle control and the MBCD treatment provided similar results. Our data strongly suggests that RGD-binding integrins involved in the activation of Notch signaling following $~ 12$ $\mathrm{dyn} / \mathrm{cm}^{\wedge} 2$ of shear stress. 
a

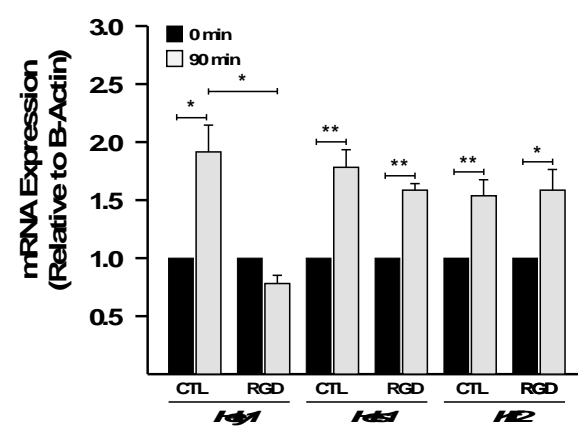

b

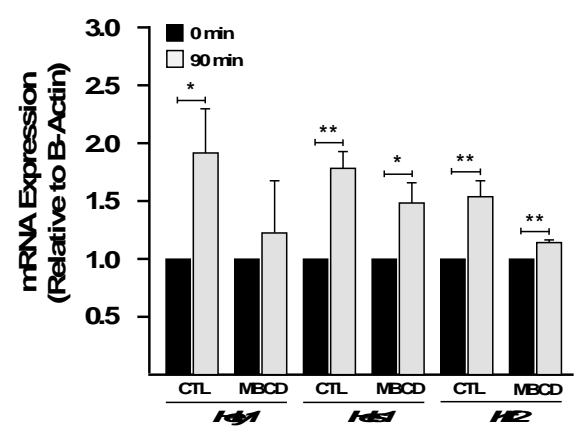

C
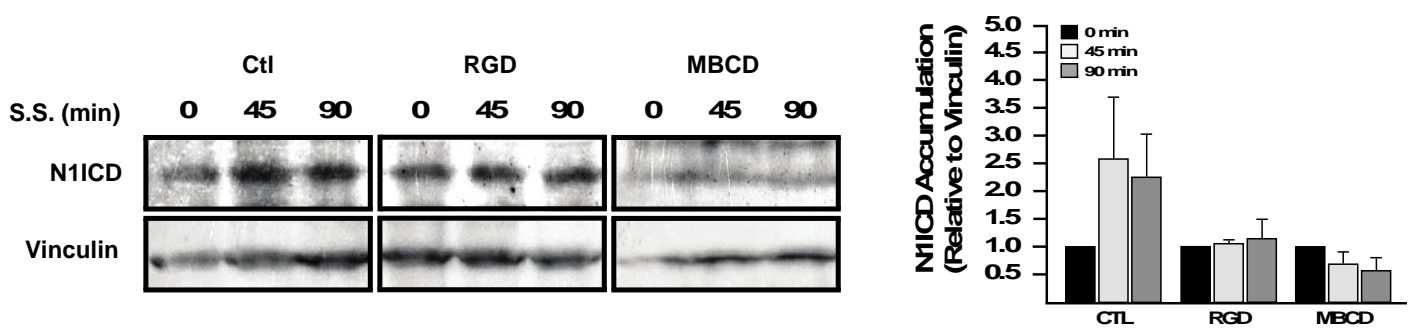

Figure 2.2: Shear Stress-induced Notch is regulated through integrins. HMEC1s exposed to $\sim 12 \mathrm{dyn} / \mathrm{cm}^{\wedge 2}$ of shear stress following integrin inhibition. a) Notch downstream genes Heyl and Hes1 mRNA expression detected by qPCR following treatment with RGD peptides $(5 \mu \mathrm{g} / \mathrm{ml})$ and 90 minutes of orbital shear stress. $K l f 2$ used as a positive shear stress control. b) Notch downstream genes Heyl and Hes1 mRNA expression detected by qPCR following treatment with MBCD $(10 \mathrm{mM})$ and 90 minutes of orbital shear stress. Klf 2 used as a positive shear stress control. Values are mean $+/$ - SEM; $*=\mathbf{p}<0.05, * *=p<0.01$. c) N1ICD fragment whole cell lysate detected via western blot and folded to Vinculin following treatment with RGD peptide and MBCD and exposed to orbital shear stress for 45 and 90 minutes.

Notch Activation from Shear Stress Is Regulated Via Integrin Downstream Pathways Src and Enos

Because Hey1 expression via Notch signaling is regulated by RGD-binding integrins under shear stress forces, we investigated common downstream pathways of integrin activation. Src kinase is a tyrosine kinase that is involved in numerous pathways aiding in functions like cell survival, proliferation, and angiogenesis (Pan et al., 2014; Roskoski, 2015), and studies have shown that Src's phosphorylating activity can be 
generated through integrin activation (Arias-Salgado et al., 2003; Xiao, Xi, Chen, Chen, \& Meng, 2013). Studies have also shown that Src phosphorylation can be induced via shear stress integrin activation (Y. Liu, 2002; Tahimic et al., 2016). To determine if Src kinase is involved in Notch signaling from shear stress, HMEC1s were treated with the Src inhibitor AZM for a five-hour incubation and then were exposed to orbital shear stress. mRNA Expression levels of Notch downstream genes, Heyl and Hesl, were assessed following treatment with AZM and shear stress (figure 2.3a). From these experiments, we found that after cells were treated with AZM, a reduction in the shear stress response occurred. As with the RGD and MBCD data, Heyl showed a reduction in shear stress response following AZM treatment, whereas Hesl again did not. Due to the high variance of shear stress response, significance was not achieved between the two variables of Heyl when compared to the static control, but when the 90 minute AZM flow response was folded to the 90-minute flow response of the vehicle control, the AZM treatment was significantly reduced from the latter, firmly suggesting that when inhibition of Src does occur, Notch shear stress response through Heyl expression is abrogated.

Another molecule that has been shown to be downstream of integrin activation and is also a reported shear stress indicator is endothelial nitric oxide synthase (eNOS) (Hwang et al., 2015; Yang \& Rizzo, 2013). Upon activation, eNOS facilitates the production of nitric oxide through the amino acid L-arginine, leading to relaxation of the surrounding vascular smooth muscle cells, vasodilation and increased blood flow 
(Förstermann \& Sessa, 2012; Moncada, 1997). Src has also been shown to activate eNOS via tyrosine phosphorylation (Fulton et al., 2005). It has also been reported that Notch activation and eNOS are associated. One study identified that Notch inhibition reduced NO production by inhibiting eNOS activity in tumor vasculature (Patenaude et al., 2014), while another study suggests that Notch signaling is induced by extracellular nitric oxide in human glioma cells (Charles et al., 2010). Given that integrins, Src, and Notch have both shown connections to eNOS, and also that eNOS is activated from shear stress forces, we hypothesized that eNOS plays a catalytic role in shear-stress-activation of Notch signaling. To probe this question, we treated HMEC1s with diphenyliodonium chloride (DPI), a flavoprotein inhibitor that has been shown to effectively inhibit eNOS activation (Nathan, Stuehr, Gonzalez, Kwon, \& Gross, 1991; Peng, Zhuang, Chen, Rizzo, \& Chen, 2015; Sundaresan, Giri, \& Chatterjee, 2015), for a 5 hour incubation before applying shear stress. mRNA expression of three tested downstream Notch genes showed a significant reduction in the flow-induced response following treatment with DPI (figure 2.3b). Although Heyl expression in this scenario was not significantly different from the DPI treatment following the shear stress application, the eNOS inhibition did reduce the expression levels enough to where the shear stress response was no longer statistically significant. These results suggest that eNOS activation via shear stress in part regulates Notch signaling under shear stress conditions. 
a

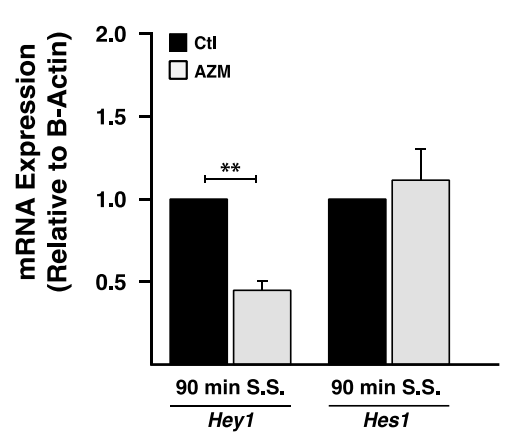

b

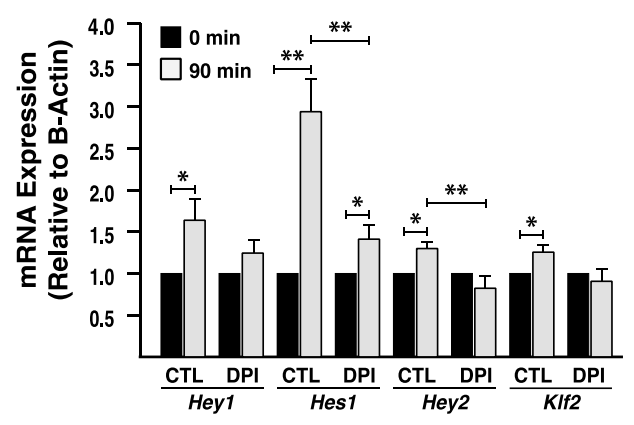

C

\begin{tabular}{|c|c|c|c|c|c|c|c|c|c|}
\hline \multirow[b]{2}{*}{ S.S. (min) } & \multicolumn{3}{|c|}{ CtI } & \multicolumn{3}{|c|}{ AZM } & \multicolumn{3}{|c|}{ DPI } \\
\hline & 0 & 45 & 90 & 0 & 45 & 90 & 0 & 45 & 90 \\
\hline N1ICD & & & 6 & $=$ & 10 & 5 & 10 & cest & 50 \\
\hline Vincul & 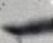 & & - & - & - & & - & & - \\
\hline
\end{tabular}

Figure 2.3: Shear stress-induced Notch activation is regulated by integrin downstream pathways, Src \& eNOS. HMEC1s exposed to $\sim 12 \mathrm{dyn} / \mathrm{cm}^{\wedge 2}$ of shear stress following treatment with AZM and DPI. a) mRNA expression of Heyl and Hes1 detected by qPCR when AZM $(10 \mu \mathrm{m})$ is folded to vehicle control following shear stress. b) mRNA expression of Hey1, Hes1, and Hey2 detected by qPCR when DPI $(100 \mu \mathrm{M})$ treatment is folded to static control following shear stress. Values are mean +/- SEM; $*=\mathbf{p}<0.05, * *=\mathbf{p}<0.01$. c) Western blot analysis of NICD with AZM, DPI, and vehicle control.

\section{Discussion:}

Vascular blood flow contributes heavily to the behavior of endothelial cells and induces specific signaling events through the hemodynamic force known as shear stress (Takahashi, Ishida, Traub, Corson, \& Berk, 1997; X.-L. Wang et al., 2007; Zhou et al., 
2014). Recent studies have revealed that the Notch receptor is activated via shear stress forces (Fang et al., 2018; Mack et al., 2017; MacK \& Luisa Iruela-Arispe, 2018; Tu et al., 2014), but the determination of whether Notch is a mechanosensor itself or if there is an upstream mechanosensor causing the activation of Notch is still unknown. From our experiments, we demonstrate that the Notch1 receptor is activated when induced under shear stress in as little as 15 minutes and between 15 and 90 minutes, the activation shows a gradient peaking at 45 minutes. The oscillatory effect could suggest that after 45 minutes of activation, the NICD is simply being degraded. A proteomic analysis has shown that Notch cleavage did happen after 10 minutes of shear stress but failed to show the variation in early levels of activation (X.-L. Wang et al., 2007), where we have shown that early in the response of shear stress, NICD cleavage shows an incremental increase in NICD accumulation. NOTCH1 protein levels prior to cleavage show no change in quantity during the application of shear stress, suggesting that Notch is activated via shear stress either mechanically or through another shear stress response mechanism rather than upregulation of the full length NOTCH1 receptor itself. This is consistent to a recent publication also showing no change in Notch1 expression levels occurring in the first 6 hours of shear stress (Fang et al., 2018), whereas other recent publications show full-length Notch1 upregulation increasing after four hours (Mack et al., 2017; Masumura et al., 2009). Collectively, these findings suggest a sequential activation of Notch from shear stress by first cleaving the existing receptors for signaling, then leading to an upregulation of the full length receptor to possibly replenish the diminished quantity of 
receptors at the membrane. From the shear stress response, we were also able to verify significant Notch upregulation via the well-characterized downstream Notch-activated genes, Heyl, Hey2, and Hes1, which is consistent with the majority of the recent literature (Fang et al., 2018; Mack et al., 2017; Tu et al., 2014; White et al., 2015). Interestingly, also consistent from recent studies (Fang et al., 2018; Jahnsen et al., 2015), Hey2 upregulation from shear stress is minimal compared to the activation of other downstream Notch genes, suggesting that Notch activated transcriptional regulation is gene-specific.

Since fluid force seems to have no impact on the upregulation of the expression of the Notch receptor in the first 90 minutes of shear stress, we decided to investigate possible upstream mechanisms that might be involved in shear-stress-activated Notch signaling. It has been widely reported that integrins can be activated by shear stress forces (J. Chen et al., 2015; K. Chen et al., 1999a; Y. Liu, 2002; Y. Wang et al., 2002), and that apically located integrins may be responsible (Yang et al., 2012; Yang \& Rizzo, 2013). A Previous study has also revealed that RGD-binding integrins play a pivotal role in Notch signaling and that by inhibiting the activity of these integrins, the Notch signaling pathways were upregulated (Deford et al., 2016). Knowing this, we investigated a potential role with RGD-binding integrins by applying soluble RGD peptides to the culture media. From this analysis, we were able to determine that RGD did reduce NICD activation from shear stress, and that Heyl but not Hes 1 upregulation was significantly reduced following the shear stress application. These results suggest that NICD 
transcriptional activity in the Hes family genes is specific under Notch receptor activation via shear stress and that RGD-binding integrins play a role in this specification. This is different behavior from the reported relationship between Notch and integrins, showing that when RGD-binding integrins are inhibited, the flow-induced response of Notch is decreased rather than increased. Although, our Western blot analysis did show slightly increased basal levels of NICD, confirming the before mentioned publication.

Because the RGD-binding integrins did show a significant impact on the Notch response to shear stress, and we do know that integrins are linked to mechanotransductional signaling, we demonstrated that integrins are in-part responsible for Notch activation via shear stress by eliminating lipid rafts with methyl-betacyclodextrin, another method in reducing integrin activation. After doing this, we saw similar results to the RGD peptide response, MBCD reduced NICD activation and Heyl expression following shear stress, with no response from Hes 1. Although the Heyl response following treatment with $\mathrm{MBCD}$ was not significantly different from the shear stress vehicle control, it did eliminate the significant upregulation when comparing it to the static control, whereas the shear stress vehicle control did show significant upregulation compared to the static control. MBCD also reduced the response from the protein receptor itself, analogous with the RGD-peptide response. From these data, we suggest that integrins play a role in Notch activation and signaling specification from shear stress. 
Through identification of integrins regulating Notch shear stress responses, we investigated downstream integrin molecules, Src and eNOS. Data from these experiments indicated that inhibition of Src kinase reduces the shear stress response in Heyl but not in Hesl, consistent with the integrin data previously mentioned. We have also identified that eNOS may be downstream of Src activation through shear stress from integrins.

Taken together, our data suggests that Notch is activated under shear stress and that integrins regulate this activation. Our data also suggests that this activation via integrins follows a downstream pathway involving Src kinase and eNOS (figure 2.4).

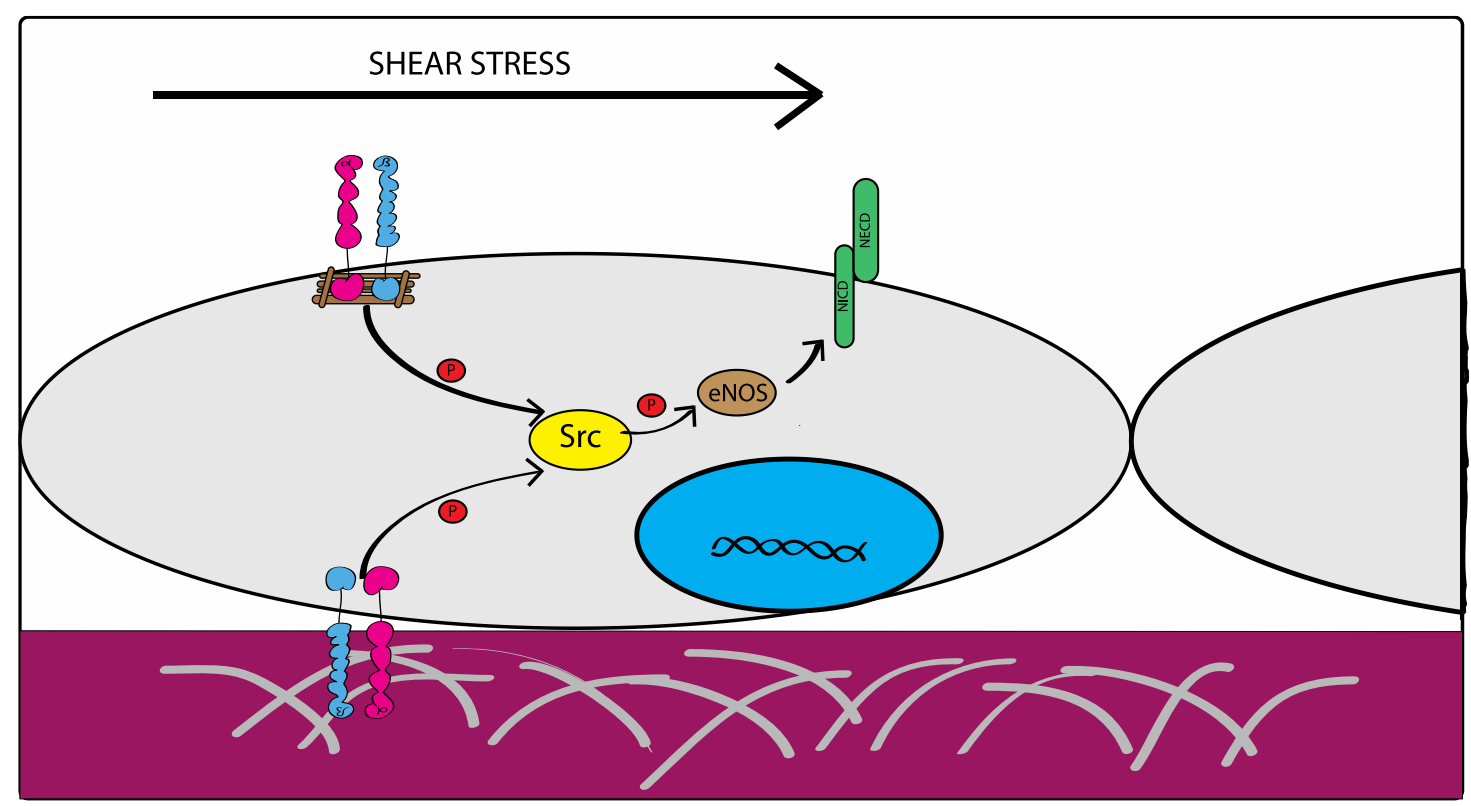

Figure 2.4: Shear stress induces Notch activation through Integrin-Src-eNOS pathway. Illustration representing the suggested regulation of Notch activation following shear stress via an integrin-Src-eNOS pathway. 


\section{Methods:}

\section{Cell Culture:}

HMEC1s were cultured in complete MCDB131 media (Sigma-Aldrich, Co., M8537-10L) with 10\% EquaFetal Bovine Serum (Atlas Biologicals; EquaFetal, EF-0500A). Cells were cultured on 60 x 15 mm culture dishes (Greiner Bio-One; Cellstar, 628160) at $37^{\circ} \mathrm{C}$ and $5 \% \mathrm{CO}_{2}$ in a humidified incubator.

\section{Shear Stress:}

To measure mRNA expression and Protein following shear stress, HMEC1s were cultured in 60 x 15 mm culture dishes (Greiner Bio-One; Cellstar, 628-160) to confluency in MCDB131 media (Sigma-Aldrich, Co., M8537-10L) with 10\% EquaFetal Bovine Serum (Atlas Biologicals; EquaFetal, EF-0500-A) and were placed on an orbital shaker (VWR International; VWR Standard Orbital Shaker, Model 1000, 89032-088) which was situated inside the humidified incubator at $37^{\circ} \mathrm{C}$ and $5 \% \mathrm{CO}_{2}$ consistent with standard cell culture environment. The cells were shaken at $\sim 180 \mathrm{rpm}$ for the time periods of 45 and 90 minutes, with control plates at 0 minutes. Orbital shear stress was determined by using the equation $\mathrm{a} \sqrt{n \rho(2 \pi f)^{3}}$ where a is the radius of rotation of the oribital shaker, $n$ is the viscosity of the medium, $\rho$ is the density of the medium, and $f$ is the rotations/sec of the shaker (Dardik et al., 2005). From this equation, we determined the shear stress force acting on the cells from orbital shaking to be $\sim 12 \mathrm{dyn} / \mathrm{cm}^{2}$. Prior to being exposed to shear stress, HMEC1s were treated with either an integrin binding RGD peptide (5 $\mu \mathrm{g} / \mathrm{ml}$ ) (GenScript; RGD, RP20297) for a 24 hour incubation, an eNOS inhibitor 
diphenyliodonium chloride (DPI) $(100 \mu \mathrm{M})$ for a 5 hour incubation, a Src inhibitor AZM $(10 \mu \mathrm{M})$ (Tocris Bioscience; AZM, 475271) for a 5 hour incubation, or Methyl-betacyclodextrin (MBCD) (10mM)(Alfa Aesar; Methyl-beta-cyclodestrin, J66847) for a 90 minute incubation. mRNA Expression Analysis:

Following the orbital shear stress application to HMEC1s, total mRNA was collected by lysing the cells with Ribozol (VWR; Ribozol RNA Extraction Reagent, N580-200ML). mRNA was reverse transcribed to complimentary DNA using High Capacity cDNA Reverse Transcription Kit (Thermofisher; High Capacity cDNA Reverse Transcription Kit, 4368814). qRT-PCR analysis was then applied using a qPCR Master Mix (Biotium; Fast EvaGreen qPCR Master Mix, 31003-1) with oligos specified for human mRNA. The dependent variable genes were folded to the house keeping gene $\beta$ actin, and the independent variable, shear stress, was folded to the static control. Western Blot Analysis:

HMEC1s were lysed with 1X SDS following the orbital shear stress application. The separation of proteins was performed with SDS-PAGE gels ranging from 6-15\% and were then transferred to a nitrocellulose membrane. Primary antibodies were incubated on the membranes at $4{ }^{\circ} \mathrm{C}$ overnight. Primary antibodies include cleaved Notch1 rabbit monoclonal antibody (Cell Signaling Technology; Cleaved Notch1 (D3B8), 4147S), antiVinculin rabbit polyclonal antibody (Santa Cruz Biotechnology; Vinculin (H-300), sc5573), and anti-Notch1 rabbit polyclonal antibody (Santa Cruz Biotechnology; Notch1 
Antibody (C-20), sc-6014). Secondary antibodies with HRP-conjugates were applied at room temperature for a period of 45 - 60 minutes. Protein bands were imaged using a chemoluminescence imager (Bio Rad; Chemidoc Tough Imaging System, 1708370) and were quantified using ImageJ 1.50 i software. 


\title{
CHAPTER THREE: MATRIX STIFFNESS REGULATES NOTCH ACTIVATION
}

\author{
Abstract: \\ Extracellular matrix stiffness has been highly recognized as a determining factor \\ for cellular behavior and phenotype. Many signaling pathways have been shown to be \\ regulated through the composition of the ECM. Polyacrylamide gels have been \\ experimentally used to aid in determining cellular behavior and signaling pathways. \\ Fibrosis is a condition that effects the stiffness of ECM and Notch receptors have shown \\ to play a role in fibrosis. Our results now show that when HMEC1s were cultured on \\ varying degrees of stiffness, Notch signaling was significantly upregulated. This data \\ suggests that another micro environmental force is regulating Notch signaling.

\section{Introduction:} \\ Cells throughout the body are exposed to many different types of physical \\ pressures like hemodynamic forces (e.g. shear stress, stretch, and pressure) and \\ extracellular matrix (ECM) stiffness. Variations in these forces can alter cellular behavior \\ and morphology (K. Chen et al., 1999b; Peter F Davies, 2009; Du et al., 2016; Wells, \\ 2008). The ECM is composed of a meshwork of mainly fibrous proteins (e.g. collagen), \\ proteoglycans, and even growth factors that make up interstitial spaces between cells and \\ the basement membrane in the vasculature. The ECM can vary in stiffness, which is in
}


turn, regulated by the concentration of the ECM proteins, namely collagen, produced mainly by fibroblasts. Stiffness of the ECM can be measured by using Young's elastic modulus and is identified in units of pascals. The degree of ECM stiffness throughout the body is highly diverse ranging from 100-300 $\mathrm{Pa}$ (brain) (Georges, Miller, Meaney, Sawyer, \& Janmey, 2006) to $\sim 3 \mathrm{GPa}$ (bone) (Cox \& Erler, 2011). Many pathologies are associated with ECM stiffness, including fibrosis and sclerosis. Fibrosis typically occurs in organs when an injury has taken place causing inflammatory cells (e.g. macrophages) to elicit a response from effector cells (e.g. fibroblasts) resulting in an overproduction of fibrotic proteins into the ECM which can lead to scarring and possible organ failure (Rockey, Bell, \& Hill, 2015). Attachment of cells to the ECM substrate is implemented through integrin receptors by binding to ECM molecules like collagen. Integrins are heterodimerizing proteins made up of alpha and beta subunits and when attached to these ECM molecules form focal adhesions, connecting the extracellular space to the actin cytoskeleton of cells. Not only are integrins well known for initiating downstream signaling events, varying degrees of matrix stiffness have also been shown to regulate cellular behavior through integrin receptors (Du et al., 2016; Shih et al., 2011; You et al., 2015).

Notch receptors are also heterodimerizing proteins that aid in numerous cellular functions including proliferation, cell survival, and differentiation. Notch signaling takes place when DSL Ligands (Delta or Jagged) on adjacent cells bind the Notch receptor and induce endocytosis, causing the metalloproteinase ADAM to cleave the extracellular 
domain. Following the extracellular domain cleavage, gamma secretase will then cleave the intracellular domain (NICD) from the transmembrane portion, allowing the NICD to travel to the nucleus where it will become a co-transcription factor by binding to RBPJ (CSL). Many downstream genes are activated by Notch signaling, but the most notable Notch-induced genes are of the Hairy and Enhancer of Split family (Hes, Hey). Notch signaling has been shown to be over-activated in liver and kidney fibrogenesis (Bielesz et al., 2010; Y. Chen et al., 2012). Through our experiments, we aim to confirm our hypothesis that Notch signaling is regulated through integrins via extracellular matrix stiffness.

\section{Results:}

Notch Activation Changes with Varying Degrees of Matrix Stiffness in Endothelial Cells

Notch signaling in the endothelium is important for many functions including inhibition of proliferation, cellular alignment, and inhibiting endothelial cell (EC) activation (Anais Briot et al., 2016; Theodoris et al., 2015; Venkatesh et al., 2011). Notch signaling has been shown to be regulated by hemodynamic forces like shear stress in the vasculature (Fang et al., 2018; Mack et al., 2017; Tu et al., 2014; X.-L. Wang et al., 2007) and lymphatic system (Choi et al., 2017) in endothelial cells. Endothelial barrier function has also been linked to matrix stiffness, where softer substrates have less F-actin stress fibers than a stiffer matrix substrate in microvascular and macrovascular ECs (Birukova et al., 2013). To investigate if Notch signaling changed from varying matrices stiffness in ECs, HMEC1s were plated on slides containing hydrogels with 10, 20, and 40 
$\mathrm{kPa}$ of stiffness. Expression levels of downstream Notch genes were analyzed via qPCR and revealed that Heyl showed a significant increase at $20 \mathrm{kPa}$ compared to 10 and 40 kPa matrix stiffnesses (figure 3.1a). Hes 1 also showed the same trend but were not statistically significant. To verify this trend a luciferase assay was conducted under the same $\mathrm{kPa}$ variation and revealed that Hes5 also showed a significant increase from 10 to $20 \mathrm{kPa}$, although significance from 20 to $40 \mathrm{kPa}$ was not achieved (figure 3.1b). From this data, we can conclude that matrix stiffness regulates Notch activation in endothelial cells, suggesting Notch is controlled via integrin focal adhesion.

a

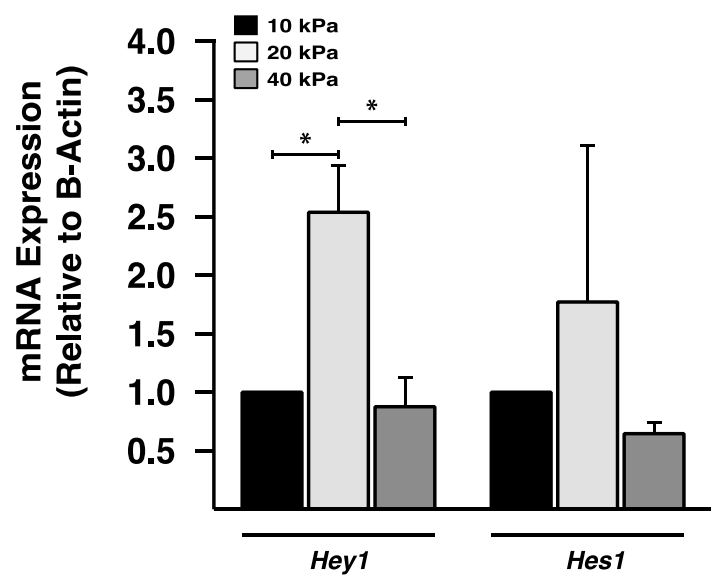

b

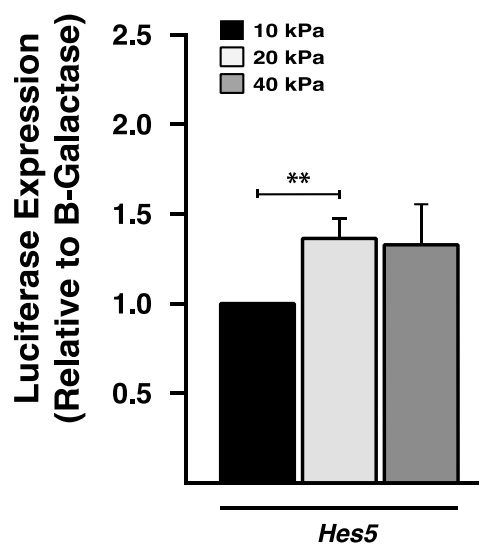

Figure 3.1: Notch downstream genes are regulated through ECM stiffness. a) Downstream Notch genes Heyl and Hesl were analyzed via qPCR following culturing on polyacrylamide hydrogels with stiffnesses of 10,20 , and $40 \mathrm{kPa}$. B) Downstream Notch gene Hes5 was analyzed via luciferase assay after being cultured on various stiffness of polyacrylamide hydrogels at $10,20, \& 40 \mathrm{kPa}$. Values are mean $+/-$ SEM; $*=\mathbf{p}<.05, * *=\mathbf{p}<.01$. 


\section{Discussion:}

Extracellular matrix stiffness has relevancy in cellular behavior and signaling. ECM stiffness can vary throughout the body and changes under various conditions like fibrosis. Upregulation of Notch has been shown in diseases like fibrosis where the ECM stiffness was increased due to collagen overproduction (Kavian, Servettaz, Weill, \& Batteux, 2012). Since Notch has shown to change from microenvironment physical stimuli like shear stress, we hypothesized that Notch changes from varying degrees of stiffness. Through our analysis of mRNA expression levels and luciferase assays of downstream Notch genes, we have confirmed that Notch signaling significantly changes when the ECM stiffness changes from 10 to $20 \mathrm{kPa}$. These results suggest that another micro environmental force, ECM stiffness, regulates Notch signaling through the microenvironment.

\section{Methods:}

\section{Cell Culture:}

HMEC1s were cultured in complete MCDB131 media (Sigma-Aldrich, Co., M8537-10L) with 10\% EquaFetal Bovine Serum (Atlas Biologicals; EquaFetal, EF-0500A). Cells were cultured on polyacrylamide gels of varying stiffnesses at $37^{0} \mathrm{C}$ and $5 \%$ $\mathrm{CO}_{2}$ in a humidified incubator. Human adult dermal fibroblasts (HDFa) and Human hepatic stellate cells (LX2) were cultured in complete DMEM media (Corning Cellgro, 50-003-PB) with 10\% EquaFetal Bovine Serum (Atlas Biologicals; EquaFetal, EF-0500- 
A). Cells were cultured on polyacrylamide gels with varying stiffnesses at $37^{\circ} \mathrm{C}$ and $5 \%$ $\mathrm{CO}_{2}$ in a humidified incubator.

Polyacrylamide Hydrogels:

Polyacrylamide gels were created in accordance with Young's modulus following protocols by Tse et al. (Tse \& Engler, 2010) and Wouters et al. (Wouters et al., 2016a). In brief, gels were created with mixtures of acrylamide and biz-acrylamide and polymerized on $12 \mathrm{~mm}$ glass discs or $25 \times 75 \mathrm{~mm}$ glass slides. L-DOPA $(2 \mathrm{mg} / \mathrm{ml})$ solution was incubated on gels for 1 hour in the dark for the purpose of crosslinking the acrylamide mixture and collagen $1(40 \mu \mathrm{g} / \mathrm{ml})$. Collagen1 was incubated on the gels following LDOPA overnight at $37^{\circ} \mathrm{C}$ with $5 \% \mathrm{CO}_{2}$ in a humidified incubator. Gels were then washed with PBS and sterilized with UV light for a period of 30 minutes before cell incubation. mRNA Analysis:

After confluency on 25 x 75mm slides, HMEC1s were lysed with Ribozol (VWR; Ribozol RNA Extraction Reagent, N580-200ML) for total mRNA collection. Total mRNA was reverse transcribed to complimentary DNA using High Capacity cDNA Reverse Transcription Kit (Thermofisher; High Capacity cDNA Reverse Transcription Kit, 4368814). qRT-PCR analysis was then applied using a qPCR Master Mix (Biotium; Fast EvaGreen qPCR Master Mix, 31003-1) with oligos specified for human mRNA. The dependent variable genes were folded to the house keeping gene $\beta$-actin, and the independent variable, matrix stiffness of $20 \mathrm{kPa}$ and $40 \mathrm{kPa}$, was folded to the $10 \mathrm{kPa}$ of stiffness. 
Transfection:

HMEC1s were transfected with Hes5-luciferase construct (Addgene \#41724) and CMV-Beta-Galactosidase construct () using polythylenimine (PEI) transfection agent (Polysciences, Inc., \#23966-1).

Luciferase Assay:

HMEC1s cultured on hydrogels on $12 \mathrm{~mm}$ discs were transiently transfected with $150 \mathrm{ng}$ of Hes5-luciferase plasmid and $30 \mathrm{ng}$ of CMV-B-Galactase and incubated for 48 hours. The cells were lysed with $100 \mu$ l of 1x Firefly Luciferase lysis buffer (Biotium, 5X Firefly Luciferase Lysis Buffer, 99923) and froze at $-80^{\circ} \mathrm{C}$ for 20 minutes. Firefly luciferase and Beta-Galactosidase levels were recorded using the Promega Glomax Multidetection System. Luciferase values were folded to B-Galactase values. 


\section{REFERENCES}

Albig, A. R., Becenti, D. J., Roy, T. G., \& Schiemann, W. P. (2008). MicrofibrilAssociate Glycoprotein-2 (MAGP-2) Promotes Angiogenic cell sprouting by Blocking Notch Signaling in Endothelial Cells. Microvascular Research, 76(1), 7 14. http://doi.org/10.1016/j.dci.2009.07.003.Characterization

Arias-Salgado, E. G., Lizano, S., Sarkar, S., Brugge, J. S., Ginsberg, M. H., \& Shattil, S. J. (2003). Src kinase activation by direct interaction with the integrin cytoplasmic domain. Proceedings of the National Academy of Sciences, 100(23), 13298-13302. http://doi.org/10.1073/pnas.2336149100

Asano, S., Ito, S., Takahashi, K., Furuya, K., Kondo, M., Sokabe, M., \& Hasegawa, Y. (2017). Matrix stiffness regulates migration of human lung fibroblasts. Physiological Reports, 5(9), 1-11. http://doi.org/10.14814/phy2.13281

Ballermann, B. J., Dardik, A., Eng, E., \& Liu, A. (1998). Shear stress and the endothelium. Kidney International, 54, S100-S108. http://doi.org/10.1046/j.15231755.1998.06720.x

Bielesz, B., Sirin, Y., Si, H., Niranjan, T., Gruenwald, A., Ahn, S., ... Susztak, K. (2010). Epithelial Notch signaling regulates insterstitial firbrosis development in the kidneys of mice and humans. The Journal of Clinical Investigation, 120(11). http://doi.org/10.1172/JCI43025.The

Birukova, A. A., Tian, X., Cokic, I., Beckham, Y., Gardel, M., \& Birukov, K. G. (2013). Endothelial barrier disruption and recovery is controlled by substrate stiffness. Microvascular Research, 87, 50-57. http://doi.org/10.1016/j.chemosphere.2012.12.037.Reactivity

Bozkulak, E. C., \& Weinmaster, G. (2009). Selective Use of ADAM10 and ADAM17 in Activation of Notch1 Signaling $\square, 29(21), 5679-5695$. http://doi.org/10.1128/MCB.00406-09 
Briot, A., Bouloumie, A., \& Iruela-Arispe, M. L. (2016). Notch, Lipids, and Endothelial cells. Curr Opin Lipidol, 27(5), 513-520.

http://doi.org/10.1038/nn.3945.Dopaminergic

Briot, A., Civelek, M., Seki, A., Hoi, K., Mack, J. J., Lee, S. D., ... Iruela-Arispe, M. L. (2015). Endothelial NOTCH1 is suppressed by circulating lipids and antagonizes inflammation during atherosclerosis. The Journal of Experimental Medicine, 212(12), 2147-2163. http://doi.org/10.1084/jem.20150603

Caolo, V., Peacock, H. M., Kasaai, B., Swennen, G., Gordon, E., Claesson-Welsh, L., ... Jones, E. A. V. (2018). Shear Stress and VE-Cadherin. Arteriosclerosis, Thrombosis, and Vascular Biology, 38(9), 2174-2183. http://doi.org/10.1161/ATVBAHA.118.310823

Chan, S. M., Weng, A. P., Tibshirani, R., Aster, J. C., Utz, P. J., Dc, W., ... Utz, P. J. (2013). Notch signals positively regulate activity of the mTOR pathway in T-cell acute lymphoblastic leukemia, 110(1), 278-286. http://doi.org/10.1182/blood-200608-039883

Charles, N., Ozawa, T., Squatrito, M., Bleau, A. M., Brennan, C. W., Hambardzumyan, D., \& Holland, E. C. (2010). Perivascular Nitric Oxide Activates Notch Signaling and Promotes Stem-like Character in PDGF-Induced Glioma Cells. Cell Stem Cell, 6(2), 141-152. http://doi.org/10.1016/j.stem.2010.01.001

Chen, J., Green, J., Yurdagul, A., Albert, P., Mcinnis, M. C., \& Orr, A. W. (2015). avB3 Integrins Mediate Flow-Induced NF-kB Activation, Proin fl ammatory Gene Expression, and Early Atherogenic In fl ammation, 185(9).

Chen, K., Li, Y., Kim, M., Li, S., Yuan, S., Chien, S., \& Shyy, J. Y. (1999a). Mechanotransduction in Response to Shear Stress. The Journal of Biological Chemistry, 274(26), 18393-18400. http://doi.org/10.1074/jbc.274.26.18393 
Chen, K., Li, Y., Kim, M., Li, S., Yuan, S., Chien, S., \& Shyy, J. Y. (1999b).

Mechanotransduction in Response to Shear Stress. The Journal of Biological Chemistry, 274(26), 18393-18400. http://doi.org/10.1074/jbc.274.26.18393

Chen, Y., Zheng, S., Qi, D., Zheng, S., Guo, J., Zhang, S., \& Weng, Z. (2012). Inhibition of Notch Signaling by a $\gamma$-Secretase Inhibitor Attenuates Hepatic Fibrosis in Rats. PLoS ONE, 7(10), 1-11. http://doi.org/10.1371/journal.pone.0046512

Chistiakov, D. A., Orekhov, A. N., \& Bobryshev, Y. V. (2015). Endothelial barrier and its abnormalities in cardiovascular disease. Frontiers in Physiology, 6(DEC), 1-11. http://doi.org/10.3389/fphys.2015.00365

Chistiakov, D. A., Orekhov, A. N., \& Bobryshev, Y. V. (2016). Effects of shear stress on endothelial cells : go with the flow. Acta Physiol, 1-27. http://doi.org/10.1111/apha.12725

Chiu, J.-J., \& Chien, S. (2011). Effects of Disturbed Flow on Vascular Endothelium: Pathophysiological Basis and Clinical Perspectives. Physiol Rev, 91(1), 1-106. http://doi.org/10.1152/physrev.00047.2009.Effects

Choi, D., Park, E., Jung, E., Seong, Y. J., Yoo, J., Lee, E., ... Hong, Y. K. (2017). Laminar flow downregulates Notch activity to promote lymphatic sprouting. Journal of Clinical Investigation, 127(4), 1225-1240. http://doi.org/10.1172/JCI87442

Christian, L. M. (2012). The ADAM family insights into Notch proteolysis. Fly, 6(1), 30-34. http://doi.org/10.4161/fly.18823

Colombo, M., Galletti, S., Garavelli, S., Platonova, N., Paoli, A., Basile, A., ... Chiaramonte, R. (2015). Notch signaling deregulation in multiple myeloma: A rational molecular target. Oncotarget, 6(29), 26826-26840. http://doi.org/10.18632/oncotarget.5025 
Cox, T. R., \& Erler, J. T. (2011). Remodeling and homeostasis of the extracellular matrix: implications for fibrotic diseases and cancer. Disease Models \& Mechanisms, 4(2), 165-178. http://doi.org/10.1242/dmm.004077

Cunningham, K. S., \& Gotlieb, A. I. (2004). The role of shear stress in the pathogenesis of atherosclerosis. Laboratory Investigation, 85(1), 9-23. http://doi.org/10.1038/labinvest.3700215

Dardik, A., Chen, L., Frattini, J., Asada, H., Aziz, F., Kudo, F. A., \& Sumpio, B. E. (2005). Differential effects of orbital and laminar shear stress on endothelial cells. Journal of Vascular Surgery, 41(5), 869-880.

http://doi.org/10.1016/j.jvs.2005.01.020

Davies, P. F. (1997). Temporal and spatial relationships in shear stress-mediated endothelial signaling - overview. Journal of Vascular Research, 34, 208-211.

Davies, P. F. (2009). Hemodynamic shear stress and the endothelium in cardiovascular pathophysiology. Engineering, 6(1), 16-26.

http://doi.org/10.1038/ncpcardio1397.Hemodynamic

Deford, P., Brown, K., Richards, R. L., King, A., Newburn, K., Westover, K., \& Albig, A. R. (2016). MAGP2 controls Notch via interactions with RGD binding integrins: Identification of a novel ECM-integrin-Notch signaling axis. Experimental Cell Research, 341(1), 84-91. http://doi.org/10.1016/j.yexcr.2016.01.011

dela Paz, N. G., Walshe, T. E., Leach, L. L., Saint-Geniez, M., \& D’Amore, P. A. (2012). Role of shear-stress-induced VEGF expression in endothelial cell survival. Journal of Cell Science, 125(4), 831-843. http://doi.org/10.1242/jcs.084301

DeMaio, L., Chang, Y. S., Gardner, T. W., Tarbell, J. M., \& Antonetti, D. a. (2001). Shear stress regulates occludin content and phosphorylation. American Journal of Physiology. Heart and Circulatory Physiology, 281, H105-H113. http://doi.org/10.1152/ajpheart.2001.281.1.H105 
Discher, D. E., Janmey, P., \& Wang, Y. (2005). Tissue Cells Feel and Respond to the Stiffness of Their Substrate Author(s): Dennis E. Discher, Paul Janmey and Yu-li Wang Source: Science, 310(5751), 1139-1143.

Du, J., Zu, Y., Li, J., Du, S., Xu, Y., Zhang, L., ... Yang, C. (2016). Extracellular matrix stiffness dictates Wnt expression through integrin pathway. Scientific Reports, 6(April 2015), 20395. http://doi.org/10.1038/srep20395

Fang, J. S., Coon, B. G., Gillis, N., Chen, Z., Qiu, J., Chittenden, T. W., ... Hirschi, K. K. (2018). Shear-induced Notch-Cx37-p27 axis arrests endothelial cell cycle to enable arterial specification. http://doi.org/10.1038/s41467-017-01742-7

Fischer, A., \& Gessler, M. (2003). Hey genes in cardiovascular development. Trends in Cardiovascular Medicine, 13(6), 221-226. http://doi.org/10.1016/S10501738(03)00082-3

Fischer, A., \& Gessler, M. (2007). Delta-Notch-and then? Protein interactions and proposed modes of repression by Hes and Hey bHLH factors. Nucleic Acids Research, 35(14), 4583-4596. http://doi.org/10.1093/nar/gkm477

Fiuza, U.-M., \& Arias, A. M. (2007). Cell and molecular biology of Notch. Journal of Endocrinology, 194(3), 459-474. http://doi.org/10.1677/JOE-07-0242

Förstermann, U., \& Sessa, W. C. (2012). Nitric oxide synthases: Regulation and function. European Heart Journal, 33(7), 829-837. http://doi.org/10.1093/eurheartj/ehr304

Frangos, J. A., Eskin, S. G., McIntire, L. V, \& Ives, C. L. (1985). Flow effects on prostacyclin production by cultured human endothelial cells. Science (New York, N.Y.), 227(4693), 1477-9. http://doi.org/10.1126/science.3883488

Frisch, S., \& Francis, H. (1994). Disruption of epithelial cell matrix interactions induces apoptosis. J. Cell Biol., 124(4), 619-626. Retrieved from internal-pdf:/Anoikis (Frisch, 1994).pdf 
Fulton, D., Church, J. E., Ruan, L., Li, C., Sood, S. G., Kemp, B. E., ... Venema, R. C. (2005). Src kinase activates endothelial nitric-oxide synthase by phosphorylating Tyr-83. Journal of Biological Chemistry, 280(43), 35943-35952. http://doi.org/10.1074/jbc.M504606200

Gallahan, D., \& Callahan, R. (1997). The mouse mammary tumor associated gene INT3 is a unique member of the NOTCH gene family (NOTCH4). Oncogene, 14(16), 1883-1890. http://doi.org/10.1038/sj.onc.1201035

Georges, P. C., Miller, W. J., Meaney, D. F., Sawyer, E. S., \& Janmey, P. A. (2006). Matrices with compliance comparable to that of brain tissue select neuronal over glial growth in mixed cortical cultures. Biophysical Journal, 90(8), 3012-3018. http://doi.org/10.1529/biophysj.105.073114

Giancotti, F. G., \& Ruoslahti, E. (1999). Integrin Signaling. Science, 285(5430), 10281032.

Gillies, R. J., \& Gatenby, R. A. (2007). Hypoxia and adaptive landscapes in the evolution of carcinogenesis. Cancer and Metastasis Reviews, 26(2), 311-317. http://doi.org/10.1007/s10555-007-9065-z

Gimbrone, M. A., \& Garcia-Cardena, G. (2013). Vascular endothelium, hemodynamics, and the pathobiology of atherosclerosis. Cardiovasc Pathol, 22(1), 9-15. http://doi.org/10.1016/j.carpath.2012.06.006.Vascular

Ginsberg, M. H. (2014). Integrin activation. BMB Rep., 47(12), 655-659. http://doi.org/10.1042/BST0360229

Gulino-Debrac, D. (2013). Mechanotransduction at the basis of endothelial barrier function. Tissue Barriers, 1(2), e24180. http://doi.org/10.4161/tisb.24180

Heo, K.-S., Fujiwara, K., \& Abe, J. (2011). Disturbed-Flow-Mediated Vascular Reactive Oxygen Species Induce Endothelial Dysfunction Kyung-Sun. Circ J., 75(12), 27222730. http://doi.org/10.2217/nnm.12.167.Gene 
Heo, K.-S., Fujiwara, K., \& Abe, J. (2014). Shear Stress and Atherosclerosis. Molecules and Cells, 37(6), 435-440. http://doi.org/10.14348/molcells.2014.0078

Hwang, S., Lee, H. J., Kim, G., Won, K. J., Park, Y. S., \& Jo, I. (2015). CCN1 acutely increases nitric oxide production via integrin $\alpha \mathrm{v} \beta 3$-Akt-S6K-phosphorylation of endothelial nitric oxide synthase at the serine 1177 signaling axis. Free Radical Biology and Medicine, 89, 229-240.

http://doi.org/10.1016/j.freeradbiomed.2015.08.005

Jahnsen, E. D., Trindade, A., Zaun, H. C., Lehoux, S., Duarte, A., \& Jones, E. A. V. (2015). Notch1 Is pan-endothelial at the onset of flow and regulated by flow. PLoS ONE, 10(4), 1-14. http://doi.org/10.1371/journal.pone.0122622

Juczewska, M., \& Chyczewski, L. (1997). Angiogenesis in cancer. Rocz Akad Med Bialymst, 42 Suppl 1(3), 86-100. Retrieved from http://www.ncbi.nlm.nih.gov/pubmed/9337527

Kavian, N., Servettaz, A., Weill, B., \& Batteux, F. (2012). New insights into the mechanism of notch signalling in fibrosis. The Open Rheumatology Journal, 6, 96102. http://doi.org/10.2174/1874312901206010096

Kim, C., Ye, F., \& Ginsberg, M. H. (2011). Regulation of Integrin Activation. Annual Review of Cell and Developmental Biology, 27(1), 321-345. http://doi.org/10.1146/annurev-cellbio-100109-104104

Kim, H., Yang, K. H., Cho, H., Gwak, G., Park, S. C., Kim, J. Il, .. Moon, I. S. (2015). Different Effects of Orbital Shear Stress on Vascular Endothelial Cells: Comparison with the Results of In Vivo Study with Rats. Vascular Specialist International, 31(2), 33-40. http://doi.org/10.5758/vsi.2015.31.2.33 
Kornberg, L. J., Earp, H. S., Turner, C. E., Prockop, C., \& Juliano, R. L. (1991). Signal transduction by integrins: increased protein tyrosine phosphorylation caused by clustering of beta 1 integrins. Proceedings of the National Academy of Sciences of the United States of America, 88(19), 8392-6.

http://doi.org/10.1073/pnas.88.19.8392

Lafoya, B., Munroe, J. A., Miyamoto, A., Detweiler, M. A., Crow, J. J., Gazdik, T., \& Albig, A. R. (2018). Beyond the Matrix: The Many Non-ECM Ligands for Integrins. International Journal of Molecular Sciences, 1-33. http://doi.org/10.3390/ijms 19020449

LaValley, D. J., Zanotelli, M. R., Bordeleau, F., Wang, W., Schwager, S. C., \& ReinhartKing, C. A. (2017). Matrix stiffness enhances VEGFR-2 internalization, signaling, and proliferation in endothelial cells. Convergent Science Physical Oncology, 3(4), 044001. http://doi.org/10.1088/2057-1739/aa9263

Liu, Y. (2002). Shear Stress Activation of SREBP1 in Endothelial Cells Is Mediated by Integrins. Arteriosclerosis, Thrombosis, and Vascular Biology, 22(1), 76-81. http://doi.org/10.1161/hq0102.101822

Liu, Z. J., Tan, Y., Beecham, G. W., Seo, D. M., Tian, R., Li, Y., ... Velazquez, O. C. (2012). Notch activation induces endothelial cell senescence and pro-inflammatory response: Implication of Notch signaling in atherosclerosis. Atherosclerosis, 225(2), 296-303. http://doi.org/10.1016/j.atherosclerosis.2012.04.010

Logeat, F., Bessia, C., Brou, C., LeBail, O., Jarriault, S., Seidah, N. G., \& Israël, A. (1998). The Notch1 receptor is cleaved constitutively by a furin-like convertase. Proceedings of the National Academy of Sciences of the United States of America, 95(14), 8108-12. http://doi.org/10.1073/pnas.95.14.8108 
Louvi, A., \& Artavanis-Tsakonas, S. (2012). Notch and disease: A growing field. Seminars in Cell and Developmental Biology, 23(4), 473-480. http://doi.org/10.1016/j.semcdb.2012.02.005

MacK, J. J., \& Luisa Iruela-Arispe, M. (2018). NOTCH regulation of the endothelial cell phenotype. Current Opinion in Hematology, 25(3), 212-218. http://doi.org/10.1097/MOH.0000000000000425

Mack, J. J., Mosqueiro, T. S., Archer, B. J., Jones, W. M., Sunshine, H., Faas, G. C., ... Iruela-Arispe, M. L. (2017). NOTCH1 is a mechanosensor in adult arteries. Nature Communications, 8(1), 1620. http://doi.org/10.1038/s41467-017-01741-8

Malek, A. M., \& Alper, S. L. (1999). Hemodynamic Shear Stress and Its Role in Atherosclerosis. JAMA, 282(21), 2035-2042.

Malek, A. M., \& Izumo, S. (1996). Mechanism of endothelial cell shape change and cytoskeletal remodeling in response to fluid shear stress. Journal of Cell Science, 109 ( Pt 4, 713-726. http://doi.org/10.1007/bf02623896

Masumura, T., Yamamoto, K., Shimizu, N., Obi, S., \& Ando, J. (2009). Shear stress increases expression of the arterial endothelial marker ephrinB2 in murine ES cells via the VEGF-notch signaling pathways. Arteriosclerosis, Thrombosis, and Vascular Biology, 29(12), 2125-2131. http://doi.org/10.1161/ATVBAHA.109.193185

Mengistu, M., Brotzman, H., Ghadiali, S., \& Lowe-Krentz, L. (2011). Fluid Shear StressInduced JNK Activity Leads to Actin Remodeling for Cell Alignment. J Cell Physiol., 226(1), 110-121. http://doi.org/10.1016/j.immuni.2010.12.017.Two-stage

Meredith Jr., J. E., Fazeli, B., \& Schwartz, M. A. (1993). The extracellular matrix as a cell survival factor. Mol.Biol.Cell, 4(9), 953-961. 
Metz, C. W., \& Bridges, C. B. (1917). INCOMPATIBILITY OF MUTANT RACES IN DROSOPHILA. National Academy of Sciences, 3(12), 673-678. http://doi.org/10.1126/science.132.3438.1488

Miller, K., Chinzei, K., Orssengo, G., \& Bednarz, P. (2000). Mechanical properties of brain tissue in-vivo: Experiment and computer simulation. Journal of Biomechanics, 33(11), 1369-1376. http://doi.org/10.1016/S0021-9290(00)00120-2

Miranti, C. K., \& Brugge, J. S. (2002). Sensing the environment:a historical perspective on integrin signal transduction. Nature Cell Biology, 4(4), E83-E90. Retrieved from http://www.nature.com/ncb/journal/v4/n4/pdf/ncb0402-e83.pdf

Moncada, S. (1997). Nitric oxide in the vasculature: Physiology and pathophysiology. Annals of the New York Academy of Sciences, 811, 60-69. http://doi.org/10.1111/j.1749-6632.1997.tb51989.x

Mukherjee, T., Kim, W. S., Mandal, L., \& Banerjee, U. (2011). Interaction Between Notch and Hif- $\alpha$ in Development and Survival of Drosophila Blood Cells. Science, 332(6034), 1210-1213. http://doi.org/10.1126/science.1199643.Interaction

Nathan, C. F., Stuehr, D. J., Gonzalez, J. A., Kwon, S. O. O., \& Gross, S. (1991). Inhibition of Macrophage and enothelial cell nitric oxide synthase by diphenyleneiodonium and its analogs. The FASEB Journal, 5(1), 98-103.

Noria, S., Xu, F., McCue, S., Jones, M., Gotlieb, A. I., \& Langille, B. L. (2004). Assembly and Reorientation of Stress Fibers Drives Morphological Changes to Endothelial Cells Exposed to Shear Stress. American Journal of Pathology, 164(4), 1211-1223. http://doi.org/10.1016/S0002-9440(10)63209-9

Palmer, W. H., \& Deng, W. M. (2015). Ligand-Independent Mechanisms of Notch Activity. Trends in Cell Biology, 25(11), 697-707. http://doi.org/10.1016/j.tcb.2015.07.010 
Palmer, W. H., Jia, D., \& Deng, W. M. (2014). Cis-interactions between Notch and its ligands block ligand-independent Notch activity. ELife, 3, 1-11. http://doi.org/10.7554/eLife.04415

Pan, C. C., Kumar, S., Shah, N., Hoyt, D. G., Hawinkels, L. J. A. C., Mythreye, K., \& Lee, N. Y. (2014). Src-mediated post-translational regulation of endoglin stability and function is critical for angiogenesis. Journal of Biological Chemistry, 289(37), 25486-25496. http://doi.org/10.1074/jbc.M114.578609

Patenaude, A., Fuller, M., Chang, L., Wong, F., Paliouras, G., Shaw, R., ... Karsan, A. (2014). Endothelial-specific notch blockade inhibits vascular function and tumor growth through an enos-dependent mechanism. Cancer Research, 74(9), 24022411. http://doi.org/10.1158/0008-5472.CAN-12-4038

Peng, H., Zhuang, Y., Chen, Y., Rizzo, A. N., \& Chen, W. (2015). The characteristics and regulatory mechanisms of superoxide generation from eNOS reductase domain. PLoS ONE, 10(10), 1-17. http://doi.org/10.1371/journal.pone.0140365

Qin, W. D., Zhang, F., Qin, X. J., Wang, J., Meng, X., Wang, H., ... Zhang, M. X. (2016). Notch1 inhibition reduces low shear stress-induced plaque formation. International Journal of Biochemistry and Cell Biology, 72, 63-72. http://doi.org/10.1016/j.biocel.2016.01.007

Ratnikov, B. I., Partridge, A. W., \& Ginsberg, M. H. (2005). Integrin activation by talin. Journal of Thrombosis and Haemostasis, 3(8), 1783-1790. http://doi.org/10.1111/j.1538-7836.2005.01362.x

Ravensbergen, J., Ravensbergen, J. W., Hillen, B., \& Hoogstraten, H. W. (1998). Localizing Role of Hemodynamics in Atherosclerosis in Several Human Vertebrobasilar Junction Geometries. Arteriosclerosis, Thrombosis, and Vascular Biology, 18, 708-717. 
Resnick, N., Yahav, H., Shay-Salit, A., Shushy, M., Schubert, S., Zilberman, L. C. M., \& Wofovitz, E. (2003). Fluid shear stress and the vascular endothelium: for better and for worse. Progress in Biophysics, 81, 177-199.

Rockey, D. C., Bell, P. D., \& Hill, J. A. (2015). Fibrosis - A Common Pathway to Organ Injury and Failure. New England Journal of Medicine, 372(12), 1138-1149. http://doi.org/10.1056/NEJMra1300575

Rohrschneider, L. R. (1980). Adhesion plaques of Rous sarcoma virus-transformed cells contain the src gene product. Proceedings of the National Academy of Sciences of the United States of America, 77(6), 3514-3518.

http://doi.org/10.1073/pnas.77.6.3514

Roskoski, R. (2015). Src protein-tyrosine kinase structure, mechanism, and small molecule inhibitors. Pharmacological Research: The Official Journal of the Italian Pharmacological Society, 94, 9-25. http://doi.org/10.1016/j.phrs.2015.01.003

Ross, T. D., Coon, B. G., Yun, S., Baeyens, N., Tanaka, K., Ouyang, M., \& Schwartz, M. A. (2013). Integrins in mechanotransduction. Current Opinion in Cell Biology, 25(5), 613-618. http://doi.org/10.1016/j.ceb.2013.05.006

Ruoslahti, E. (1996). Rgd and Other Recognition Sequences for Integrins. Annual Review of Cell and Developmental Biology, 12(1), 697-715. http://doi.org/10.1146/annurev.cellbio.12.1.697

Shih, Y. R. V., Tseng, K. F., Lai, H. Y., Lin, C. H., \& Lee, O. K. (2011). Matrix stiffness regulation of integrin-mediated mechanotransduction during osteogenic differentiation of human mesenchymal stem cells. Journal of Bone and Mineral Research, 26(4), 730-738. http://doi.org/10.1002/jbmr.278

Sorensen, E., \& Conner, S. (2010). Gamma secretase-dependent cleavage initiates Notch signaling from the plasma membrane. Traffic, 11(9), 1234-1245. http://doi.org/10.1016/j.neuron.2009.09.030.Various 
Struhl, G., \& Adachi, A. (2000). Requirements for Presenilin-dependent cleavage of notch and other transmembrane proteins. Molecular Cell, 6(3), 625-636. http://doi.org/10.1016/S1097-2765(00)00061-7

Sundaresan, L., Giri, S., \& Chatterjee, S. (2015). Inhibitors of Nitric Oxide Synthase : What's up and What's Next? Inhibitors of Nitric Oxide Synthase : What's up and What's Next?, (November). http://doi.org/10.2174/1573408012666151126185922

Tahimic, C. G. T., Long, R. K., Kubota, T., Sun, M. Y., Elalieh, H., Fong, C., ... Bikle, D. D. (2016). Regulation of ligand and shear stress-induced insulin-like growth factor 1 (IGF1) signaling by the integrin pathway. Journal of Biological Chemistry, 291(15), 8140-8149. http://doi.org/10.1074/jbc.M115.693598

Takahashi, M., Ishida, T., Traub, O., Corson, M. A., \& Berk, B. C. (1997). Mechanotransduction in endothelial cells: temporal signaling events in response to shear stress. Journal of Vascular Research, 34(3), 212-9. http://doi.org/10.1159/000159225

Theodoris, C. V., Li, M., White, M. P., Liu, L., He, D., Pollard, K. S., .. Srivastava, D. (2015). Human Disease Modeling Reveals Integrated Transcriptional and Epigenetic Mechanisms of NOTCH1 Haploinsufficiency. Cell, 160(6), 1072-1086. http://doi.org/10.1158/1541-7786.MCR-15-0224.Loss

Tosello, V., \& Ferrando, A. A. (2013). The NOTCH signaling pathway: role in the pathogenesis of T-cell acute lymphoblastic leukemia and implication for therapy. Therapeutic Advances in Hematology, 4(3), 199-210. http://doi.org/10.1177/2040620712471368

Tse, J. R., \& Engler, A. J. (2010). Preparation of hydrogel substrates with tunable mechanical properties. Current Protocols in Cell Biology, (SUPPL. 47), 1-16. http://doi.org/10.1002/0471143030.cb1016s47 
Tu, J., Li, Y., \& Hu, Z. (2014). Notch1 and 4 Signaling Responds to an Increasing Vascular Wall Shear Stress in a Rat Model of Arteriovenous Malformations, 2014, $10-12$.

Tzima, E. (2006). Role of small GTPases in endothelial cytoskeletal dynamics and the shear stress response. Circulation Research, 98(2), 176-185. http://doi.org/10.1161/01.RES.0000200162.94463.d7

Tzima, E., Del Pozo, M. A., Shattil, S. J., Chien, S., \& Schwartz, M. A. (2001). Activation of integrins in endothelial cells by fluid shear stress mediates Rhodependent cytoskeletal alignment. EMBO Journal, 20(17), 4639-4647. http://doi.org/10.1093/emboj/20.17.4639

Venkatesh, D., Fredette, N., Rostama, B., Tang, Y., Vary, C. P. H., Liaw, L., \& Urs, S. (2011). RhoA mediated signaling in Notch-induced senescence like growth arrest and endothelial barrier dysfunction. Arteriosclerosis, Thrombosis, and Vascular Biology, 31(4), 876-882. http://doi.org/10.1021/n1061786n.Core-Shell

Wang, X.-L., Fu, A., Raghavakaimal, S., \& Lee, H.-C. (2007). Proteomic analysis of vascular endothelial cells in response to laminar shear stress. Proteomics, 7(4), 588596. http://doi.org/10.1002/pmic.200600568

Wang, Y., Miao, H., Li, S., Chen, K.-D., Li, Y.-S., Yuan, S., .. Chien, S. (2002). Interplay between integrins and FLK-1 in shear stress-induced signaling. American Journal of Physiology. Cell Physiology, 283(July 2002), C1540-C1547. http://doi.org/10.1152/ajpcell.00222.2002

Wells, R. G. (2008). The role of matrix stiffness in regulating cell behavior. Hepatology, 47(4), 1394-1400. http://doi.org/10.1002/hep.22193 
Wharton, K. A., Johansen, K. M., Xu, T., \& Artavanis-Tsakonas, S. (1985). Nucleotide sequence from the neurogenic locus Notch implies a gene product that shares homology with proteins containing EGF-like repeats. Cell, 43(3 PART 2), 567-581. http://doi.org/10.1016/0092-8674(85)90229-6

White, M. P., Theodoris, C. V., Liu, L., Collins, W. J., Blue, K. W., Lee, J. H., ... Srivastava, D. (2015). NOTCH1 regulates matrix gla protein and calcification gene networks in human valve endothelium. Journal of Molecular and Cellular Cardiology, 84, 13-23. http://doi.org/10.1016/j.yjmcc.2015.04.006

Wouters, O. Y., Ploeger, D. T. A., van Putten, S. M., \& Bank, R. A. (2016a). 3,4Dihydroxy-L-Phenylalanine as a Novel Covalent Linker of Extracellular Matrix Proteins to Polyacrylamide Hydrogels with a Tunable Stiffness. Tissue Engineering Part C: Methods, 22(2), ten.tec.2015.0312. http://doi.org/10.1089/ten.tec.2015.0312

Wouters, O. Y., Ploeger, D. T., van Putten, S. M., \& Bank, R. A. (2016b). Linker of Extracellular Matrix Proteins to Polyacrylamide Hydrogels with a Tunable Stiffness. Tissue Engineering Part C: Methods, 22(2), 91-101. http://doi.org/10.1089/ten.tec.2015.0312

Wragg, J. W., Durant, S., Mcgettrick, H. M., Sample, K. M., Egginton, S., \& Bicknell, R. (2014). Shear stress regulated gene expression and angiogenesis in vascular endothelium. Microcirculation, 21(4), 290-300. http://doi.org/10.1111/micc.12119

Xiao, R., Xi, X. D., Chen, Z., Chen, S. J., \& Meng, G. (2013). Structural framework of cSrc activation by integrin $\beta 3$. Blood, 121(4), 700-706. http://doi.org/10.1182/blood2012-07-440644

Yang, B., Radel, C., Hughes, D., Kelemen, S., \& Rizzo, V. (2012). p190RhoGAP links the $\beta 1$ integrin/caveolin-1 mechano-signaling complex to RhoA and actin remodeling, 31(2), 376-383. http://doi.org/10.1161/ATVBAHA.110.217794.p190RhoGAP 
Yang, B., \& Rizzo, V. (2013). Shear Stress Activates eNOS at the Endothelial Apical Surface Through $\beta 1$ Containing Integrins and Caveolae, 6(3), 346-354. http://doi.org/10.1002/nbm.3066.Non-invasive

You, Y., Zheng, Q., Dong, Y., Wang, Y., Zhang, L., Xue, T., ... Ren, Z. (2015). Higher matrix stiffness upregulates osteopontin expression in hepatocellular carcinoma cells mediated by integrin $\beta 1 / \mathrm{GSK} 3 \beta / \beta$-catenin signaling pathway. PLoS ONE, 10(8), 113. http://doi.org/10.1371/journal.pone.0134243

Yuan, X., Wu, H., Xu, H., Xiong, H., Chu, Q., Yu, S., ... Wu, K. (2015). Notch signaling: an emerging therapeutic target for cancer treatment. Cancer Lett, 369(1), 20-27. http://doi.org/10.1016/j.canlet.2015.07.048

Zhou, J., Lee, P., Tsai, C., Lee, C., Yang, T., Chuang, H., \& Lin, W. (2012). Forcespecific activation of Smad1 / 5 regulates vascular endothelial cell cycle progression in response to disturbed flow. Proceedings of The, 109, 1-6. http://doi.org/10.1073/pnas.1205476109//DCSupplemental.www.pnas.org/cgi/doi/10.1073/pnas.1205476109

Zhou, J., Li, Y., \& Chien, S. (2014). Shear stress-initiated signaling and its regulation of endothelial function. Arteriosclerosis, Thrombosis, and Vascular Biology, 34(10), 2191-2198. http://doi.org/10.1016/j.immuni.2010.12.017.Two-stage 
APPENDIX 


\title{
Notch: A multi-functional integrating system of microenvironmental signals.
}

\author{
Bryce LaFoya $^{2}$, Jordan A. Munroe ${ }^{1}$, Masum M. Mia ${ }^{1}$, Michael A. Detweiler ${ }^{1}$, Jacob J. \\ Crow $^{2}$, Travis Wood ${ }^{1}$, Steven Roth $^{1}$, Bikram Sharma ${ }^{3}$, and Allan R. Albig ${ }^{2,1}$
}

\begin{abstract}
:
The Notch signaling cascade is an evolutionarily ancient system that allows cells to interact with their microenvironmental neighbors through direct cell-cell interactions, thereby directing a variety of developmental processes. Recent research is discovering that Notch signaling is also responsive to a broad variety of stimuli beyond cell-cell interactions, including: ECM composition, crosstalk with other signaling systems, shear stress, hypoxia, and hyperglycemia. Given this emerging understanding of Notch responsiveness to microenvironmental conditions, it appears that the classical view of Notch as a mechanism enabling cell-cell interactions, is only a part of a broader function to integrate microenvironmental cues. In this review, we summarize and discuss published data supporting the idea that the full function of Notch signaling is to serve as an integrator of microenvironmental signals thus allowing cells to sense and respond to a multitude of conditions around them.
\end{abstract}




\section{The Cellular Microenvironment:}

Conditions of the local environment in which a cell resides can vary widely depending on the species and its anatomical location within the organism. In recent years, cellular microenvironments have gained wide acceptance as major determinants influencing cellular physiology, especially as it pertains to the cancer microenvironment (Liotta and Kohn 2001), the stem cell niche (Morrison and Spradling 2008), the vascular system (Giordano and Johnson 2001), and wound healing/granulation tissue (Junker, Caterson et al. 2013). A multitude of components contribute to a cell's microenvironment. Extracellular matrices which surround and support cells contribute chemical and physical properties to the microenvironment. Both the chemical composition and the physical stiffness of the matrix provide signaling cues that are actively monitored by cells. Neighboring epithelial cells, endothelial cells, leukocytes, and fibroblasts are all known to influence nearby cells chemically through cytokine and hormone secretions, and physically through cell-cell interactions. Other properties of the cellular microenvironment include concentrations of dissolved gases such as $\mathrm{O}_{2}$ and $\mathrm{CO}_{2}$, blood sugar concentrations, temperature, shear stress, oxidative stress, the presence/absence of foreign antigens, and osmolality. Moreover, cellular microenvironments can change rapidly and dramatically in response to situations such as wounding and subsequent healing, tumor development, hypoxia, glucose availability, and fibrosis. Due to the potentially dynamic nature of the cellular microenvironment, cellular responses to both static and changing microenvironments need to be calibrated to properly and rapidly respond to these situations. Understanding how cells respond to the incredible complexity of the 
microenvironment requires a systems biology approach to integrate the micro environmental information, a task that is immensely complicated.

\section{Notch:}

The Notch signaling mechanism is a highly conserved developmental pathway that is used during differentiation in numerous tissues in most, if not all, multicellular organisms. Evolutionary evidence for the emergence of the Notch receptors first appears in the choanoflagellates, unicellular flagellated free-living eukaryotic cells widely considered the closest extant protist relative to metazoans (King, Westbrook et al. 2008, Richter and King 2013). The genome of the choanoflagellate Monosiga brevicollis encodes three domains that show similarity to metazoan Notch receptors (Figure A.1A). However, these domains are split amongst three separate transmembrane proteins in the $M$. brevicollis genome including one gene that encodes 36 epidermal growth factor (EGF) like domains, a second gene that encodes two Lin-12-Notch repeats (LNR domains), and a third gene that encodes six ankyrin repeats (King, Westbrook et al. 2008). Presumably, these three ancestral partial Notch homologs were responsible for individual functions. This suggests that modern metazoan Notch receptors, which unify these domains in a single receptor, might represent an amalgamation of three independent proteins with independent ancestral functions and may help explain why Notch is capable of integrating a multitude of cellular microenvironmental signals and conditions as described in this review. Despite the lack of a bona fide Notch receptor or Notch ligands, M. brevicollis genome does encode several other components of the Notch system (Gazave, Lapebie et al. 2009) (Figure A.1B). 
Therefore, the origin of Notch domains (if not function) likely predates the rise of the metazoans. It has been postulated that these proto-Notch receptors might have served an adhesive function that was independent of Notch signaling activity and is conserved in modern Notch function (reviewed in (Murata and Hayashi 2016)). It was not until the rise of sponges however, that bona fide Notch receptors and ligands appeared and exhibited the developmental roles that are representative of the metazoan Notch mechanism (Richards and Degnan 2012). Thereafter, Notch receptors, ligands, and other Notch processing and/or modifying proteins are expressed throughout all metazoans examined to date (Gazave, Lapebie et al. 2009).

In mammals, the core of the Notch mechanism consists of five Notch ligands (Jagged1, 2 and Delta like (Dll) 1,3,4) present on the "signaling cell". The Jagged and Dll 1 and 4 ligands directly interact with and activate a transmembrane Notch receptor (four different isoforms in mammals) present on the "receiving cell" (Kopan and Ilagan 2009, Kopan 2010) (Figure A.1B). The Dll3 ligand is a decoy receptor that interferes with Notch activation (Ladi, Nichols et al. 2005). Notch receptors undergo a maturation process involving three proteolytic cleavage events that ultimately result in Notch activation. The first cleavage is performed by a furin convertase during translocation through the Golgi complex on the way to the cell membrane (Logeat, Bessia et al. 1998). The resulting two Notch fragments remain non-covalently associated at the membrane where canonical Notch activation is initiated by interaction between Notch receptors and ligands. Canonical Notch activation at the membrane is commonly thought to be dependent on a physical 
tugging mechanism of $\sim 4-12 \mathrm{pN}$ (Gordon, Zimmerman et al. 2015, Chowdhury, Li et al. 2016) that is initiated by Notch ligand endocytosis in the signaling cell (Parks, Klueg et al. 2000). This pulling force sets up a second cleavage by an ADAM metalloprotease ( $\alpha$ secretase) producing the transient NEXT (Notch Extracellular Truncation) fragment (Brou, Logeat et al. 2000), and a third cleavage by $\gamma$-secretase (Mumm, Schroeter et al. 2000) thus releasing the intracellular NICD domain of Notch that translocates to the nucleus and functions as a co-transcription factor in association with the CSL transcription factor and other co-transcription factors including MAML and p300. In addition to this canonical mechanism, evidence for several non-canonical Notch activation mechanisms have also been gaining traction. In particular, Notch activation that is independent of canonical ligands (Palmer and Deng 2015), NICD cleavage and transcriptional activity (Guruharsha, Kankel et al. 2012), as well as several non-canonical ligands (D'Souza, Meloty-Kapella et al. 2010) have all been described in the literature. Finally, in addition to the core receptors and ligands, a wide variety of cellular and secreted proteins have been characterized that modify Notch signaling either through direct interaction and/or modification of extracellular Notch receptor or ligand domains (Kadesch 2004) or via post-translational modification of intracellular NICD fragments (Fortini 2009). References (Kopan and Ilagan 2009, Kopan 2010) provide excellent in-depth reviews of the Notch signaling mechanism. 


\section{Notch as an Integrator of Cellular Microenvironments:}

While the traditional view of Notch activation focuses on Notch receptor - ligand interactions, it is becoming increasingly clear that Notch signaling is also influenced by a wide array of molecules and events in the cellular microenvironment. In particular, extracellular matrix (ECM) mediated Notch signaling is emerging as a new paradigm for controlling Notch signaling. Regulation of Notch by ECM occurs on several levels, including direct interaction between ECM and Notch receptor/ligands, transcriptional control of Notch receptors and/or ligands, and via cross-talk with other ECM stimulated signaling networks, such as integrins. In addition, Notch is engaged in crosstalk with a number of signaling pathways that are initiated by growth factors and cytokines commonly present in cellular microenvironments including, TGF- $\beta$, WNT/ $\beta$-catenin, and VEGF. Finally, Notch can also be regulated by additional conditions such as shear stress, hypoxia, and hyperglycemia. These microenvironmental conditions are summarized in Table A.1. Taking into consideration the wide variety of cellular microenvironmental cues that regulate Notch signaling output, a new picture of Notch is emerging which depicts Notch as an integrating system for the cellular microenvironment, which enables cells to respond appropriately to changing ECM composition, growth factor secretions, oxygen tension, shear stress, and glucose levels. Importantly, this idea is not inconsistent with the classical model of Notch receptor activation by Notch ligands on adjacent cells, but rather builds on this model since cellular neighbors are also an important part of a cell's microenvironment. The goal of this review is to summarize what is known about the role Notch signaling plays 
in responding to and integrating changing microenvironmental conditions, and to explore and develop the idea of Notch as a multi-functional integrating system of microenvironmental signals.

\section{ECM-Notch Interactions:}

Extracellular matrices are a major component of a cell's microenvironment. In some instances, ECM can be stable over decades. In other situations, ECM is rapidly turned over and remodeled. Therefore, cells need to be able to adjust to these stable or changing conditions. Notch responsiveness to the composition of the ECM has only recently begun to be characterized. The interactions between ECM and Notch can be summarized as either direct interactions between ECM and Notch receptors or ligands, indirect (transcriptional) responses of Notch receptors or ligands to ECM, and indirect (crosstalk) interactions between Notch and ECM stimulated signaling cascades (Figure A.2). Below, we summarize and discuss these interactions between ECM and Notch signaling.

\section{Direct ECM-Notch Interactions That Control Notch Signaling}

Direct interactions between Notch receptors and several ECM proteins have been described in the literature. Below, we summarize the current data available for several ECM proteins including Microfibril Associated Glycoprotein-2 (MAGP-2), Epidermal Growth Factor-like 7 (EGFL7), Nephroblastoma Overexpressed (NOV, CCN3), Thrombospondin-2 (TSP-2), syndecans 2/3, collagens type I and IV, the Y-box binding protein (YB-1), and Galectin-3. An interesting observation is that while all these proteins have been shown to regulate Notch signaling via direct interactions with Notch receptors 
or ligands, there is not a common thread of increased or decreased activity connecting these proteins. Thus, the Notch regulatory activities of these molecules most likely do not rely solely on mechanisms involving a simple steric hindrance model. Moreover, several of these molecules appear to control Notch via multiple mechanisms, suggesting that ECM control of Notch may be a highly regulated activity.

MAGP-2 is a component of elastic fibrils that are thought to help recruit tropoelastin to fibrillin containing microfibrils during the development of elastin networks (Gibson, Hatzinikolas et al. 1996). Since elastin is critical for Windkessel function and structural integrity of the aortic wall (Belz 1995), it is not surprising that loss of function of MAGP-2 is linked to aortic dilation in mice (Combs, Knutsen et al. 2013) and familiar thoracic aortic aneurisms in humans (Barbier, Gross et al. 2014). MAGP-2 may also serve other functions in the cardiovascular system since MAGP- 2 contains an $\alpha v \beta 3$ integrin binding RGD domain and has been shown to control angiogenesis (Albig, Roy et al. 2007) and vascular density in ovarian cancers (Mok, Bonome et al. 2009). The link between MAGP-2 and Notch was first made when MAGP-2 was identified as a Jagged1 interacting protein by yeast-two hybrid screening (Nehring, Miyamoto et al. 2005) and was shown to induce Jagged1 shedding from the cell surface (Miyamoto, Lau et al. 2006). Subsequent analysis determined that MAGP-2 and the related protein MAGP-1 both increased Notch signaling in COS cells (Miyamoto, Lau et al. 2006). Mechanistically, MAGP-2 mediated stimulation of Notch signaling was shown to involve direct binding between the MAGP-2 C-terminal domain, and the EGF-like domains of Notch1 and Jagged1 (Miyamoto, Lau et 
al. 2006). In addition, RGD $\rightarrow$ RGE mutation of the MAGP-2 integrin binding domain converted MAGP-2 from a suppressor to an activator of Notch signaling in endothelial cells suggesting that MAGP-2 may also regulate Notch via interactions with integrins (Deford, Brown et al. 2016). This finding may help to explain the cell type dependent effects of MAGP-2 on Notch signaling previously observed (Albig, Becenti et al. 2008) and suggests that cell type specific control of Notch may be dependent on several factors including integrin and Notch ligand expression profiles.

EGFL7 is a secreted protein that is specifically expressed from endothelial cells during development (Fitch, Campagnolo et al. 2004, Parker, Schmidt et al. 2004). EGFL7 is predominantly found in the vascular microenvironment where it appears to be an important regulator of elastogenesis (Lelievre, Hinek et al. 2008) and angiogenesis (Nichol, Shawber et al. 2010, Nikolic, Stankovic et al. 2013). In particular, EGFL7 is important for the formation and maintenance of vascular lumen structures (Parker, Schmidt et al. 2004, Charpentier, Tandon et al. 2015) and suppressing angiogenic sprouting (Nichol, Shawber et al. 2010). The first observations that EGFL7 could control Notch signaling were made in neural stem cell cultures where it was found that the N-terminal half of EGFL7 specifically interacted with EGF domains in Notch1-4 and inhibited Notch signaling (Schmidt, Bicker et al. 2009). Subsequent work showed that EGFL7 control of Notch in endothelial and placental trophoblast cells was important for placenta development and that decreased EGFL7 expression may be linked to preeclampsia (Lacko, Massimiani et al. 2014, Massimiani, Vecchione et al. 2015). In addition to controlling Notch via direct 
interaction with Notch receptors, recent work showed that RGD $\rightarrow$ RGE mutation of the EGFL7 integrin-binding domain enhanced Notch signaling in endothelial cells (Deford, Brown et al. 2016). By regulating Notch via direct interactions with Notch receptors and via RGD integrin binding, EGFL7 demonstrates similarities with MAGP-2 and suggest that dual control of Notch by ECM molecules is a common theme.

In addition to MAGP-2 and EGFL7, CCN3 (NOV) has also been implicated in the regulation of Notch signaling (Sakamoto, Yamaguchi et al. 2002). CCN3 belongs to the ECM CCN family of proteins (CCN1-6) that share a modular structure including of conserved cysteine knot C-terminal (CT) domain and are multi-functional regulators of diverse processes including development, osteogenesis, and angiogenesis (Katsube, Sakamoto et al. 2009). The Notch regulatory activity of CCN3 appears to be important for controlling a variety of activities including osteoblast differentiation (Minamizato, Sakamoto et al. 2007, Katsuki, Sakamoto et al. 2008) and trophoblast senescence (Wagener, Yang et al. 2013, Kipkeew, Kirsch et al. 2016). Regulation of Notch signaling may be a general feature of the $\mathrm{CCN}$ family since CCN2 (CTGF) suppresses Notch signaling (Smerdel-Ramoya, Zanotti et al. 2008) and CCN1 (Cyr61) is linked to suppression of Notch1 during the epithelial to mesenchymal transition (EMT) (Haque, De et al. 2012). Although, mechanistic details describing how CCN3 manipulates Notch signaling are lacking, the cysteine rich $\mathrm{C}$-terminal tail of $\mathrm{CCN} 3$ binds to Notch1 (Sakamoto, Yamaguchi et al. 2002) and is required for Notch regulation (Katsuki, Sakamoto et al. 2008). Similar to MAGP-2 and EGFL7, CCN3 also interacts with several 
integrins (in an RGD independent manner) (Lin, Leu et al. 2003) although it is unknown if control of Notch by CCN3 involves integrin ligation. Interestingly however, CCN1 is highly expressed near developing blood vessels where it enhances Notch signaling in an integrin dependent manner (Chintala, Krupska et al. 2015).

Although MAGP-2, EGFL7, and CCN3 are the best characterized examples of ECM proteins known to regulate Notch activity via direct Notch receptor and/or ligand interactions, several other ECM molecules have also been implicated in the Notch pathway and appear to control Notch via direct interactions with Notch receptors and/or ligands. A common thread among these molecules is Notch3, which appears to be frequently targeted by ECM interactions compared to other Notch receptors. For instance, Thrombospondin-2 (TSP-2) and Syndecan-2 specifically interact with Notch3 and promote Notch3 - Jagged1 signaling (Meng, Zhang et al. 2009, Zhao, Liu et al. 2012). Conversely, collagen type I and IV also bind to Notch3 and Jagged1 but suppress downstream Notch signaling (Zhang, Meng et al. 2013). An additional example of Notch3 regulation by microenvironment is YB-1. The multi-functional YB-1 protein has widespread DNA/RNA binding activities (Kohno, Izumi et al. 2003) and has historically been thought of as a cold shock protein (Kohno, Izumi et al. 2003). Interestingly however, YB-1 can be secreted from mesangial and immune cells after cytokine stimulation via a non-classical mechanism that involves ubiquitin E3 ligase HACE-1 mediated K27 ubiquitination and association with the Tumor Susceptibility Gene 101 (TSG101) (Frye, Halfter et al. 2009, Palicharla and Maddika 2015). In turn, secreted YB-1 has been found to specifically interact with Notch3 EGF 
repeats and to control Notch3 downstream signaling, but not Notch1 signaling (Rauen, Raffetseder et al. 2009, Raffetseder, Rauen et al. 2011). More recently, non-secreted YB1 was found to control Notch4 expression in triple negative breast cancer cells suggesting that YB-1 may control Notch on multiple levels (Reipas, Law et al. 2013). Finally, while Notch3 appears to be a common target for many ECM molecules, it is not the only target. For instance, while Syndecan-2 regulates Notch3 - Jagged1 signaling (Zhao, Liu et al. 2012), Syndecan-3 interacts with Notch1 receptor, regulates processing by ADAM17/TACE, and is required for Notch signaling activity in skeletal muscle progenitor cells (Pisconti, Cornelison et al. 2010). Finally, the sugar binding protein Galectin-3 has been reported to directly interact with Notch1 in a sugar-dependent manner and to activate downstream Notch signaling without affecting expression of Notch1 receptor (Nakajima, Kho et al. 2014).

Collectively, these examples demonstrate that a diverse array of ECM molecules can influence Notch utilizing a wide variety of mechanisms. Given that each of these molecules exhibits tissue and/or temporal specific expression patterns, these examples serve as a dynamic illustration of how Notch responds to changing ECM microenvironments. With this understanding, it will be interesting to see how future work refines our understanding of ECM - Notch interactions. 


\section{Indirect ECM-Notch Interactions that Control Notch Signaling (Transcriptional}

$\underline{\text { Mechanisms) }}$

Each of the examples described thus far involve matricellular control of Notch that appears to be mediated at least in part by direct protein interactions with Notch receptors and/or Notch ligands. However, other matricellular proteins control Notch activity in a less direct manner by influencing the expression of Notch signaling components. For instance, the SPARC protein (Secreted Protein, Acidic, and Rich in Cysteine) stimulates differentiation of medulloblastoma cells by suppressing Notch signaling (Bhoopathi, Chetty et al. 2011). However, instead of direct interaction with Notch receptors or ligands, SPARC seems to transcriptionally control Notch signaling since SPARC null osteoblasts express increased Notch1 protein (Kessler and Delany 2007) and SPARC protein transcriptionally suppresses Notch1 expression (Bhoopathi, Chetty et al. 2011). In comparison to SPARC, which seems to control Notch via direct manipulation of Notch1 expression, other ECM proteins such as Fibulin-3, basement membrane laminins, and MGP influence Notch signaling by controlling expression of Notch ligands. Fibulin-3 is a member of the fibulin family of extracellular matrix glycoproteins that are characterized by tandem repeats of calcium binding EGF sites and a C-terminus fibulin-type module (Timpl, Sasaki et al. 2003). Fibulin proteins are commonly misregulated during cancer and have emerged as important microenvironmental regulators of cancer and tumor angiogenesis (Albig, Neil et al. 2006). In particular, Fibulin-3 has emerged as a biomarker for pleural mesothelioma and malignant glioma where Fibulin-3 appears to enhance glioma 
malignancy by stimulating tumor cell motility and invasion $(\mathrm{Hu}$, Thirtamara-Rajamani et al. 2009). Fibulin-3 also enhances tumor angiogenesis in glioma by increasing endothelial expression of the Notch ligand Dll-4 and simultaneously stimulating ADAM10/17 activity and downstream Notch signaling (Nandhu, Hu et al. 2014). An interesting observation however, is that Dll-4 has been extensively shown to limit branching angiogenesis by suppressing the endothelial tip cell phenotype (Hu, Lu et al. 2011). As an example of this idea, basement membrane laminins including Laminin- $\alpha 4$ and Laminin-111 promote Notch activation by increasing Dll-4 expression via interaction with integrins (Estrach, Cailleteau et al. 2011, Stenzel, Franco et al. 2011). As opposed to Fibulin-3 however, Dll4 induction by these laminins appears to be an important mechanism to maintain endothelial quiescence by limiting tip cell behaviors. Thus, perhaps simultaneous regulation of ADAM10/17 and Dll-4 enables Fibulin-3 to behave as an angiogenic promoter in glioma, but to inhibit angiogenesis in other tumors as previously described (Albig, Neil et al. 2006). Finally, Matrix Gla Protein (MGP) is a well-known inhibitor of vascular calcification (Luo, Ducy et al. 1997) that functions by binding to and suppressing the osteogenic programs initiated by BMP-2 and other BMPs (Zebboudj, Imura et al. 2002). In addition to suppressing vascular calcification, MGP has additional roles in the vasculature since MGP deficiency in mice leads to increased vascular densities, enhanced tumor angiogenesis (Sharma and Albig 2013), and the development of arteriovenous malformations (Yao, Jumabay et al. 2011). Mechanistically, MGP deletion results in increased Notch signaling via enhanced expression of the Notch ligand Jagged1 (Sharma 
and Albig 2013) and accordingly, deletion of a single Jagged1 or Jagged2 allele in MGP knockout animals suppresses arteriovenous malformations (Yao, Yao et al. 2013). Although it is not yet clear how MGP controls Jagged1 expression, it appears that MGP expression is also controlled by Notch in shear-stressed aortic valve endothelium, (White, Theodoris et al. 2015) suggesting that Notch and MGP are coordinated by a feedback regulation.

An important observation is that many of the ECM proteins discussed above not only control Notch signaling, but have also been implicated in the matricellular control of angiogenesis. Indeed, MAGP-2, EGFL7, the CCN family of proteins (CCN1, 2, 3), Thrombospondin-2, Syndecan-2, SPARC, collagens I and IV, Fibulin-3, MGP, and laminins have all been characterized as angiogenic regulators. Given that Notch has emerged as a major regulator in the cardiovascular system (discussed below), matricellular control of Notch activity may be a common mechanism whereby the vascular microenvironment exerts control over angiogenic activity. Hopefully, future research will be able to determine the relative contributions of these matrix molecules towards Notch regulation during angiogenic processes and begin to understand how these multiple signals integrate to control Notch.

Direct ECM Notch Interactions That Control Notch Signaling (Crosstalk Mechanisms).

Reelin is a secreted glycoprotein that is an important regulator of neuronal cell migration in the developing brain, (Dulabon, Olson et al. 2000, Yip, Yip et al. 2000) and provides one last mechanism to demonstrate how ECM molecules may control Notch. 
Deletion of Reelin in mice causes an abnormal "reeling" gait referred to as a Reeler phenotype (D'Arcangelo, Miao et al. 1995). Reelin has several cell surface receptors including the VLDLR and ApoER2 lipoprotein receptors on neuronal cells that have been described by several investigators (Hiesberger, Trommsdorff et al. 1999, Ballif, Arnaud et al. 2003, Bock and Herz 2003). In addition, Reelin has also been described to interact with integrins $\alpha 3 \beta 1$ and $\alpha 5 \beta 1$ (Dulabon, Olson et al. 2000, Sekine, Kawauchi et al. 2012). Downstream from these receptors, Reelin signaling typically propagates through Disabled1 (DAB-1) phosphorylation and downstream PI-3K, AKT, and SRC signaling mechanisms (Ballif, Arnaud et al. 2003, Bock and Herz 2003, Hashimoto-Torii, Torii et al. 2008, Keilani and Sugaya 2008, Keilani, Healey et al. 2012, Sekine, Kawauchi et al. 2012). Early work by Keilani et al (Keilani and Sugaya 2008) and Hashimoto-Torii et al (HashimotoTorii, Torii et al. 2008) suggested that Notch may be important for activities downstream of Reelin. For example, Reelin induces a radial glial phenotype in human neural progenitor cells, and this effect is phenocopied by activation of the Notch signaling cascade (Keilani and Sugaya 2008). Moreover, the Notch NICD domain is sufficient to rescue abnormal migration in neurons from reeler mice (Hashimoto-Torii, Torii et al. 2008). Mechanistically, Reelin does not appear to directly interact with, or control the expression of Notch receptors and/or ligands. Instead, Reelin appears to control Notch via manipulation of downstream signaling networks. For instance, it has been shown that the downstream Reelin signaling intermediate, DAB-1, physically associates with NICD (Keilani and Sugaya 2008), that Notch works through DAB-1 to regulate axon guidance in 
Drosophila (Le Gall, De Mattei et al. 2008), and that DAB-1 phosphorylation and SRC activity are essential for Notch1 activation by Reelin (Keilani, Healey et al. 2012). Taken together, these results suggest that Reelin may regulate Notch via a mechanism independent of Notch expression or Notch processing, but dependent on downstream DAB-1 and/or SRC kinase activities. Although further research is required to confirm this, the molecular interaction between Notch and SRC is further explored in the Integrin/Notch crosstalk section below.

\section{Notch crosstalk with other signaling networks. Integrins, TGF- $\beta$, WNT, and VEGF:}

An important distinction between Notch regulation by Reelin compared to other molecules mentioned in the previous section is that Reelin does not depend on direct Notch receptor/ligand interactions nor on transcriptional control of individual Notch signaling components. Instead, the evidence supports a mechanism whereby Reelin interaction with its cell surface receptors triggers downstream signaling (DAB-1 and SRC) that then regulates Notch via undefined mechanisms. Thus, Reelin serves as an example of how Notch signaling can be influenced by crosstalk with other signaling pathways. Similarly, crosstalk between Notch and several other signaling mechanisms initiated by molecules including integrins, TGF- $\beta$ /BMP, VEGF, and WNTs in the cellular microenvironment (Figure A.3) have been described and are discussed below.

\section{Crosstalk between Notch and Integrins:}

The earliest evidence that integrins and Notch coordinate comes from studies which explored the effect of Notch on integrin activation. For instance, Leong et al. demonstrated 
that Notch4 activation in microvascular endothelium increased $\beta 1$ integrin affinity for collagen (Leong, Hu et al. 2002). This was taken one step further by Hodkinson et al., who demonstrated that activation of the small GTPase R-Ras by Notch1 resulted in increased $\beta 1$ affinity for collagen (Hodkinson, Elliott et al. 2007). Subsequent work on this topic began to uncover the reciprocal interaction wherein integrins also exert control over Notch. Initially, integrin control of Notch was focused on transcriptional regulation of Notch receptors or ligands. For example, work by Weijers et al. (Weijers, van Wijhe et al. 2010) described an effect of integrin blocking low molecular weight fibronectin fragments on the expression of the Notch ligand Dll-4 and subsequent Notch activation in endothelial cells. Similarly, Estrach et al. (Estrach, Cailleteau et al. 2011) and Stenzel et al. (Stenzel, Franco et al. 2011) demonstrated that Laminin 111 and Laminin $\alpha 4$ increase Dll-4 expression in endothelial cells via $\alpha 2 \beta 1$ and $\alpha 6 \beta 1$ integrins, and that disruption of this signaling system had dramatic complications for normal angiogenesis. While these studies suggested a functional coordination of ECM, integrins, and Notch they did little to dissect a molecular mechanism, beyond transcriptional control, through which coordination occurs. A handful of reports however have suggested that Notch control by integrins is not restricted to transcriptional regulation, but rather, may also engage Integrin Linked Kinase (ILK) and/or SRC signaling downstream from activated integrins. For instance, Mo et al. (Mo, Kim et al. 2007) observed that ILK decreased Notch signaling by stimulating ubiquitination and rapid degradation of the NICD fragment. Similarly, Suh et al. (Suh and Han 2011) showed that collagen type I increased ILK signaling and NICD accumulation through interaction 
with $\alpha 2 \beta 1$ integrin. In addition to ILK, the non-receptor tyrosine kinase SRC which is commonly activated by integrin ligation, may also regulate Notch. As eluded to above, Reelin has been shown to control Notch in a DAB-1 and SRC dependent manner (Keilani, Healey et al. 2012). Although a molecular interaction between Notch and SRC was not explored in this study, the authors did show that SRC inhibitors did not affect expression of Notch1, suggesting a more direct Reelin-SRC-Notch interaction. In support of this, SRC was found to be an important regulator of Notch S1 processing by furin and that the kinase domain of SRC binds to and phosphorylates the ankyrin domain of active NICD (Ma, Shi et al. 2012). Moreover, a genetic interaction between SRC and Notch has been uncovered during Drosophila development that is critical for normal eye formation (Ho, Pallavi et al. 2015). Taken as a whole, these publications show that Notch can control integrin adhesion (i.e. inside out signaling), and that integrins can control Notch (i.e. outside in signaling). Therefore, these data suggest that integrins and Notch are coordinated into a cellular signaling network that involves feedback control between Notch and integrins and may involve ILK and/or SRC signaling.

The implications of integrin/Notch crosstalk are potentially quite numerous. In particular, one field of research that may be impacted by this crosstalk is the study of pathological tissue fibrosis. Fibrotic diseases are defined by excessive deposition of fibrotic ECM molecules, increased tissue stiffness, and can occur in most any tissue although fibrosis of the liver, lung, kidney, and heart represent the major impacts of fibrosis on human health. Given the increased ECM present in fibrotic tissues, it is not surprising that 
integrins figure predominantly in the pathology of fibrosis (Patsenker and Stickel 2011, Pozzi and Zent 2013, Chen, Li et al. 2016). Adding to this, it has become apparent that Notch is also an important regulator of fibrosis in the lung, liver, kidney, and skin (Kavian, Servettaz et al. 2012, Hu and Phan 2016). For example, strong expression of Notch was observed in myofibroblasts, the pathological cells associated with the progression of fibrosis, in lung specimens from patients with idiopathic interstitial pneumonias and in bleomycin-induced pulmonary model of fibrosis (Aoyagi-Ikeda, Maeno et al. 2011). Moreover, in airway subepithelial fibrosis, the Notch pathway stimulated the promoter activity of collagen type I through a Hes1-dependent mechanism $(\mathrm{Hu}, \mathrm{Ou}-\mathrm{Yang}$ et al. 2014). In the kidney, Bielesz et al. showed that upregulation of Notch pathway components (Jag1/Notch1/HeyL) regulated the development of tubulointerstitial kidney fibrosis in mice and humans (Bielesz, Sirin et al. 2010). In the liver, the number of Notch1, Notch3 and Notch4 positive cells were highly upregulated in CCL4 induced fibrosis (Chen, Zheng et al. 2012). Moreover, activated hepatic stellate cells (HSC) showed an increased expression of Notch2, Notch3, Hey2 and HeyL (Zhang, Xu et al. 2015). However, after blocking with the $\gamma$-secretase inhibitor DAPT, activated HSC reversed back to quiescent HSC (Zhang, $\mathrm{Xu}$ et al. 2015) and attenuated hepatic fibrosis (Chen, Zheng et al. 2012). Collectively, these examples clearly illustrate the importance of Notch signaling during fibrotic responses. Given the crosstalk between integrins and Notch, it will be interesting to determine if integrins have a strong impact on Notch mediated fibrosis. 


\section{$\underline{\text { Notch and TGF- } \beta \text { : }}$}

The TGF- $\beta$ superfamily encompasses more than 30 ligands including TGF- $\beta$ s, BMPs, activins/inhibins, and Mullerian Inhibiting Substance (MIS) that specifically interact with at least seven ALK receptors. Activation of ALK receptors by TGF- $\beta$ or other ligands stimulates SMADs to translocate to the nucleus where they coordinate transcriptional responses (reviewed in (Gordon and Blobe 2008)). TGF- $\beta$ and Notch signaling are both involved in several physiological and patho-physiological processes including embryonic development, wound healing, cancer, and fibrosis. Several lines of evidence indicate that TGF- $\beta$ and Notch can engage in crosstalk (reviewed in (Kluppel and Wrana 2005, Tang, Urs et al. 2010)). The first molecular evidence for this interaction was revealed in a series of papers showing that Notch is synergistic with both TGF- $\beta$ and BMP signaling. Specifically, Blokzijl et al. demonstrated that NICD can form a transcription factor complex with SMAD3, an intracellular transducer of TGF- $\beta$ signaling, in chicken embryos and in mouse myoblast C2C12 cells (Blokzijl, Dahlqvist et al. 2003). In this study, it was also observed that TGF- $\beta$ upregulated the expression of Hes-1, a Notch target gene, and the effect was abolished by using a dominant negative form of CSL (Blokzijl, Dahlqvist et al. 2003). A similar interaction was observed in mouse regulatory $\mathrm{T}$ cells in which NICD cooperates with activated SMAD3 and accelerates its nuclear translocation (Asano, Watanabe et al. 2008). The importance of TGF- $\beta$ /Notch crosstalk is illustrated by several reports showing that Notch activity is required for some TGF- $\beta$ effects such as 
TGF $\beta$-induced EMT (Zavadil, Cermak et al. 2004) and the well-known pro-fibrotic activity of TGF- $\beta$ (Kavian, Servettaz et al. 2010, Nyhan, Faherty et al. 2010, Chen, Zheng et al. 2012, Xiao, Zhang et al. 2014). Finally, although the majority of interactions between TGF$\beta$ and Notch appear to be synergistic, this may be an oversimplified view of the TGF$\beta /$ Notch interaction. In support of this, Fu et al (Fu, Chang et al. 2009), found that while Notch did enhance expression of some TGF- $\beta$ responsive genes including PAI1, CTGF, and CYR61, other TGF- $\beta$ responsive genes including ID1, and ID2, were decreased by Notch activity. The authors also found that Notch enhanced expression of SMAD3 while decreasing expression of SMAD1, 2, and 6, suggesting that differential regulation of RSMADs by Notch may be responsible for positive and negative TGF- $\beta$ /Notch interactions. From this analysis, it appears that the interaction between TGF- $\beta$ and Notch may be more complex than currently thought.

TGF- $\beta$ however is not the only member of the TGF- $\beta$ superfamily that engages in crosstalk with Notch. Early work observed that BMP and Notch signals synergistically reinforced one another during various developmental processes such as Xenopus tail bud formation (Beck, Whitman et al. 2001) and tooth morphogenesis (Mustonen, Tummers et al. 2002). Mechanistically, the BMP/Notch crosstalk involves the formation of a SMAD/NICD transcription factor complex, much like the TGF- $\beta$ /Notch crosstalk mechanism. Formation of this complex was observed and found to be important for endothelial function and neuroepithelial cell differentiation (Mustonen, Tummers et al. 
2002, Itoh, Itoh et al. 2004). Follow up work has now determined that crosstalk between Notch and BMP is important for a wide variety of cellular responses including osteoblastic differentiation (Nobta, Tsukazaki et al. 2005, Sharff, Song et al. 2009, Hill, Yuasa et al. 2014) and vascular biology/angiogenesis (Larrivee, Prahst et al. 2012, Moya, Umans et al. 2012). Finally, besides TGF- $\beta$ and BMP, little is known regarding crosstalk between other TGF- $\beta$ superfamily members and Notch. However, given that the majority of the other TGF- $\beta$ superfamily members utilize ALK receptors and SMAD signaling intermediates, it seems likely that future research may uncover new crosstalk mechanisms between members of the TGF- $\beta$ superfamily and Notch.

Notch and WNT:

Like Notch, the WNT signaling network is evolutionarily ancient and heavily utilized during development. Consisting of $\sim 19$ ligands that can bind to $\sim 10$ frizzled receptors and their co-receptors (LRP5/6), the canonical WNT signaling pathway is mediated by ligand binding to receptor, stabilization and nuclear translocation of $\beta$-catenin, and subsequent association with LEF/TCF transcription factors to activate gene specific promoters. In the absence of WNT signaling, $\beta$-catenin is phosphorylated by GSK3 $\beta$ which triggers $\beta$-catenin ubiquitination and rapid protein turnover (reviewed in (Komiya and Habas 2008)). The first evidence suggesting a crosstalk between WNT and Notch signaling was uncovered in Drosophila where it was shown that Notch and WNT cooperate to control wing development (Couso and Martinez Arias 1994, Hing, Sun et al. 1994). The first molecular evidence supporting crosstalk between Notch and WNT was made by Ross 
and Kadesch (Ross and Kadesch 2001), when N1ICD was found to increase transcriptional activity of the LEF transcription factor independently of the canonical Notch transcription factor, CSL. Instead, it was found that the NICD/WNT crosstalk was mediated by a NICD/LEF transcriptional complex that regulated a unique subset of promoters compared to the $\beta$-catenin/LEF complex (Ross and Kadesch 2001). Similarly, NICD/ $\beta$-catenin complexes have been identified and found to be important for suppression of neural precursor cells (Shimizu, Kagawa et al. 2008) and for inducing an arterial fate in vascular progenitors (Yamamizu, Matsunaga et al. 2010). Despite these results, this NICD/ $\beta$-catenin complex does not appear to be required for all instances of Notch/WNT crosstalk. Instead, Hayward et al. demonstrated that membrane-bound Notch is capable of interacting with, and deactivating $\beta$-catenin at the cell membrane in a Notch ligand and cleavage independent fashion (Hayward, Brennan et al. 2005). Subsequent reports reinforced this finding by showing that $\beta$-catenin's association with uncleaved Notch at the membrane is also important for $\beta$-catenin regulation in stem cells (Kwon, Cheng et al. 2011), and imaginal disc development in Drosophila (Sanders, Munoz-Descalzo et al. 2009). Thus, Notch signaling can alternatively increase or decrease $\beta$-catenin function, depending on the nature of Notch/ $\beta$-catenin interaction. Finally, while these reports show that $\beta$-catenin is a shared point of overlap during crosstalk between WNT and Notch, other WNT signaling intermediates have also been shown to interact with the Notch mechanism. For instance, GSK3 $\beta$, a serine/threonine kinase that is inactivated by WNT signaling (Komiya and Habas 2008), directly phosphorylates NICD resulting in decreased NICD stability and 
signaling output (Foltz, Santiago et al. 2002, Espinosa, Ingles-Esteve et al. 2003). In this way, inhibition of GSK3 3 by WNT signaling results in a positive interaction between the WNT and Notch signaling mechanisms. In contrast to this, WNT activation of the Dishevelled protein triggers an inhibitory interaction between WNT and Notch. It is not completely clear how this is accomplished however since Dishevelled has been shown to interact both with NICD itself, and with the NICD transcriptional factor CSL in the nucleus, where it inhibits NICD/CSL mediated transcription (Axelrod, Matsuno et al. 1996, Collu, Hidalgo-Sastre et al. 2012).

In summary, the interplay between WNT and Notch is very complex and involves at least four independent mechanisms. This extensive co-regulation may reflect the fact that both Notch and WNT are both heavily utilized during development, where WNT and Notch must cooperate for proper development (Collu, Hidalgo-Sastre et al. 2014). Future studies will no doubt further dissect and define the relative contributions of these pathways to crosstalk between Notch and WNT signaling.

Notch and VEGF:

The vascular endothelial growth factor (VEGF) signaling pathway coordinates vascular development through VEGF ligand binding to cell surface receptor tyrosine kinases. The core of VEGF signaling consists of six broadly expressed VEGF ligands and four VEGF receptors that are highly restricted to vascular and lymphatic tissues (reviewed in (Koch and Claesson-Welsh 2012)). A flurry of publishing activity in recent years now supports a strong crosstalk between the Notch and VEGF signaling mechanisms in the 
vascular system. The basis for Notch/VEGF crosstalk appears to be rooted in the reciprocal transcriptional control of Notch ligands by VEGF, and VEGF receptors by Notch. For instance, early work determined that VEGF was an important regulator of Notch receptors and ligands (Lawson, Vogel et al. 2002, Liu, Shirakawa et al. 2003). Around the same time, it was also becoming apparent that Notch activity was an important determinant of VEGF receptor expression (Taylor, Henderson et al. 2002, Holderfield, Henderson Anderson et al. 2006, Williams, Li et al. 2006). It was not until later, however, when a more complete picture of the interaction between Notch and VEGF began to come into focus. The prime example demonstrating reciprocal regulation between Notch and VEGF occurs during angiogenesis, wherein Notch/VEGF crosstalk has been implicated in the selection and differentiation of tip versus stalk cells on growing columns of endothelial cells (reviewed in (Blanco and Gerhardt 2013)). During tip cell selection, VEGF binding to VEGF Receptor 2 (VEGFR2) at the quiescent endothelial membrane causes a phenotypic switch into a motile cell state known as a tip cell, while also inducing the expression of Dll-4 (Hellstrom, Phng et al. 2007, Lobov, Renard et al. 2007, Suchting, Freitas et al. 2007). Dll4 expression in tip cells and subsequent binding to Notch receptors on adjacent endothelial cells (stalk cells) reduces stalk cell sensitivity to VEGF through the down regulation of VEGFR2, thereby preventing stalk cells from taking on the tip cell phenotype and restricting the number of new vascular branches (Hellstrom, Phng et al. 2007, Leslie, ArizaMcNaughton et al. 2007). Dll-4 signaling in tip cells also increases Jagged1 expression in stalk cells which in a twist of understanding, inhibits Dll-4-Notch signaling in tip cells 
resulting in increased VEGFR2 expression and VEGF sensitivity (Benedito, Roca et al. 2009, Pedrosa, Trindade et al. 2015). In this way, VEGF first elevates Dll-4 expression, which then represses VEGF sensitivity in adjacent cells, thus demonstrating reciprocal regulation between Notch and VEGF. Beyond tip/stalk cell differentiation, crosstalk between Notch and VEGF has also been shown to be an important mechanism controlling other aspects of cardiovascular biology such as arteriovenous differentiation (Fish and Wythe 2015), differentiation of vascular progenitors from stem cells (Sahara, Hansson et al. 2014), heart valve development (van den Akker, Caolo et al. 2012), tumor angiogenesis (Liu, Fan et al. 2014), as well as neuronal development (Thomas, Baker et al. 2013).

\section{Other Microenvironment Conditions That Control Notch (Shear stress, hypoxia, and hyperglycemia).}

As an integrator of cellular microenvironments, the crosstalk between Notch and other signaling pathways is fairly well described compared to crosstalk between Notch and other micro environmental conditions. Nonetheless, compelling evidence has been emerging in recent years, that stimuli such as shear stress in the cardiovascular system, low oxygen levels (hypoxia), and even hyperglycemia all have significant impacts on Notch signaling (Figure A.4). Additionally, Notch has been reported to respond to other micro environmental conditions including high salt in endothelial precursor cell media (Karcher, Hoffmann et al. 2015) and temperature flux in Drosophila (Shimizu, Woodcock et al. 2014, Ishio, Sasamura et al. 2015), however these responses will not be further discussed here. Below we summarize the data and provide mechanistic information (where possible) for 
interactions between Notch and shear stress, hypoxia, and hyperglycemia.

\section{Notch and Shear Stress:}

Notch signaling has in recent years been shown to be an extremely important regulator in the development and function of vascular systems, and many excellent reviews have been published on the role of Notch in vascular development and function (Gridley 2010, Benedito and Hellstrom 2013). In addition, Notch has also been tightly linked to several vascular malfunctions including the development of atherosclerotic lesions (Rusanescu, Weissleder et al. 2008). Recently however, a previously unrecognized role for Notch in sensing shear stress in the vascular system has also begun to emerge. Shear stress in the vascular system is a mechanical force applied to endothelial cells by fluid flow and normally ranges from 1-5 $\mathrm{Pa}\left(10-50\right.$ dynes $\left./ \mathrm{cm}^{2}\right)$ in arteries and capillaries, to $0.1-0.5 \mathrm{~Pa}(1-$ 5 dynes $/ \mathrm{cm}^{2}$ ) in veins (Cohen, Wang et al. 1995). Shear stress is an important component of the endothelial cellular microenvironment that strongly influences endothelial cell biology. Laminar (undisturbed) shear stress provides an athero-protective signal to endothelium, while non-laminar, disturbed, or oscillatory shear stress provokes the development of endothelial dysfunction and atherogenesis (Glagov, Zarins et al. 1988). Several endothelial shear stress sensors have been identified and include a wide range of transmembrane proteins on both the apical and basolateral endothelial surfaces and the intracellular kinases and signaling networks that are stimulated by these surface proteins (Zhou, Li et al. 2014). The first demonstration that Notch can serve as a sensor for shear stress was provided by Wang et al. who showed that Notch signaling targets were 
differentially regulated after exposure to shear stress for as little as 10 minutes (Wang, Fu et al. 2007). Masumura et al. subsequently showed that shear stress activates Notch signaling and that this signal is critical for embryonic stem cell differentiation to endothelium (Masumura, Yamamoto et al. 2009). Although protein expression of Notch1 and 4, as well as the Notch ligands Dll-4, Jagged1 and 2 increased after exposure to laminar flow, increased abundance of the active Notch NICD domain was observed prior to increased Notch receptor/ligand expression, suggesting that shear stress may regulate Notch signaling on both transcriptional and post-translational levels (Masumura, Yamamoto et al. 2009). Mechanotransduction by Notch signaling has since been demonstrated to be an important player in both vascular development (Jahnsen, Trindade et al. 2015) and dysfunction ( $\mathrm{Tu}, \mathrm{Li}$ et al. 2014). Interestingly, inhibition of Notch under atherogenic / low shear stress conditions was shown to inhibit several pro-inflammatory molecules, suggesting that inappropriate activation of Notch by low shear stress may also be linked to the early stages of atherogenesis (Qin, Zhang et al. 2016). While these findings clearly implicate Notch in endothelial shear stress responses, it is not currently understood how Notch signaling is activated by shear stress. It seems unlikely that activation of Notch is wholly dependent on transcriptional mechanisms since Notch activation is observed after as little as 10 minutes of shear stress (Wang, Fu et al. 2007). However, it has also been shown that inhibition of VEGFR2 signaling during shear stress blocks Notch activation (Masumura, Yamamoto et al. 2009), suggesting that if Notch receptors are flow sensors, that they do not act alone during endothelial response to shear stress. Taken together, these 
findings illustrate the important role Notch plays in responding to shear stress in the endothelial microenvironment. Future work will hopefully further explore the mechanism by which Notch is activated by shear stress and continue to define the importance of Notch in endothelial/vascular response to shear stress.

\section{Notch and Hypoxia}

Notch signaling responds to oxygen content within the cellular microenvironment, showing differential activity under normoxic and hypoxic conditions. The first evidence suggesting that Notch might be involved in hypoxic responses came when researchers observed that Dll4 expression was increased in hypoxic tissues (Mailhos, Modlich et al. 2001). Soon after, Notch signaling was observed to be increased in hypoxic neuroblastoma cells (Jogi, Ora et al. 2002). Further investigation has discovered a physical interaction between NICD and HIF-1 $\alpha$ (Hypoxia Inducible Factor $\alpha$ ), which was promoted by hypoxia and lead to inhibition of cellular differentiation (Gustafsson, Zheng et al. 2005). A similar observation was also made in Drosophila when it was observed that Sima (the Drosophila HIF1- $\alpha$ homolog) could also activate Notch receptor in a ligand-independent manner (Mukherjee, Kim et al. 2011). HIF-1 $\alpha$ binds to NICD, stabilizes it, and enhances the transcriptional activation of Notch downstream genes through an association with NICD transcriptional complexes (Gustafsson, Zheng et al. 2005). Subsequently, it was shown that hypoxia induced HIF- $1 \alpha$ also serves to activate $\gamma$-secretase through a direct interaction, promoting invasiveness and metastasis in murine breast cancer cells (Villa, Chiu et al. 2014). Furthermore, HIF-1 $\alpha$ can upregulate expression of the Notch ligand D11-4 in 
endothelial progenitor cells (Diez, Fischer et al. 2007), and lymphatic vessels (Min, Lee et al. 2016). Finally, further sophistication of this mechanism is achieved through FIH (Factor Inhibiting HIF-1 $\alpha$ ), an asparagine hydroxylase (Scholz, Rodriguez et al. 2016), which works to inhibit HIF-1 $\alpha$ activity in an $\mathrm{O}_{2}$ dependent mechanism (Mahon, Hirota et al. 2001). FIH also negatively regulates Notch target gene transcription (Gustafsson, Zheng et al. 2005), likely through its hydroxylation and destabilization of NICD under normoxic conditions (Zheng, Linke et al. 2008). Collectively, the multiple mechanisms by which hypoxia controls Notch including HIF-1 $\alpha$ association with Notch transcriptional complexes, $\gamma$-secretase induction, promotion of ligand expression, and FIH activity provide at least four independent mechanisms by which Notch cooperates in hypoxic responses. Notch and Hyperglycemia:

Recent work has begun to dissect a molecular mechanism by which Notch signaling may respond to increased or decreased blood sugar and possibly play a role in diabetes and the vascular and renal complications associated with diabetes. For example, Notch signaling in hepatocytes is increased in response to high sugar concentrations (Valenti, Mendoza et al. 2013) and hyperglycemia induced Jagged1 expression in endothelium was proposed to be an important mediator of diabetic vasculopathy (Yoon, Choi et al. 2014). Moreover, several investigators have shown that hyperglycemia elevates Notch receptor expression/signaling in cultured podocytes (Gao, Yao et al. 2013, Wang, Yao et al. 2014, Liu, Zhang et al. 2015), and elevated Notch signaling has been linked to a loss of glomerular filtration due to a negative impact on podocyte function (Niranjan, Bielesz et 
al. 2008, Waters, Wu et al. 2008). Thus, hyperglycemic stimulation of Notch may be extremely important for understanding the pathology of diabetic nephropathy, especially since podocyte damage in diabetic kidneys has been proposed to be an early triggering event leading to other downstream renal complications (Lin and Susztak 2016). In support of this, treatment of Streptozotocin induced diabetic mice with the angiotensin inhibitor Valsartan, simultaneously decreased renal damage and Notch activation (Gao, Yao et al. 2016). Mechanistically, the link between hyperglycemia and Notch has been elusive, however it is known that hyperglycemia (as well as hypoglycemia) induce VEGF secretion and signaling (Natarajan, Bai et al. 1997, Kemeny, Figueroa et al. 2013). Given the reciprocal transcriptional regulation between VEGF and Notch (as described above), it seems likely that VEGF and Notch may pathologically synergize in hyperglycemic conditions. In support of this, a recent report by Chiu et al. found that hyperglycemia increased endothelial secretion of heparinase leading to increased VEGF release from neighboring myocytes thus enhancing endothelial Notch activity (Chiu, Wan et al. 2016). Interestingly, anti-VEGF therapies have shown some success in reducing diabetic renal dysfunction (de Vriese, Tilton et al. 2001, Flyvbjerg, Dagnaes-Hansen et al. 2002), although it is unknown whether these anti-VEGF approaches also reciprocally decrease Notch signaling. It has also been shown that inhibition of Notch reduced the elevated VEGF secretions in podocytes cultured under hyperglycemic conditions, as well as diabetic nephropathy in diabetic rats (Lin, Wang et al. 2010). Finally, there may be other Notch regulatory mechanisms beyond VEGF that are operant during hyperglycemic conditions. 
For example, hyperglycemia induced Notch activity seems to be also be linked to decreased CARM1 methyltransferase activity (Kim, Lim et al. 2014), a recently discovered negative regulator of Notch signaling (Hein, Mittler et al. 2015). Hopefully future research will be able to more clearly define the molecular mechanism by which hyperglycemia controls Notch in order to more fully understand the downstream implications of Notch signaling in diabetes.

\section{Conclusions:}

Through the examples presented in this review, it is clear that Notch signaling is capable of responding to a range of changing microenvironmental conditions that go far beyond the basic model of receptor-ligand interaction for Notch activation. Instead, evidence is building that the basic model of Notch activation is manipulated by a variety of microenvironmental cues and that the basic cell-cell interaction model of Notch activation represents only a part of the broader function of Notch to sense and respond to a wide variety of microenvironmental conditions. Despite these findings, many of the results discussed here have been gained from simplified models of cellular microenvironment. In order to build a more complete understanding of how Notch serves its role as an integrator of cellular microenvironments, future studies will need to examine how Notch responds to these conditions in more complex in vivo models, an undoubtedly complex task. In addition, fleshing out the molecular underpinnings of how Notch responds to microenvironmental conditions is an important goal that should provide opportunities for pharmacological intervention in the many diseases and processes that are characterized 
by altered microenvironments. Lastly, efforts to therapeutically manipulate Notch are ongoing for the treatment of a wide variety of diseases (reviewed in (Andersson and Lendahl 2014)). Therefore, an understanding of the full spectrum of activities that Notch serves in the microenvironment is an important consideration in developmental biology and various Notch targeting strategies.

\section{Acknowledgements:}

This work was supported by funding from the NIGMS to ARA (1R15GM10285201) and (P20GM109095), the INBRE program (NIH Grant \# P20 RR016454 (National Center for Research Resources) and \# P20 GM103408 (National Institute of General Medical Sciences). 


\section{Table A.1: Basic and proposed mechanisms by which Notch responds to various microenvironmental signals.}

\section{ECM - Notch (Direct interaction mechanism)}

\begin{tabular}{|c|c|c|}
\hline Protein Name & Basic/Proposed Mechanism(s): & Ref. \\
\hline MAGP-2 & $\begin{array}{l}\text {-Decrease Notch in RGD/integrin dependent manner } \\
\text {-Interacts with EGF-like domains of Notch1 + Jagged1, activates cleavage }\end{array}$ & $\begin{array}{l}\text { (Deford, } \\
\text { Brown et al. } \\
2016 \text { ) } \\
\text { (Nehring, } \\
\text { Miyamoto et } \\
\text { al. 2005, } \\
\text { Miyamoto, } \\
\text { Lau et al. } \\
\text { 2006) }\end{array}$ \\
\hline EGFL7 & $\begin{array}{l}\text {-RGD/integrin dependent Notch activation } \\
\text {-Interaction with Notch EGF domains and resultant Notch inhibition }\end{array}$ & $\begin{array}{l}\text { (Deford, } \\
\text { Brown et al. } \\
2016 \text { ) } \\
\text { (Schmidt, } \\
\text { Bicker et al. } \\
2009 \text { ) }\end{array}$ \\
\hline CCN3 & -Binds Notch1 receptor and stimulates Notch receptor activation & $\begin{array}{l}\text { (Sakamoto, } \\
\text { Yamaguchi } \\
\text { et al. 2002, } \\
\text { Katsuki, } \\
\text { Sakamoto et } \\
\text { al. 2008) }\end{array}$ \\
\hline TSP-2 & -Binds Notch3, activates Notch3/Jagged signaling & $\begin{array}{l}\text { (Meng, } \\
\text { Zhang et al. } \\
\text { 2009) }\end{array}$ \\
\hline Syndecans & $\begin{array}{l}\text {-Syndecan-2 binds Notch3, activates Notch3/Jagged signaling } \\
\text {-Syndecan-3 interacts with Notch1 }\end{array}$ & $\begin{array}{l}\text { (Zhao, Liu et } \\
\text { al. 2012) } \\
\text { (Pisconti, } \\
\text { Cornelison et } \\
\text { al. 2010) }\end{array}$ \\
\hline Col IV & -Interacts with Notch3, blocks Jagged1 - Notch3 signaling & $\begin{array}{l}\text { (Zhang, } \\
\text { Meng et al. } \\
\text { 2013) }\end{array}$ \\
\hline Col I & -Interacts with Notch3, blocks Jagged1 - Notch3 signaling & $\begin{array}{l}\text { (Zhang, } \\
\text { Meng et al. } \\
\text { 2013) }\end{array}$ \\
\hline YB-1 & -Binds Notch3 EGF-like repeats, blocks Notch3 but not Notch1 signaling & $\begin{array}{l}\text { (Rauen, } \\
\text { Raffetseder } \\
\text { et al. 2009, } \\
\text { Raffetseder, } \\
\text { Rauen et al. } \\
\text { 2011) }\end{array}$ \\
\hline Galectin-3 & -Binds Notch1 glycosylations, increases NICD processing & $\begin{array}{l}\text { (Nakajima, } \\
\text { Kho et al. } \\
\text { 2014) }\end{array}$ \\
\hline
\end{tabular}


ECM - Notch (Indirect transcriptional mechanism)

\begin{tabular}{|c|c|c|}
\hline Protein Name & Basic/Proposed Mechanism: & Ref. \\
\hline SPARC & -Suppresses Notch by blocking Notch1 transcription & $\begin{array}{l}\text { (Kessler and } \\
\text { Delany 2007, } \\
\text { Bhoopathi, } \\
\text { Chetty et al. } \\
\text { 2011) }\end{array}$ \\
\hline Fibulin-3 & -Enhances DII-4 expression, ADAM10/17 activity, and Notch signaling & $\begin{array}{l}\text { (Nandhu, } \mathrm{Hu} \\
\text { et al. 2014) }\end{array}$ \\
\hline Laminin $\alpha 4$ & -Increases DII-4 expression, stimulates Notch & $\begin{array}{l}\text { (Stenzel, } \\
\text { Franco et al. } \\
\text { 2011) }\end{array}$ \\
\hline Laminin-111 & -Increases DII-4 expression, stimulates Notch & $\begin{array}{l}\text { (Estrach, } \\
\text { Cailleteau et } \\
\text { al. 2011) }\end{array}$ \\
\hline MGP & -Decreases Jagged1 expression, suppresses Notch & $\begin{array}{l}\text { (Sharma and } \\
\text { Albig 2013, } \\
\text { Yao, Yao et } \\
\text { al. 2013) }\end{array}$ \\
\hline
\end{tabular}

ECM - Notch (Indirect cross-talk mechanism)

\begin{tabular}{|l|l|l|}
\hline Protein Name & Basic/Proposed Mechanism: & Ref. \\
\hline & -Stimulates DAB-1 and SRC signaling. Increases Notch activity & (Hashimoto- \\
& & Torii, Torii et \\
& al. 2008, \\
Reelin & & Keilani and \\
& & Sugaya \\
& & 2008, \\
& & Keilani, \\
& Healey et al. \\
& $2012)$ \\
\hline
\end{tabular}

Cross-talk with other signaling pathways

\begin{tabular}{|c|c|c|}
\hline Pathway: & Basic/Proposed Mechanism: & Ref. \\
\hline Integrin & $\begin{array}{l}\text {-RGD/RGE control of Notch activity. Possible SRC or ILK involvement } \\
\text {-Notch4 / R-Ras mediate increase in } \beta 1 \text { integrin affinity }\end{array}$ & $\begin{array}{l}\text { (Mo, Kim et } \\
\text { al. 2007, Ma, } \\
\text { Shi et al. } \\
2012 \text {, } \\
\text { Deford, } \\
\text { Brown et al. } \\
2016) \\
\text { (Leong, Hu } \\
\text { et al. 2002, } \\
\text { Hodkinson, } \\
\text { Elliott et al. } \\
\text { 2007) }\end{array}$ \\
\hline TGF- $\beta /$ BMP & -Transcriptional complex between NICD and SMAD3 & $\begin{array}{l}\text { (Mustonen, } \\
\text { Tummers et } \\
\text { al. 2002, } \\
\text { Blokzijl, } \\
\text { Dahlqvist et } \\
\text { al. 2003, } \\
\text { ltoh, Itoh et } \\
\text { al. 2004, } \\
\text { Asano, } \\
\text { Watanabe et } \\
\text { al. 2008) }\end{array}$ \\
\hline WNT & $\begin{array}{l}\text {-Transcriptional complex between NICD and } \beta \text {-catenin } \\
\text { - } \beta \text {-Catenin interaction with uncleaved Notch receptor } \\
\text {-GSK3 } \beta \text { mediated phosphorylation of NICD, Notch inhibition } \\
\text {-Dishevelled interaction with CSL, Notch inhibition }\end{array}$ & $\begin{array}{l}\text { (Ross and } \\
\text { Kadesch } \\
2001, \\
\text { Shimizu, } \\
\text { Kagawa et }\end{array}$ \\
\hline
\end{tabular}




\begin{tabular}{|c|c|c|}
\hline . & & $\begin{array}{l}\text { al. 2008, } \\
\text { Yamamizu, } \\
\text { Matsunaga } \\
\text { et al. 2010) } \\
\text { (Hayward, } \\
\text { Brennan et } \\
\text { al. 2005, } \\
\text { Sanders, } \\
\text { Munoz- } \\
\text { Descalzo et } \\
\text { al. 2009, } \\
\text { Kwon, } \\
\text { Cheng et al. } \\
\text { 2011) } \\
\text { (Foltz, } \\
\text { Santiago et } \\
\text { al. 2002, } \\
\text { Espinosa, } \\
\text { Ingles- } \\
\text { Esteve et al. } \\
\text { 2003) } \\
\text { (Axelrod, } \\
\text { Matsuno et } \\
\text { al. 1996, } \\
\text { Collu, } \\
\text { Hidalgo- } \\
\text { Sastre et al. } \\
\text { 2012) } \\
\end{array}$ \\
\hline 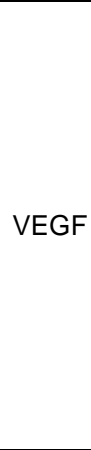 & $\begin{array}{l}\text {-Suppression of VEGFR2 receptors by DII-4 } \\
\text {-VEGF signaling increases Notch1 and DII-4 expression }\end{array}$ & $\begin{array}{l}\text { Lawson, } \\
\text { Vogel et al. } \\
\text { 2002, Liu, } \\
\text { Shirakawa et } \\
\text { al. 2003) } \\
\text { (Taylor, } \\
\text { Henderson } \\
\text { et al. 2002, } \\
\text { Holderfield, } \\
\text { Henderson } \\
\text { Anderson et } \\
\text { al. 2006, } \\
\text { Williams, Li } \\
\text { et al. 2006) }\end{array}$ \\
\hline
\end{tabular}

Other microenvironmental conditions

\begin{tabular}{|c|c|c|}
\hline Condition: & Basic Mechanism: & Ref. \\
\hline Shear Stress & $\begin{array}{l}\text {-Rapid NICD cleavage, transcriptional control of receptor/ligands, possible } \\
\text { involvement of VEGFR2 }\end{array}$ & $\begin{array}{l}\text { (Masumura, } \\
\text { Yamamoto et } \\
\text { al. 2009, Tu, } \\
\text { Li et al. } \\
2014 \text {, } \\
\text { Jahnsen, } \\
\text { Trindade et } \\
\text { al. 2015) }\end{array}$ \\
\hline Hypoxia & $\begin{array}{l}\text {-Transcriptional complex between NICD and Hif } 1 \alpha \\
\text {-Activation of } \gamma \text {-secretase } \\
\text {-Increase of DII- } 4 \text { expression by Hif } 1 \alpha \\
\text {-FIH mediated hydroxylation and destabilization of NICD (Normoxia) }\end{array}$ & $\begin{array}{l}\text { (Gustafsso } \\
\text { Zheng et al. } \\
\text { 2005) } \\
\text { (Villa, Chiu et } \\
\text { al. 2014) } \\
\text { (Benedito, } \\
\text { Roca et al. } \\
\text { 2009, Min, }\end{array}$ \\
\hline
\end{tabular}




\begin{tabular}{|c|c|c|}
\hline & & $\begin{array}{l}\text { Lee et al. } \\
2016 \text { ) } \\
\text { (Mahon, } \\
\text { Hirota et al. } \\
2001 \text {, Zheng, } \\
\text { Linke et al. } \\
\text { 2008) }\end{array}$ \\
\hline Hyperglycemia & $\begin{array}{l}\text {-VEGF mediated increase in Notch receptor expression and NICD accumulation. } \\
\text {-Possible involvement of NICD methylation by CARM1 }\end{array}$ & $\begin{array}{l}\text { (Gao, Yao et } \\
\text { al. 2013, } \\
\text { Wang, Yao } \\
\text { et al. 2014, } \\
\text { Liu, Zhang et } \\
\text { al. 2015) } \\
\text { (Kim, Lim et } \\
\text { al. 2014) }\end{array}$ \\
\hline
\end{tabular}



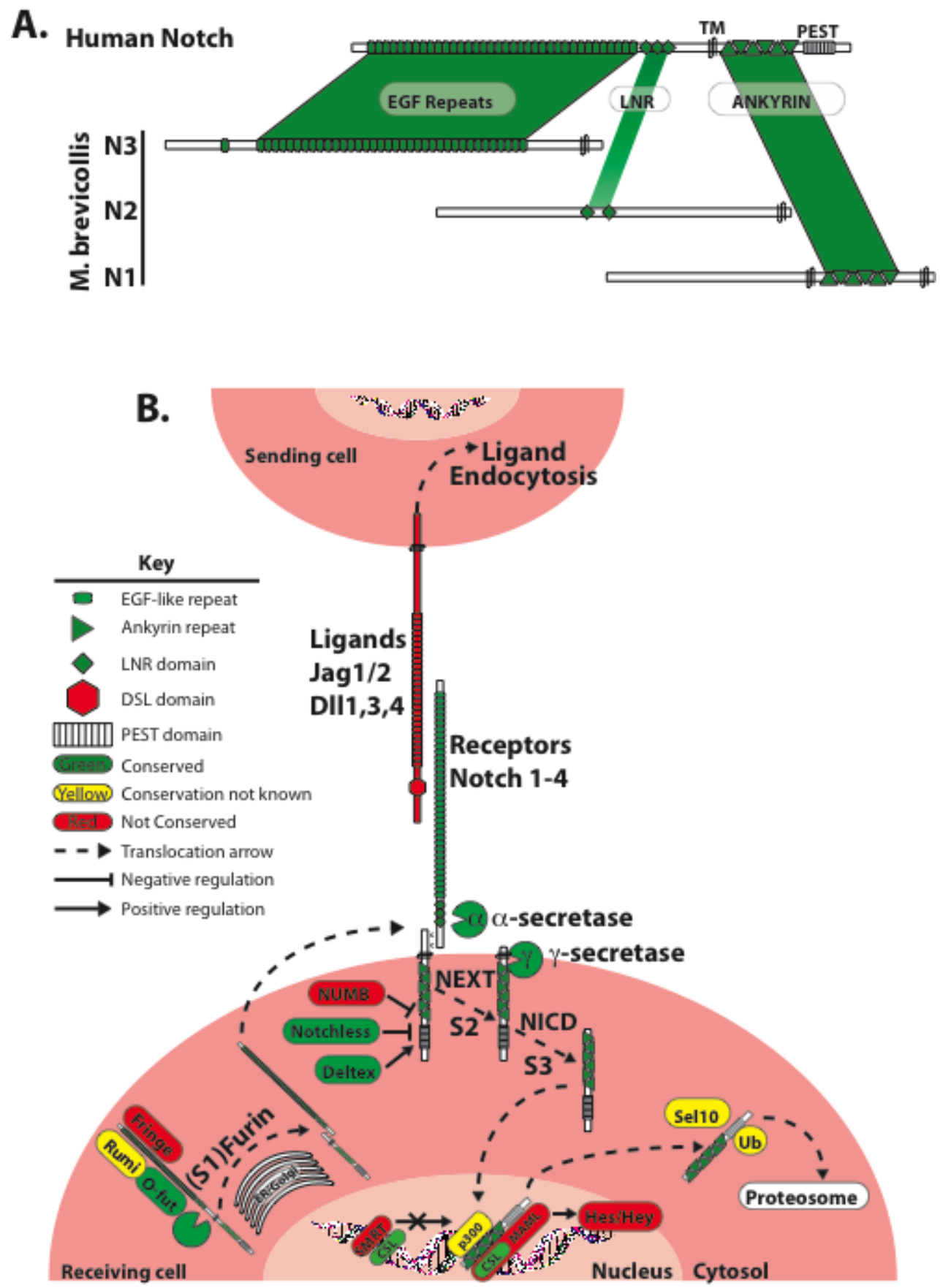
Figure A.1: Canonical Notch signaling and Notch conservation between human and Monosiga brevicollis. Throughout Figure 1, conservation of Notch proteins or domains between human and $M$. brevicollis is indicated by green (positive), yellow (unknown), or red (negative) shading according to references (King, Westbrook et al. 2008) and (Gazave, Lapebie et al. 2009). (A) Conservation of mammalian Notch receptor domains in $M$. brevicollis. Mammalian (human) Notch receptors contain 36 EGF-like repeats and three LNR or NRR (Lin-12 Notch Repeats or Negative Regulatory Region) repeats in the extracellular domain. The intracellular portion of human Notch contains seven ankyrin domains and a PEST sequence at the $C$ terminal. For simplicity, the intracellular RAM (RBPj Association Module) domain, two NLS (Nuclear Localization sequence) domains, and TAD (Transactivation Domain) are not shown in this figure. Please refer to references (Kopan and Ilagan 2009, Kopan 2010) for complete details. Three separate proteins (N1, N2, and N3) in M. brevicollis contain six Ankyrin domains, two LNR domains, and 36 EGF-like repeats respectively (King, Westbrook et al. 2008). (B) Model of canonical Notch activation mechanism. Notch receptors are modified in the secretory pathway (ER/golgi) by Furin cleavage (S1 cleavage) and glycosylation of EGF-like domains by O-fucosyltransferase (O-fut), Rumi/Poglut1 (Protein O-Glycosyltransferase 1), and fringe family glycosyltransferases. The Furin cleavage products remain noncovalently associated in the membrane where a pulling force initiated by Notch ligand endocytosis in sending cells enables further cleavage by $\alpha$-secretase (S2 cleavage, NEXT fragment) at the LNR domain, and $\gamma$-secretase (S3 cleavage, NICD fragment) in the membrane of receiving cells. Several regulatory proteins including Numb, Notchless, and Deltex control Notch availability at the membrane. After $\gamma$-secretase cleavage, the NICD fragment translocates to the nucleus where it displaces the transcriptional co-repressor SMRT from CSL/RBP-jk. NICD participates in a transcriptional complex with CSL, MAML, and p300 to drive transcription of Notch targets such as Hes and Hey genes. NICD steady-state levels are controlled by nuclear export, ubiquitination (Ub) by Sel10, and subsequent degradation in the proteasome. 


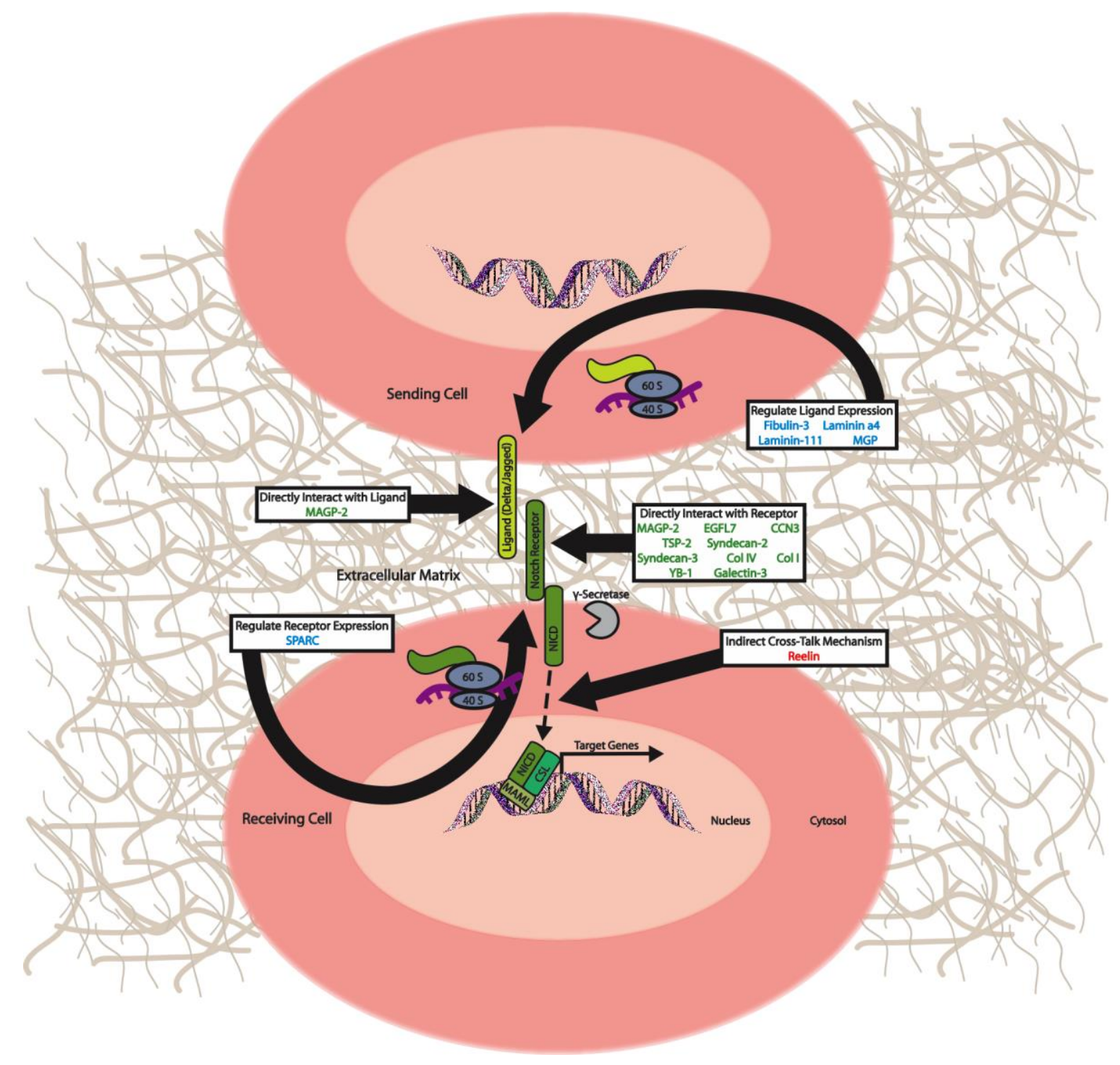

Figure A.2: Summary of ECM control of Notch signaling. Canonical activation of Notch receptors by Notch ligands can be manipulated in three ways by cellular interactions with ECM. 1.) Direct interactions between Notch receptors or ligands and various ECM molecules can either inhibit or promote activation of Notch signaling. 2.) Indirect interactions between ECM and Notch are characterized by ECM mediated increased or decreased expression of Notch ligands on sending cells or Notch receptors on receiving cells. 3.) Indirect interactions between Notch and ECM are characterized by ECM mediated activation of signaling pathways that post-translationally intersect with Notch proteins or signaling intermediates. 


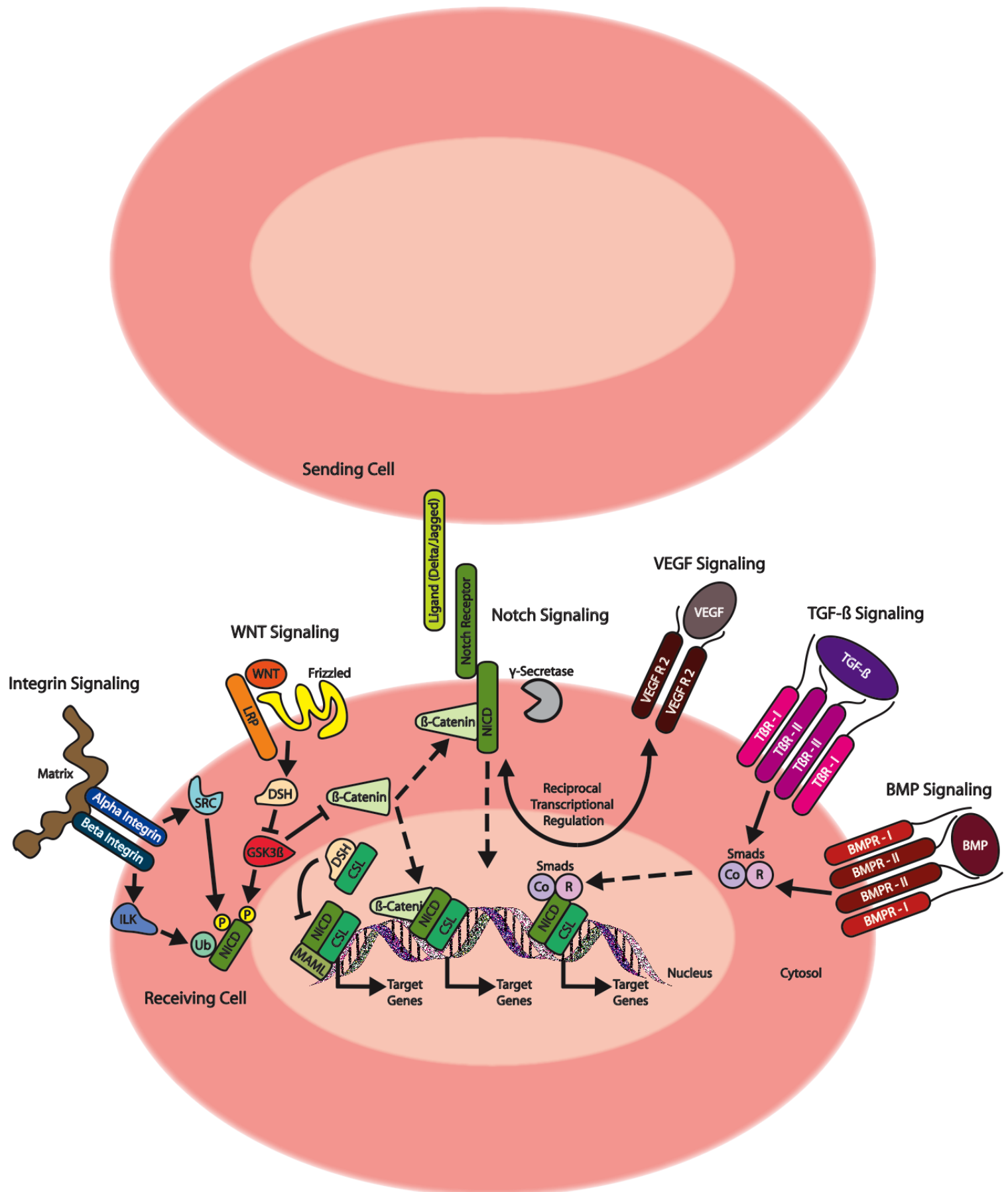

Figure A.3: Crosstalk between Notch and other signaling pathways. Crosstalk between WNT and Notch occurs on several levels including the formation of a $\beta$ catenin-NICD transcriptional complex, interaction between Notch receptors and $\beta$ catenin at the membrane, phosphorylation of NICD by GSK3 $\beta$, and inhibitory 
interactions between Dishevelled and CSL. The mechanistic interaction between integrins and Notch is poorly characterized, but existing evidence suggests ubiquitination and/or phosphorylation of NICD by SRC and ILK kinases. Interaction between the Notch and VEGF pathways involves the reciprocal transcriptional regulation of Notch ligands by VEGF, and VEGFR2 by Notch. Notch/TGF- $\beta$, or Notch/BMP crosstalk occurs downstream of ALK (TBR1/TBR2 or BMPR1/BMPR2) receptors and is dependent on R-SMAD and Co-SMAD activation and subsequent formation of a SMAD/NICD transcriptional complex similar to the $\beta$-catenin/NICD complex.

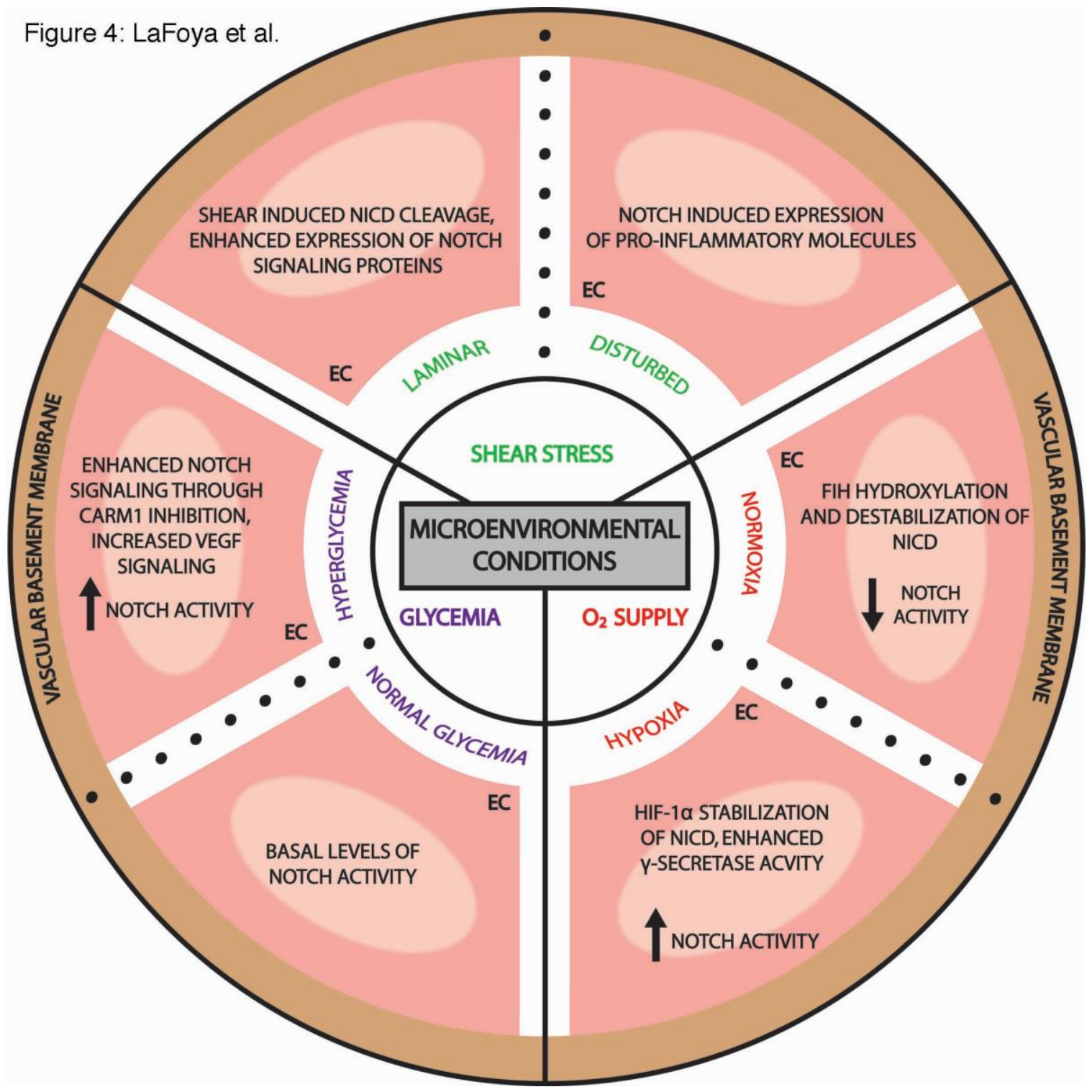


Figure A.4: Summary of microenvironmental conditions (shear stress, hypoxia, and hyperglycemia) that control Notch. Depicted is a cross-sectional view through a blood vessel showing endothelial cells (EC) and vascular basement membrane. Shear stress (laminar versus disturbed or non-laminar) controls Notch by largely undefined mechanisms that may include regulation of Notch receptors and/or ligands. Hypoxia controls Notch signaling by several mechanisms including the formation of HIF1 $\alpha$ NICD transcriptional complexes, HIF1 $\alpha$ mediated stabilization of NICD, enhanced $\gamma$ secretase activity, and FIH mediated NICD destabilization. Hyperglycemia controls Notch by largely uncharacterized mechanisms that may include increased NICD stability due to decreased CARM1 expression and/or increased VEGF release from other cells in the vascular microenvironement. 


\section{REFERENCES CITED}

Albig, A. R., D. J. Becenti, T. G. Roy and W. P. Schiemann (2008). "Microfibrilassociate glycoprotein-2 (MAGP-2) promotes angiogenic cell sprouting by blocking notch signaling in endothelial cells." Microvasc Res.

Albig, A. R., J. R. Neil and W. P. Schiemann (2006). "Fibulins 3 and 5 antagonize tumor angiogenesis in vivo." Cancer Res 66(5): 2621-2629.

Albig, A. R., T. G. Roy, D. J. Becenti and W. P. Schiemann (2007). "Transcriptome analysis of endothelial cell gene expression induced by growth on matrigel matrices: identification and characterization of MAGP-2 and lumican as novel regulators of angiogenesis." Angiogenesis 10(3): 197-216.

Andersson, E. R. and U. Lendahl (2014). "Therapeutic modulation of Notch signalling-are we there yet?" Nat Rev Drug Discov 13(5): 357-378.

Aoyagi-Ikeda, K., T. Maeno, H. Matsui, M. Ueno, K. Hara, Y. Aoki, F. Aoki, T.

Shimizu, H. Doi, K. Kawai-Kowase, T. Iso, T. Suga, M. Arai and M. Kurabayashi (2011). "Notch induces myofibroblast differentiation of alveolar epithelial cells via transforming growth factor-\{beta\}-Smad3 pathway." Am J Respir Cell Mol Biol 45(1): 136-144.

Asano, N., T. Watanabe, A. Kitani, I. J. Fuss and W. Strober (2008). "Notch1 signaling and regulatory T cell function." J Immunol 180(5): 2796-2804.

Axelrod, J. D., K. Matsuno, S. Artavanis-Tsakonas and N. Perrimon (1996). "Interaction between Wingless and Notch signaling pathways mediated by dishevelled." Science 271(5257): 1826-1832. 
Ballif, B. A., L. Arnaud and J. A. Cooper (2003). "Tyrosine phosphorylation of Disabled1 is essential for Reelin-stimulated activation of Akt and Src family kinases." Brain Res Mol Brain Res 117(2): 152-159.

Barbier, M., M. S. Gross, M. Aubart, N. Hanna, K. Kessler, D. C. Guo, L. Tosolini, B. Ho-Tin-Noe, E. Regalado, M. Varret, M. Abifadel, O. Milleron, S. Odent, S. Dupuis-Girod, L. Faivre, T. Edouard, Y. Dulac, T. Busa, L. Gouya, D. M. Milewicz, G. Jondeau and C. Boileau (2014). "MFAP5 loss-of-function mutations underscore the involvement of matrix alteration in the pathogenesis of familial thoracic aortic aneurysms and dissections." Am J Hum Genet 95(6): 736-743.

Beck, C. W., M. Whitman and J. M. Slack (2001). "The role of BMP signaling in outgrowth and patterning of the Xenopus tail bud." Dev Biol 238(2): 303-314.

Belz, G. G. (1995). "Elastic properties and Windkessel function of the human aorta." Cardiovasc Drugs Ther 9(1): 73-83.

Benedito, R. and M. Hellstrom (2013). "Notch as a hub for signaling in angiogenesis." Exp Cell Res 319(9): 1281-1288.

Benedito, R., C. Roca, I. Sorensen, S. Adams, A. Gossler, M. Fruttiger and R. H. Adams (2009). "The notch ligands Dll4 and Jagged1 have opposing effects on angiogenesis." Cell 137(6): 1124-1135.

Bhoopathi, P., C. Chetty, R. Dontula, M. Gujrati, D. H. Dinh, J. S. Rao and S. S. Lakka (2011). "SPARC stimulates neuronal differentiation of medulloblastoma cells via the Notch1/STAT3 pathway." Cancer Res 71(14): 4908-4919.

Bielesz, B., Y. Sirin, H. Si, T. Niranjan, A. Gruenwald, S. Ahn, H. Kato, J. Pullman, M. Gessler, V. H. Haase and K. Susztak (2010). "Epithelial Notch signaling regulates interstitial fibrosis development in the kidneys of mice and humans." $\mathrm{J}$ Clin Invest 120(11): 4040-4054. 
Blanco, R. and H. Gerhardt (2013). "VEGF and Notch in tip and stalk cell selection." Cold Spring Harb Perspect Med 3(1): a006569.

Blokzijl, A., C. Dahlqvist, E. Reissmann, A. Falk, A. Moliner, U. Lendahl and C. F. Ibanez (2003). "Cross-talk between the Notch and TGF-beta signaling pathways mediated by interaction of the Notch intracellular domain with Smad3." $\underline{\mathrm{J} \text { Cell }}$ Biol 163(4): 723-728.

Bock, H. H. and J. Herz (2003). "Reelin activates SRC family tyrosine kinases in neurons." Curr Biol 13(1): 18-26.

Brou, C., F. Logeat, N. Gupta, C. Bessia, O. LeBail, J. R. Doedens, A. Cumano, P. Roux, R. A. Black and A. Israel (2000). "A novel proteolytic cleavage involved in Notch signaling: the role of the disintegrin-metalloprotease TACE." Mol Cell 5(2): 207216.

Charpentier, M. S., P. Tandon, C. E. Trincot, E. K. Koutleva and F. L. Conlon (2015). "A Distinct Mechanism of Vascular Lumen Formation in Xenopus Requires EGFL7." PLoS One 10(2): e0116086.

Chen, C., R. Li, R. S. Ross and A. M. Manso (2016). "Integrins and integrin-related proteins in cardiac fibrosis." J Mol Cell Cardiol 93: 162-174.

Chen, Y., S. Zheng, D. Qi, S. Zheng, J. Guo, S. Zhang and Z. Weng (2012). "Inhibition of Notch signaling by a gamma-secretase inhibitor attenuates hepatic fibrosis in rats." PLoS One 7(10): e46512.

Chintala, H., I. Krupska, L. Yan, L. Lau, M. Grant and B. Chaqour (2015). "The matricellular protein $\mathrm{CCN} 1$ controls retinal angiogenesis by targeting VEGF, Src homology 2 domain phosphatase-1 and Notch signaling." Development 142(13): 2364-2374.

Chiu, A. P., A. Wan, N. Lal, D. Zhang, F. Wang, I. Vlodavsky, B. Hussein and B. Rodrigues (2016). "Cardiomyocyte VEGF Regulates Endothelial Cell GPIHBP1 
to Relocate Lipoprotein Lipase to the Coronary Lumen During Diabetes Mellitus." Arterioscler Thromb Vasc Biol 36(1): 145-155.

Chowdhury, F., I. T. Li, T. T. Ngo, B. J. Leslie, B. C. Kim, J. E. Sokoloski, E. Weiland, X. Wang, Y. R. Chemla, T. M. Lohman and T. Ha (2016). "Defining Single Molecular Forces Required for Notch Activation Using Nano Yoyo." Nano Lett.

Cohen, M. I., D. M. Wang and J. M. Tarbell (1995). "Measurement of oscillatory flow pressure gradient in an elastic artery model." Biorheology 32(4): 459-471.

Collu, G. M., A. Hidalgo-Sastre, A. Acar, L. Bayston, C. Gildea, M. K. Leverentz, C. G. Mills, T. W. Owens, O. Meurette, K. Dorey and K. Brennan (2012). "Dishevelled limits Notch signalling through inhibition of CSL." Development 139(23): 44054415.

Collu, G. M., A. Hidalgo-Sastre and K. Brennan (2014). "Wnt-Notch signalling crosstalk in development and disease." Cell Mol Life Sci 71(18): 3553-3567.

Combs, M. D., R. H. Knutsen, T. J. Broekelmann, H. M. Toennies, T. J. Brett, C. A. Miller, D. L. Kober, C. S. Craft, J. J. Atkinson, J. M. Shipley, B. C. Trask and R. P. Mecham (2013). "Microfibril-associated glycoprotein 2 (MAGP2) loss of function has pleiotropic effects in vivo." J Biol Chem 288(40): 28869-28880.

Couso, J. P. and A. Martinez Arias (1994). "Notch is required for wingless signaling in the epidermis of Drosophila." Cell 79(2): 259-272.

D'Arcangelo, G., G. G. Miao, S. C. Chen, H. D. Soares, J. I. Morgan and T. Curran (1995). "A protein related to extracellular matrix proteins deleted in the mouse mutant reeler." Nature 374(6524): 719-723.

D'Souza, B., L. Meloty-Kapella and G. Weinmaster (2010). "Canonical and noncanonical Notch ligands." Curr Top Dev Biol 92: 73-129. 
de Vriese, A. S., R. G. Tilton, M. Elger, C. C. Stephan, W. Kriz and N. H. Lameire (2001). "Antibodies against vascular endothelial growth factor improve early renal dysfunction in experimental diabetes." J Am Soc Nephrol 12(5): 993-1000.

Deford, P., K. Brown, R. L. Richards, A. King, K. Newburn, K. Westover and A. R. Albig (2016). "MAGP2 controls Notch via interactions with RGD binding integrins: Identification of a Novel ECM - Integrin - Notch Signaling Axis." Exp Cell Res.

Diez, H., A. Fischer, A. Winkler, C. J. Hu, A. K. Hatzopoulos, G. Breier and M. Gessler (2007). "Hypoxia-mediated activation of Dll4-Notch-Hey2 signaling in endothelial progenitor cells and adoption of arterial cell fate." Exp Cell Res 313(1): 1-9.

Dulabon, L., E. C. Olson, M. G. Taglienti, S. Eisenhuth, B. McGrath, C. A. Walsh, J. A. Kreidberg and E. S. Anton (2000). "Reelin binds alpha3beta1 integrin and inhibits neuronal migration." Neuron 27(1): 33-44.

Espinosa, L., J. Ingles-Esteve, C. Aguilera and A. Bigas (2003). "Phosphorylation by glycogen synthase kinase-3 beta down-regulates Notch activity, a link for Notch and Wnt pathways." J Biol Chem 278(34): 32227-32235.

Estrach, S., L. Cailleteau, C. A. Franco, H. Gerhardt, C. Stefani, E. Lemichez, L. Gagnoux-Palacios, G. Meneguzzi and A. Mettouchi (2011). "Laminin-binding integrins induce Dl14 expression and Notch signaling in endothelial cells." $\underline{\text { Circ }}$ Res 109(2): 172-182.

Fish, J. E. and J. D. Wythe (2015). "The molecular regulation of arteriovenous specification and maintenance." Dev Dyn 244(3): 391-409.

Fitch, M. J., L. Campagnolo, F. Kuhnert and H. Stuhlmann (2004). "Egfl7, a novel epidermal growth factor-domain gene expressed in endothelial cells." Dev Dyn 230(2): 316-324. 
Flyvbjerg, A., F. Dagnaes-Hansen, A. S. De Vriese, B. F. Schrijvers, R. G. Tilton and R. Rasch (2002). "Amelioration of long-term renal changes in obese type 2 diabetic mice by a neutralizing vascular endothelial growth factor antibody." Diabetes 51(10): 3090-3094.

Foltz, D. R., M. C. Santiago, B. E. Berechid and J. S. Nye (2002). "Glycogen synthase kinase-3beta modulates notch signaling and stability." Curr Biol 12(12): 10061011.

Fortini, M. E. (2009). "Notch signaling: the core pathway and its posttranslational regulation." Dev Cell 16(5): 633-647.

Frye, B. C., S. Halfter, S. Djudjaj, P. Muehlenberg, S. Weber, U. Raffetseder, A. En-Nia, H. Knott, J. M. Baron, S. Dooley, J. Bernhagen and P. R. Mertens (2009). "Y-box protein-1 is actively secreted through a non-classical pathway and acts as an extracellular mitogen." EMBO Rep 10(7): 783-789.

Fu, Y., A. Chang, L. Chang, K. Niessen, S. Eapen, A. Setiadi and A. Karsan (2009). "Differential regulation of transforming growth factor beta signaling pathways by Notch in human endothelial cells." J Biol Chem 284(29): 19452-19462.

Gao, F., M. Yao, Y. Cao, S. Liu, Q. Liu and H. Duan (2016). "Valsartan ameliorates podocyte loss in diabetic mice through the Notch pathway." Int J Mol Med 37(5): 1328-1336.

Gao, F., M. Yao, Y. Shi, J. Hao, Y. Ren, Q. Liu, X. Wang and H. Duan (2013). "Notch pathway is involved in high glucose-induced apoptosis in podocytes via Bcl-2 and p53 pathways." J Cell Biochem 114(5): 1029-1038.

Gazave, E., P. Lapebie, G. S. Richards, F. Brunet, A. V. Ereskovsky, B. M. Degnan, C. Borchiellini, M. Vervoort and E. Renard (2009). "Origin and evolution of the Notch signalling pathway: an overview from eukaryotic genomes." BMC Evol Biol 9: 249. 
Gibson, M. A., G. Hatzinikolas, J. S. Kumaratilake, L. B. Sandberg, J. K. Nicholl, G. R. Sutherland and E. G. Cleary (1996). "Further characterization of proteins associated with elastic fiber microfibrils including the molecular cloning of MAGP-2 (MP25)." J Biol Chem 271(2): 1096-1103.

Giordano, F. J. and R. S. Johnson (2001). "Angiogenesis: the role of the microenvironment in flipping the switch." Curr Opin Genet Dev 11(1): 35-40.

Glagov, S., C. Zarins, D. P. Giddens and D. N. Ku (1988). "Hemodynamics and atherosclerosis. Insights and perspectives gained from studies of human arteries." Arch Pathol Lab Med 112(10): 1018-1031.

Gordon, K. J. and G. C. Blobe (2008). "Role of transforming growth factor-beta superfamily signaling pathways in human disease." Biochim Biophys Acta 1782(4): 197-228.

Gordon, W. R., B. Zimmerman, L. He, L. J. Miles, J. Huang, K. Tiyanont, D. G. McArthur, J. C. Aster, N. Perrimon, J. J. Loparo and S. C. Blacklow (2015). "Mechanical Allostery: Evidence for a Force Requirement in the Proteolytic Activation of Notch." Dev Cell 33(6): 729-736.

Gridley, T. (2010). "Notch signaling in the vasculature." Curr Top Dev Biol 92: 277-309.

Guruharsha, K. G., M. W. Kankel and S. Artavanis-Tsakonas (2012). "The Notch signalling system: recent insights into the complexity of a conserved pathway." Nat Rev Genet 13(9): 654-666.

Gustafsson, M. V., X. Zheng, T. Pereira, K. Gradin, S. Jin, J. Lundkvist, J. L. Ruas, L. Poellinger, U. Lendahl and M. Bondesson (2005). "Hypoxia requires notch signaling to maintain the undifferentiated cell state." Dev Cell 9(5): 617-628.

Haque, I., A. De, M. Majumder, S. Mehta, D. McGregor, S. K. Banerjee, P. Van Veldhuizen and S. Banerjee (2012). "The matricellular protein CCN1/Cyr61 is a 
critical regulator of Sonic Hedgehog in pancreatic carcinogenesis." J Biol Chem 287(46): 38569-38579.

Hashimoto-Torii, K., M. Torii, M. R. Sarkisian, C. M. Bartley, J. Shen, F. Radtke, T. Gridley, N. Sestan and P. Rakic (2008). "Interaction between Reelin and Notch signaling regulates neuronal migration in the cerebral cortex." Neuron 60(2): 273284.

Hayward, P., K. Brennan, P. Sanders, T. Balayo, R. DasGupta, N. Perrimon and A. Martinez Arias (2005). "Notch modulates Wnt signalling by associating with Armadillo/beta-catenin and regulating its transcriptional activity." Development 132(8): 1819-1830.

Hein, K., G. Mittler, W. Cizelsky, M. Kuhl, F. Ferrante, R. Liefke, I. M. Berger, S. Just, J. E. Strang, H. A. Kestler, F. Oswald and T. Borggrefe (2015). "Site-specific methylation of Notch1 controls the amplitude and duration of the Notch1 response." Sci Signal 8(369): ra30.

Hellstrom, M., L. K. Phng, J. J. Hofmann, E. Wallgard, L. Coultas, P. Lindblom, J. Alva, A. K. Nilsson, L. Karlsson, N. Gaiano, K. Yoon, J. Rossant, M. L. Iruela-Arispe, M. Kalen, H. Gerhardt and C. Betsholtz (2007). "Dll4 signalling through Notch1 regulates formation of tip cells during angiogenesis." Nature 445(7129): 776-780.

Hiesberger, T., M. Trommsdorff, B. W. Howell, A. Goffinet, M. C. Mumby, J. A. Cooper and J. Herz (1999). "Direct binding of Reelin to VLDL receptor and ApoE receptor 2 induces tyrosine phosphorylation of disabled-1 and modulates tau phosphorylation." Neuron 24(2): 481-489.

Hill, C. R., M. Yuasa, J. Schoenecker and S. L. Goudy (2014). "Jagged1 is essential for osteoblast development during maxillary ossification." Bone 62: 10-21.

Hing, H. K., X. Sun and S. Artavanis-Tsakonas (1994). "Modulation of wingless signaling by Notch in Drosophila." Mech Dev 47(3): 261-268. 
Ho, D. M., S. K. Pallavi and S. Artavanis-Tsakonas (2015). "The Notch-mediated hyperplasia circuitry in Drosophila reveals a Src-JNK signaling axis." Elife 4: e05996.

Hodkinson, P. S., P. A. Elliott, Y. Lad, B. J. McHugh, A. C. MacKinnon, C. Haslett and T. Sethi (2007). "Mammalian NOTCH-1 activates beta1 integrins via the small GTPase R-Ras." J Biol Chem 282(39): 28991-29001.

Holderfield, M. T., A. M. Henderson Anderson, H. Kokubo, M. T. Chin, R. L. Johnson and C. C. Hughes (2006). "HESR1/CHF2 suppresses VEGFR2 transcription independent of binding to E-boxes." Biochem Biophys Res Commun 346(3): 637648.

Hu, B. and S. H. Phan (2016). "Notch in fibrosis and as a target of anti-fibrotic therapy." Pharmacol Res 108: 57-64.

Hu, B., K. K. Thirtamara-Rajamani, H. Sim and M. S. Viapiano (2009). "Fibulin-3 is uniquely upregulated in malignant gliomas and promotes tumor cell motility and invasion." Mol Cancer Res 7(11): 1756-1770.

Hu, M., H. F. Ou-Yang, C. G. Wu, S. Y. Qu, X. T. Xu and P. Wang (2014). "Notch signaling regulates collalpha1 and collalpha2 expression in airway fibroblasts." Exp Biol Med (Maywood) 239(12): 1589-1596.

Hu, W., C. Lu, H. H. Dong, J. Huang, D. Y. Shen, R. L. Stone, A. M. Nick, M. M. Shahzad, E. Mora, N. B. Jennings, S. J. Lee, J. W. Roh, K. Matsuo, M. Nishimura, B. W. Goodman, R. B. Jaffe, R. R. Langley, M. T. Deavers, G. LopezBerestein, R. L. Coleman and A. K. Sood (2011). "Biological roles of the Delta family Notch ligand D114 in tumor and endothelial cells in ovarian cancer." Cancer Res 71(18): 6030-6039.

Ishio, A., T. Sasamura, T. Ayukawa, J. Kuroda, H. O. Ishikawa, N. Aoyama, K. Matsumoto, T. Gushiken, T. Okajima, T. Yamakawa and K. Matsuno (2015). "O- 
fucose monosaccharide of Drosophila Notch has a temperature-sensitive function and cooperates with O-glucose glycan in Notch transport and Notch signaling activation." J Biol Chem 290(1): 505-519.

Itoh, F., S. Itoh, M. J. Goumans, G. Valdimarsdottir, T. Iso, G. P. Dotto, Y. Hamamori, L. Kedes, M. Kato and P. ten Dijke Pt (2004). "Synergy and antagonism between Notch and BMP receptor signaling pathways in endothelial cells." Embo j 23(3): $541-551$.

Jahnsen, E. D., A. Trindade, H. C. Zaun, S. Lehoux, A. Duarte and E. A. Jones (2015). "Notch1 is pan-endothelial at the onset of flow and regulated by flow." PLoS One 10(4): e0122622.

Jogi, A., I. Ora, H. Nilsson, A. Lindeheim, Y. Makino, L. Poellinger, H. Axelson and S. Pahlman (2002). "Hypoxia alters gene expression in human neuroblastoma cells toward an immature and neural crest-like phenotype." Proc Natl Acad Sci U S A 99(10): 7021-7026.

Junker, J. P., E. J. Caterson and E. Eriksson (2013). "The microenvironment of wound healing." J Craniofac Surg 24(1): 12-16.

Kadesch, T. (2004). "Notch signaling: the demise of elegant simplicity." Curr Opin Genet Dev 14(5): 506-512.

Karcher, J. R., B. R. Hoffmann, P. Liu, Y. Liu, M. Liang and A. S. Greene (2015). "Genome-wide epigenetic and proteomic analysis reveals altered Notch signaling in EPC dysfunction." Physiol Rep 3(4).

Katsube, K., K. Sakamoto, Y. Tamamura and A. Yamaguchi (2009). "Role of CCN, a vertebrate specific gene family, in development." Dev Growth Differ 51(1): 5567.

Katsuki, Y., K. Sakamoto, T. Minamizato, H. Makino, A. Umezawa, M. A. Ikeda, B. Perbal, T. Amagasa, A. Yamaguchi and K. Katsube (2008). "Inhibitory effect of 
$\mathrm{CT}$ domain of $\mathrm{CCN} 3 / \mathrm{NOV}$ on proliferation and differentiation of osteogenic mesenchymal stem cells, Kusa-A1." Biochem Biophys Res Commun 368(3): 808814.

Kavian, N., A. Servettaz, C. Mongaret, A. Wang, C. Nicco, C. Chereau, P. Grange, V. Vuiblet, P. Birembaut, M. D. Diebold, B. Weill, N. Dupin and F. Batteux (2010). "Targeting ADAM-17/notch signaling abrogates the development of systemic sclerosis in a murine model." Arthritis Rheum 62(11): 3477-3487.

Kavian, N., A. Servettaz, B. Weill and F. Batteux (2012). "New insights into the mechanism of notch signalling in fibrosis." Open Rheumatol J 6: 96-102.

Keilani, S., D. Healey and K. Sugaya (2012). "Reelin regulates differentiation of neural stem cells by activation of notch signaling through Disabled-1 tyrosine phosphorylation." Can J Physiol Pharmacol 90(3): 361-369.

Keilani, S. and K. Sugaya (2008). "Reelin induces a radial glial phenotype in human neural progenitor cells by activation of Notch-1." BMC Dev Biol 8: 69 .

Kemeny, S. F., D. S. Figueroa and A. M. Clyne (2013). "Hypo- and hyperglycemia impair endothelial cell actin alignment and nitric oxide synthase activation in response to shear stress." PLoS One 8(6): e66176.

Kessler, C. B. and A. M. Delany (2007). "Increased Notch 1 expression and attenuated stimulatory $\mathrm{G}$ protein coupling to adenylyl cyclase in osteonectin-null osteoblasts." Endocrinology 148(4): 1666-1674.

Kim, D., S. Lim, M. Park, J. Choi, J. Kim, H. Han, K. Yoon, K. Kim, J. Lim and S. Park (2014). "Ubiquitination-dependent CARM1 degradation facilitates Notch1mediated podocyte apoptosis in diabetic nephropathy." Cell Signal 26(9): 17741782.

King, N., M. J. Westbrook, S. L. Young, A. Kuo, M. Abedin, J. Chapman, S. Fairclough, U. Hellsten, Y. Isogai, I. Letunic, M. Marr, D. Pincus, N. Putnam, A. Rokas, K. J. 
Wright, R. Zuzow, W. Dirks, M. Good, D. Goodstein, D. Lemons, W. Li, J. B. Lyons, A. Morris, S. Nichols, D. J. Richter, A. Salamov, J. G. Sequencing, P. Bork, W. A. Lim, G. Manning, W. T. Miller, W. McGinnis, H. Shapiro, R. Tjian, I. V. Grigoriev and D. Rokhsar (2008). "The genome of the choanoflagellate Monosiga brevicollis and the origin of metazoans." Nature 451(7180): 783-788.

Kipkeew, F., M. Kirsch, D. Klein, M. Wuelling, E. Winterhager and A. Gellhaus (2016). "CCN1 (CYR61) and CCN3 (NOV) signaling drives human trophoblast cells into senescence and stimulates migration properties." Cell Adh Migr: 1-16.

Kluppel, M. and J. L. Wrana (2005). "Turning it up a Notch: cross-talk between TGF beta and Notch signaling." Bioessays 27(2): 115-118.

Koch, S. and L. Claesson-Welsh (2012). "Signal transduction by vascular endothelial growth factor receptors." Cold Spring Harb Perspect Med 2(7): a006502.

Kohno, K., H. Izumi, T. Uchiumi, M. Ashizuka and M. Kuwano (2003). "The pleiotropic functions of the Y-box-binding protein, YB-1." Bioessays 25(7): 691-698.

Komiya, Y. and R. Habas (2008). "Wnt signal transduction pathways." Organogenesis 4(2): 68-75.

Kopan, R. (2010). "Notch Signaling." Current topics in Developmental Biology Volume 92.

Kopan, R. and M. X. Ilagan (2009). "The canonical Notch signaling pathway: unfolding the activation mechanism." Cell 137(2): 216-233.

Kwon, C., P. Cheng, I. N. King, P. Andersen, L. Shenje, V. Nigam and D. Srivastava (2011). "Notch post-translationally regulates beta-catenin protein in stem and progenitor cells." Nat Cell Biol 13(10): 1244-1251.

Lacko, L. A., M. Massimiani, J. L. Sones, R. Hurtado, S. Salvi, S. Ferrazzani, R. L. Davisson, L. Campagnolo and H. Stuhlmann (2014). "Novel expression of 
EGFL7 in placental trophoblast and endothelial cells and its implication in preeclampsia." Mech Dev 133: 163-176.

Ladi, E., J. T. Nichols, W. Ge, A. Miyamoto, C. Yao, L. T. Yang, J. Boulter, Y. E. Sun, C. Kintner and G. Weinmaster (2005). "The divergent DSL ligand D113 does not activate Notch signaling but cell autonomously attenuates signaling induced by other DSL ligands." J Cell Biol 170(6): 983-992.

Larrivee, B., C. Prahst, E. Gordon, R. Del Toro, T. Mathivet, A. Duarte, M. Simons and A. Eichmann (2012). "ALK1 Signaling Inhibits Angiogenesis by Cooperating with the Notch Pathway." Dev Cell 22(3): 489-500.

Lawson, N. D., A. M. Vogel and B. M. Weinstein (2002). "sonic hedgehog and vascular endothelial growth factor act upstream of the Notch pathway during arterial endothelial differentiation." Dev Cell 3(1): 127-136.

Le Gall, M., C. De Mattei and E. Giniger (2008). "Molecular separation of two signaling pathways for the receptor, Notch." Dev Biol 313(2): 556-567.

Lelievre, E., A. Hinek, F. Lupu, C. Buquet, F. Soncin and V. Mattot (2008). "VEstatin/egfl7 regulates vascular elastogenesis by interacting with lysyl oxidases." Embo j 27(12): 1658-1670.

Leong, K. G., X. Hu, L. Li, M. Noseda, B. Larrivee, C. Hull, L. Hood, F. Wong and A. Karsan (2002). "Activated Notch4 inhibits angiogenesis: role of beta 1-integrin activation." Mol Cell Biol 22(8): 2830-2841.

Leslie, J. D., L. Ariza-McNaughton, A. L. Bermange, R. McAdow, S. L. Johnson and J. Lewis (2007). "Endothelial signalling by the Notch ligand Delta-like 4 restricts angiogenesis." Development 134(5): 839-844.

Lin, C. G., S. J. Leu, N. Chen, C. M. Tebeau, S. X. Lin, C. Y. Yeung and L. F. Lau (2003). "CCN3 (NOV) is a novel angiogenic regulator of the $\mathrm{CCN}$ protein family." J Biol Chem 278(26): 24200-24208. 
Lin, C. L., F. S. Wang, Y. C. Hsu, C. N. Chen, M. J. Tseng, M. A. Saleem, P. J. Chang and J. Y. Wang (2010). "Modulation of notch-1 signaling alleviates vascular endothelial growth factor-mediated diabetic nephropathy." Diabetes 59(8): 19151925.

Lin, J. S. and K. Susztak (2016). "Podocytes: the Weakest Link in Diabetic Kidney Disease?" Curr Diab Rep 16(5): 45.

Liotta, L. A. and E. C. Kohn (2001). "The microenvironment of the tumour-host interface." Nature 411(6835): 375-379.

Liu, X. D., L. Y. Zhang, T. C. Zhu, R. F. Zhang, S. L. Wang and Y. Bao (2015). "Overexpression of miR-34c inhibits high glucose-induced apoptosis in podocytes by targeting Notch signaling pathways." Int J Clin Exp Pathol 8(5): 4525-4534.

Liu, Z., F. Fan, A. Wang, S. Zheng and Y. Lu (2014). "Dll4-Notch signaling in regulation of tumor angiogenesis." J Cancer Res Clin Oncol 140(4): 525-536.

Liu, Z. J., T. Shirakawa, Y. Li, A. Soma, M. Oka, G. P. Dotto, R. M. Fairman, O. C. Velazquez and M. Herlyn (2003). "Regulation of Notch1 and Dl14 by vascular endothelial growth factor in arterial endothelial cells: implications for modulating arteriogenesis and angiogenesis." Mol Cell Biol 23(1): 14-25.

Lobov, I. B., R. A. Renard, N. Papadopoulos, N. W. Gale, G. Thurston, G. D. Yancopoulos and S. J. Wiegand (2007). "Delta-like ligand 4 (D114) is induced by VEGF as a negative regulator of angiogenic sprouting." Proc Natl Acad Sci U S A 104(9): 3219-3224.

Logeat, F., C. Bessia, C. Brou, O. LeBail, S. Jarriault, N. G. Seidah and A. Israel (1998). "The Notch1 receptor is cleaved constitutively by a furin-like convertase." Proc Natl Acad Sci U S A 95(14): 8108-8112. 
Luo, G., P. Ducy, M. D. McKee, G. J. Pinero, E. Loyer, R. R. Behringer and G. Karsenty (1997). "Spontaneous calcification of arteries and cartilage in mice lacking matrix GLA protein." Nature 386(6620): 78-81.

Ma, Y. C., C. Shi, Y. N. Zhang, L. G. Wang, H. Liu, H. T. Jia, Y. X. Zhang, F. H. Sarkar and Z. S. Wang (2012). "The tyrosine kinase c-Src directly mediates growth factor-induced Notch-1 and Furin interaction and Notch-1 activation in pancreatic cancer cells." PLoS One 7(3): e33414.

Mahon, P. C., K. Hirota and G. L. Semenza (2001). "FIH-1: a novel protein that interacts with HIF-1alpha and VHL to mediate repression of HIF-1 transcriptional activity." Genes Dev 15(20): 2675-2686.

Mailhos, C., U. Modlich, J. Lewis, A. Harris, R. Bicknell and D. Ish-Horowicz (2001). "Delta4, an endothelial specific notch ligand expressed at sites of physiological and tumor angiogenesis." Differentiation 69(2-3): 135-144.

Massimiani, M., L. Vecchione, D. Piccirilli, P. Spitalieri, F. Amati, S. Salvi, S. Ferrazzani, H. Stuhlmann and L. Campagnolo (2015). "Epidermal growth factorlike domain 7 promotes migration and invasion of human trophoblast cells through activation of MAPK, PI3K and NOTCH signaling pathways." Mol Hum Reprod 21(5): 435-451.

Masumura, T., K. Yamamoto, N. Shimizu, S. Obi and J. Ando (2009). "Shear stress increases expression of the arterial endothelial marker ephrinB2 in murine ES cells via the VEGF-Notch signaling pathways." Arterioscler Thromb Vasc Biol 29(12): 2125-2131.

Meng, H., X. Zhang, K. D. Hankenson and M. M. Wang (2009). "Thrombospondin 2 potentiates notch3/jagged1 signaling." J Biol Chem 284(12): 7866-7874.

Min, J. H., C. H. Lee, Y. W. Ji, A. Yeo, H. Noh, I. Song, E. K. Kim and H. K. Lee (2016). "Activation of Dll4/Notch Signaling and Hypoxia-Inducible Factor-1 
Alpha Facilitates Lymphangiogenesis in Lacrimal Glands in Dry Eye." PLoS One 11(2): e0147846.

Minamizato, T., K. Sakamoto, T. Liu, H. Kokubo, K. Katsube, B. Perbal, S. Nakamura and A. Yamaguchi (2007). "CCN3/NOV inhibits BMP-2-induced osteoblast differentiation by interacting with BMP and Notch signaling pathways." Biochem Biophys Res Commun 354(2): 567-573.

Miyamoto, A., R. Lau, P. W. Hein, J. M. Shipley and G. Weinmaster (2006).

"Microfibrillar proteins MAGP-1 and MAGP-2 induce Notch1 extracellular domain dissociation and receptor activation." J Biol Chem 281(15): 10089-10097.

Mo, J. S., M. Y. Kim, S. O. Han, I. S. Kim, E. J. Ann, K. S. Lee, M. S. Seo, J. Y. Kim, S. C. Lee, J. W. Park, E. J. Choi, J. Y. Seong, C. O. Joe, R. Faessler and H. S. Park (2007). "Integrin-linked kinase controls Notch1 signaling by down-regulation of protein stability through Fbw7 ubiquitin ligase." Mol Cell Biol 27(15): 55655574.

Mok, S. C., T. Bonome, V. Vathipadiekal, A. Bell, M. E. Johnson, K. K. Wong, D. C. Park, K. Hao, D. K. Yip, H. Donninger, L. Ozbun, G. Samimi, J. Brady, M. Randonovich, C. A. Pise-Masison, J. C. Barrett, W. H. Wong, W. R. Welch, R. S. Berkowitz and M. J. Birrer (2009). "A gene signature predictive for outcome in advanced ovarian cancer identifies a survival factor: microfibril-associated glycoprotein 2." Cancer Cell 16(6): 521-532.

Morrison, S. J. and A. C. Spradling (2008). "Stem cells and niches: mechanisms that promote stem cell maintenance throughout life." Cell 132(4): 598-611.

Moya, I. M., L. Umans, E. Maas, P. N. Pereira, K. Beets, A. Francis, W. Sents, E. J. Robertson, C. L. Mummery, D. Huylebroeck and A. Zwijsen (2012). "Stalk cell phenotype depends on integration of notch and smad1/5 signaling cascades." Dev Cell 22(3): 501-514. 
Mukherjee, T., W. S. Kim, L. Mandal and U. Banerjee (2011). "Interaction between Notch and Hif-alpha in development and survival of Drosophila blood cells." Science 332(6034): 1210-1213.

Mumm, J. S., E. H. Schroeter, M. T. Saxena, A. Griesemer, X. Tian, D. J. Pan, W. J. Ray and R. Kopan (2000). "A ligand-induced extracellular cleavage regulates gammasecretase-like proteolytic activation of Notch1." Mol Cell 5(2): 197-206.

Murata, A. and S. Hayashi (2016). "Notch-Mediated Cell Adhesion." Biology (Basel) 5(1).

Mustonen, T., M. Tummers, T. Mikami, N. Itoh, N. Zhang, T. Gridley and I. Thesleff (2002). "Lunatic fringe, FGF, and BMP regulate the Notch pathway during epithelial morphogenesis of teeth." Dev Biol 248(2): 281-293.

Nakajima, K., D. H. Kho, T. Yanagawa, Y. Harazono, X. Gao, V. Hogan and A. Raz (2014). "Galectin-3 inhibits osteoblast differentiation through notch signaling." Neoplasia 16(11): 939-949.

Nandhu, M. S., B. Hu, S. E. Cole, A. Erdreich-Epstein, D. J. Rodriguez-Gil and M. S. Viapiano (2014). "Novel paracrine modulation of Notch-DLL4 signaling by fibulin-3 promotes angiogenesis in high-grade gliomas." Cancer Res 74(19): 5435-5448.

Natarajan, R., W. Bai, L. Lanting, N. Gonzales and J. Nadler (1997). "Effects of high glucose on vascular endothelial growth factor expression in vascular smooth muscle cells." Am J Physiol 273(5 Pt 2): H2224-2231.

Nehring, L. C., A. Miyamoto, P. W. Hein, G. Weinmaster and J. M. Shipley (2005). "The extracellular matrix protein MAGP-2 interacts with Jagged1 and induces its shedding from the cell surface." J Biol Chem 280(21): 20349-20355. 
Nichol, D., C. Shawber, M. J. Fitch, K. Bambino, A. Sharma, J. Kitajewski and H. Stuhlmann (2010). "Impaired angiogenesis and altered Notch signaling in mice overexpressing endothelial Egfl7." Blood 116(26): 6133-6143.

Nikolic, I., N. D. Stankovic, F. Bicker, J. Meister, H. Braun, K. Awwad, J. Baumgart, K. Simon, S. C. Thal, C. Patra, P. N. Harter, K. H. Plate, F. B. Engel, S. Dimmeler, J. A. Eble, M. Mittelbronn, M. K. Schafer, B. Jungblut, E. Chavakis, I. Fleming and M. H. Schmidt (2013). "EGFL7 ligates alphavbeta3 integrin to enhance vessel formation." Blood 121(15): 3041-3050.

Niranjan, T., B. Bielesz, A. Gruenwald, M. P. Ponda, J. B. Kopp, D. B. Thomas and K. Susztak (2008). "The Notch pathway in podocytes plays a role in the development of glomerular disease." Nat Med 14(3): 290-298.

Nobta, M., T. Tsukazaki, Y. Shibata, C. Xin, T. Moriishi, S. Sakano, H. Shindo and A. Yamaguchi (2005). "Critical regulation of bone morphogenetic protein-induced osteoblastic differentiation by Delta1/Jagged1-activated Notch1 signaling." J Biol Chem 280(16): 15842-15848.

Nyhan, K. C., N. Faherty, G. Murray, L. B. Cooey, C. Godson, J. K. Crean and D. P. Brazil (2010). "Jagged/Notch signalling is required for a subset of TGFbeta1 responses in human kidney epithelial cells." Biochim Biophys Acta 1803(12): 1386-1395.

Palicharla, V. R. and S. Maddika (2015). "HACE1 mediated K27 ubiquitin linkage leads to YB-1 protein secretion." Cell Signal 27(12): 2355-2362.

Palmer, W. H. and W. M. Deng (2015). "Ligand-Independent Mechanisms of Notch Activity." Trends Cell Biol 25(11): 697-707.

Parker, L. H., M. Schmidt, S. W. Jin, A. M. Gray, D. Beis, T. Pham, G. Frantz, S. Palmieri, K. Hillan, D. Y. Stainier, F. J. De Sauvage and W. Ye (2004). "The 
endothelial-cell-derived secreted factor Egfl7 regulates vascular tube formation." Nature 428(6984): 754-758.

Parks, A. L., K. M. Klueg, J. R. Stout and M. A. Muskavitch (2000). "Ligand endocytosis drives receptor dissociation and activation in the Notch pathway." Development 127(7): 1373-1385.

Patsenker, E. and F. Stickel (2011). "Role of integrins in fibrosing liver diseases." Am J Physiol Gastrointest Liver Physiol 301(3): G425-434.

Pedrosa, A. R., A. Trindade, A. C. Fernandes, C. Carvalho, J. Gigante, A. T. Tavares, R. Dieguez-Hurtado, H. Yagita, R. H. Adams and A. Duarte (2015). "Endothelial Jagged1 antagonizes Dll4 regulation of endothelial branching and promotes vascular maturation downstream of Dl14/Notch1." Arterioscler Thromb Vasc Biol 35(5): 1134-1146.

Pisconti, A., D. D. Cornelison, H. C. Olguin, T. L. Antwine and B. B. Olwin (2010). "Syndecan-3 and Notch cooperate in regulating adult myogenesis." J Cell Biol 190(3): 427-441.

Pozzi, A. and R. Zent (2013). "Integrins in kidney disease." J Am Soc Nephrol 24(7): 1034-1039.

Qin, W. D., F. Zhang, X. J. Qin, J. Wang, X. Meng, H. Wang, H. P. Guo, Q. Z. Wu, D. W. Wu and M. X. Zhang (2016). "Notch1 Inhibition Reduces Low Shear StressInduced Plaque Formation." Int J Biochem Cell Biol.

Raffetseder, U., T. Rauen, P. Boor, T. Ostendorf, L. Hanssen, J. Floege, A. En-Nia, S. Djudjaj, B. C. Frye and P. R. Mertens (2011). "Extracellular YB-1 blockade in experimental nephritis upregulates Notch-3 receptor expression and signaling." Nephron Exp Nephrol 118(4): e100-108.

Rauen, T., U. Raffetseder, B. C. Frye, S. Djudjaj, P. J. Muhlenberg, F. Eitner, U. Lendahl, J. Bernhagen, S. Dooley and P. R. Mertens (2009). "YB-1 acts as a 
ligand for Notch-3 receptors and modulates receptor activation." J Biol Chem 284(39): 26928-26940.

Reipas, K. M., J. H. Law, N. Couto, S. Islam, Y. Li, H. Li, A. Cherkasov, K. Jung, A. S. Cheema, S. J. Jones, J. A. Hassell and S. E. Dunn (2013). "Luteolin is a novel p90 ribosomal S6 kinase (RSK) inhibitor that suppresses Notch4 signaling by blocking the activation of Y-box binding protein-1 (YB-1)." Oncotarget 4(2): 329-345.

Richards, G. S. and B. M. Degnan (2012). "The expression of Delta ligands in the sponge Amphimedon queenslandica suggests an ancient role for Notch signaling in metazoan development." Evodevo 3(1): 15.

Richter, D. J. and N. King (2013). "The genomic and cellular foundations of animal origins." Annu Rev Genet 47: 509-537.

Ross, D. A. and T. Kadesch (2001). "The notch intracellular domain can function as a coactivator for LEF-1." Mol Cell Biol 21(22): 7537-7544.

Rusanescu, G., R. Weissleder and E. Aikawa (2008). "Notch signaling in cardiovascular disease and calcification." Curr Cardiol Rev 4(3): 148-156.

Sahara, M., E. M. Hansson, O. Wernet, K. O. Lui, D. Spater and K. R. Chien (2014). "Manipulation of a VEGF-Notch signaling circuit drives formation of functional vascular endothelial progenitors from human pluripotent stem cells." Cell Res 24(7): 820-841.

Sakamoto, K., S. Yamaguchi, R. Ando, A. Miyawaki, Y. Kabasawa, M. Takagi, C. L. Li, B. Perbal and K. Katsube (2002). "The nephroblastoma overexpressed gene (NOV/ccn3) protein associates with Notch1 extracellular domain and inhibits myoblast differentiation via Notch signaling pathway." J Biol Chem 277(33): 29399-29405. 
Sanders, P. G., S. Munoz-Descalzo, T. Balayo, F. Wirtz-Peitz, P. Hayward and A. M. Arias (2009). "Ligand-independent traffic of Notch buffers activated Armadillo in Drosophila." PLoS Biol 7(8): e1000169.

Schmidt, M. H., F. Bicker, I. Nikolic, J. Meister, T. Babuke, S. Picuric, W. Muller-Esterl, K. H. Plate and I. Dikic (2009). "Epidermal growth factor-like domain 7 (EGFL7) modulates Notch signalling and affects neural stem cell renewal." Nat Cell Biol 11(7): 873-880.

Scholz, C. C., J. Rodriguez, C. Pickel, S. Burr, J. A. Fabrizio, K. A. Nolan, P. Spielmann, M. A. Cavadas, B. Crifo, D. N. Halligan, J. A. Nathan, D. J. Peet, R. H. Wenger, A. Von Kriegsheim, E. P. Cummins and C. T. Taylor (2016). "FIH Regulates Cellular Metabolism through Hydroxylation of the Deubiquitinase OTUB1." PLoS Biol 14(1): e1002347.

Sekine, K., T. Kawauchi, K. Kubo, T. Honda, J. Herz, M. Hattori, T. Kinashi and K. Nakajima (2012). "Reelin controls neuronal positioning by promoting cell-matrix adhesion via inside-out activation of integrin alpha5beta1." Neuron 76(2): 353369.

Sharff, K. A., W. X. Song, X. Luo, N. Tang, J. Luo, J. Chen, Y. Bi, B. C. He, J. Huang, X. Li, W. Jiang, G. H. Zhu, Y. Su, Y. He, J. Shen, Y. Wang, L. Chen, G. W. Zuo, B. Liu, X. Pan, R. R. Reid, H. H. Luu, R. C. Haydon and T. C. He (2009). "Hey1 basic helix-loop-helix protein plays an important role in mediating BMP9-induced osteogenic differentiation of mesenchymal progenitor cells." J Biol Chem 284(1): 649-659.

Sharma, B. and A. R. Albig (2013). "Matrix Gla protein reinforces angiogenic resolution." Microvasc Res 85: 24-33. 
Shimizu, H., S. A. Woodcock, M. B. Wilkin, B. Trubenova, N. A. Monk and M. Baron (2014). "Compensatory flux changes within an endocytic trafficking network maintain thermal robustness of Notch signaling." Cell 157(5): 1160-1174.

Shimizu, T., T. Kagawa, T. Inoue, A. Nonaka, S. Takada, H. Aburatani and T. Taga (2008). "Stabilized beta-catenin functions through TCF/LEF proteins and the Notch/RBP-Jkappa complex to promote proliferation and suppress differentiation of neural precursor cells." Mol Cell Biol 28(24): 7427-7441.

Smerdel-Ramoya, A., S. Zanotti, V. Deregowski and E. Canalis (2008). "Connective tissue growth factor enhances osteoblastogenesis in vitro." J Biol Chem 283(33): 22690-22699.

Stenzel, D., C. A. Franco, S. Estrach, A. Mettouchi, D. Sauvaget, I. Rosewell, A. Schertel, H. Armer, A. Domogatskaya, S. Rodin, K. Tryggvason, L. Collinson, L. Sorokin and H. Gerhardt (2011). "Endothelial basement membrane limits tip cell formation by inducing Dll4/Notch signalling in vivo." EMBO Rep.

Suchting, S., C. Freitas, F. le Noble, R. Benedito, C. Breant, A. Duarte and A. Eichmann (2007). "The Notch ligand Delta-like 4 negatively regulates endothelial tip cell formation and vessel branching." Proc Natl Acad Sci U S A 104(9): 3225-3230.

Suh, H. N. and H. J. Han (2011). "Collagen I regulates the self-renewal of mouse embryonic stem cells through alpha2beta1 integrin- and DDR1-dependent Bmi1." J Cell Physiol 226(12): 3422-3432.

Tang, Y., S. Urs, J. Boucher, T. Bernaiche, D. Venkatesh, D. B. Spicer, C. P. Vary and L. Liaw (2010). "Notch and transforming growth factor-beta (TGFbeta) signaling pathways cooperatively regulate vascular smooth muscle cell differentiation." $\underline{\mathbf{J}}$ Biol Chem 285(23): 17556-17563.

Taylor, K. L., A. M. Henderson and C. C. Hughes (2002). "Notch activation during endothelial cell network formation in vitro targets the basic HLH transcription 
factor HESR-1 and downregulates VEGFR-2/KDR expression." Microvasc Res 64(3): 372-383.

Thomas, J. L., K. Baker, J. Han, C. Calvo, H. Nurmi, A. C. Eichmann and K. Alitalo (2013). "Interactions between VEGFR and Notch signaling pathways in endothelial and neural cells." Cell Mol Life Sci 70(10): 1779-1792.

Timpl, R., T. Sasaki, G. Kostka and M. L. Chu (2003). "Fibulins: a versatile family of extracellular matrix proteins." Nature Reviews Molecular Cell Biology 4(6): 479489.

Tu, J., Y. Li and Z. Hu (2014). "Notch1 and 4 signaling responds to an increasing vascular wall shear stress in a rat model of arteriovenous malformations." Biomed Res Int 2014: 368082.

Valenti, L., R. M. Mendoza, R. Rametta, M. Maggioni, C. Kitajewski, C. J. Shawber and U. B. Pajvani (2013). "Hepatic notch signaling correlates with insulin resistance and nonalcoholic fatty liver disease." Diabetes 62(12): 4052-4062.

van den Akker, N. M., V. Caolo and D. G. Molin (2012). "Cellular decisions in cardiac outflow tract and coronary development: an act by VEGF and NOTCH." Differentiation 84(1): 62-78.

Villa, J. C., D. Chiu, A. H. Brandes, F. E. Escorcia, C. H. Villa, W. F. Maguire, C. J. Hu, E. de Stanchina, M. C. Simon, S. S. Sisodia, D. A. Scheinberg and Y. M. Li (2014). "Nontranscriptional role of Hif-1alpha in activation of gamma-secretase and notch signaling in breast cancer." Cell Rep 8(4): 1077-1092.

Wagener, J., W. Yang, K. Kazuschke, E. Winterhager and A. Gellhaus (2013). "CCN3 regulates proliferation and migration properties in Jeg3 trophoblast cells via ERK1/2, Akt and Notch signalling." Mol Hum Reprod 19(4): 237-249. 
Wang, X. L., A. Fu, S. Raghavakaimal and H. C. Lee (2007). "Proteomic analysis of vascular endothelial cells in response to laminar shear stress." Proteomics 7(4): 588-596.

Wang, X. M., M. Yao, S. X. Liu, J. Hao, Q. J. Liu and F. Gao (2014). "Interplay between the Notch and PI3K/Akt pathways in high glucose-induced podocyte apoptosis." Am J Physiol Renal Physiol 306(2): F205-213.

Waters, A. M., M. Y. Wu, T. Onay, J. Scutaru, J. Liu, C. G. Lobe, S. E. Quaggin and T. D. Piscione (2008). "Ectopic notch activation in developing podocytes causes glomerulosclerosis." J Am Soc Nephrol 19(6): 1139-1157.

Weijers, E. M., M. H. van Wijhe, L. Joosten, A. J. Horrevoets, M. P. de Maat, V. W. van Hinsbergh and P. Koolwijk (2010). "Molecular weight fibrinogen variants alter gene expression and functional characteristics of human endothelial cells." $\underline{\mathrm{J}}$ Thromb Haemost 8(12): 2800-2809.

White, M. P., C. V. Theodoris, L. Liu, W. J. Collins, K. W. Blue, J. H. Lee, X. Meng, R. C. Robbins, K. N. Ivey and D. Srivastava (2015). "NOTCH1 regulates matrix gla protein and calcification gene networks in human valve endothelium." J Mol Cell Cardiol 84: 13-23.

Williams, C. K., J. L. Li, M. Murga, A. L. Harris and G. Tosato (2006). "Up-regulation of the Notch ligand Delta-like 4 inhibits VEGF-induced endothelial cell function." Blood 107(3): 931-939.

Xiao, Z., J. Zhang, X. Peng, Y. Dong, L. Jia, H. Li and J. Du (2014). "The Notch gammasecretase inhibitor ameliorates kidney fibrosis via inhibition of TGFbeta/Smad2/3 signaling pathway activation." Int J Biochem Cell Biol 55: 65-71.

Yamamizu, K., T. Matsunaga, H. Uosaki, H. Fukushima, S. Katayama, M. HiraokaKanie, K. Mitani and J. K. Yamashita (2010). "Convergence of Notch and beta- 
catenin signaling induces arterial fate in vascular progenitors." J Cell Biol 189(2): 325-338.

Yao, Y., M. Jumabay, A. Wang and K. I. Bostrom (2011). "Matrix Gla protein deficiency causes arteriovenous malformations in mice." J Clin Invest 121(8): 2993-3004.

Yao, Y., J. Yao, M. Radparvar, A. M. Blazquez-Medela, P. J. Guihard, M. Jumabay and K. I. Bostrom (2013). "Reducing Jagged 1 and 2 levels prevents cerebral arteriovenous malformations in matrix Gla protein deficiency." Proc Natl Acad Sci U S A 110(47): 19071-19076.

Yip, J. W., Y. P. Yip, K. Nakajima and C. Capriotti (2000). "Reelin controls position of autonomic neurons in the spinal cord." Proc Natl Acad Sci U S A 97(15): 86128616.

Yoon, C. H., Y. E. Choi, S. J. Koh, J. I. Choi, Y. B. Park and H. S. Kim (2014). "High glucose-induced jagged 1 in endothelial cells disturbs notch signaling for angiogenesis: a novel mechanism of diabetic vasculopathy." J Mol Cell Cardiol 69: 52-66.

Zavadil, J., L. Cermak, N. Soto-Nieves and E. P. Bottinger (2004). "Integration of TGFbeta/Smad and Jagged1/Notch signalling in epithelial-to-mesenchymal transition." Embo J 23(5): 1155-1165.

Zebboudj, A. F., M. Imura and K. Bostrom (2002). "Matrix GLA protein, a regulatory protein for bone morphogenetic protein-2." J Biol Chem 277(6): 4388-4394.

Zhang, Q. D., M. Y. Xu, X. B. Cai, Y. Qu, Z. H. Li and L. G. Lu (2015). "Myofibroblastic transformation of rat hepatic stellate cells: the role of Notch signaling and epithelial-mesenchymal transition regulation." Eur Rev Med Pharmacol Sci 19(21): 4130-4138. 
Zhang, X., H. Meng and M. M. Wang (2013). "Collagen represses canonical Notch signaling and binds to Notch ectodomain." Int J Biochem Cell Biol 45(7): $1274-$ 1280.

Zhao, N., H. Liu and B. Lilly (2012). "Reciprocal regulation of syndecan-2 and Notch signaling in vascular smooth muscle cells." J Biol Chem 287(20): 16111-16120.

Zheng, X., S. Linke, J. M. Dias, X. Zheng, K. Gradin, T. P. Wallis, B. R. Hamilton, M. Gustafsson, J. L. Ruas, S. Wilkins, R. L. Bilton, K. Brismar, M. L. Whitelaw, T. Pereira, J. J. Gorman, J. Ericson, D. J. Peet, U. Lendahl and L. Poellinger (2008). "Interaction with factor inhibiting HIF-1 defines an additional mode of crosscoupling between the Notch and hypoxia signaling pathways." Proc Natl Acad Sci U S A 105(9): 3368-3373.

Zhou, J., Y. S. Li and S. Chien (2014). "Shear stress-initiated signaling and its regulation of endothelial function." Arterioscler Thromb Vasc Biol 34(10): 2191-2198. 